\title{
STRUCTURAL RELIABILITY: ASSESSING THE CONDITION AND RELIABILITY OF CASING IN COMPACTING RESERVOIRS
}

\author{
A Thesis \\ by \\ PRASONGSIT JOE CHANTOSE

\begin{abstract}
Submitted to the Office of Graduate Studies of Texas A\&M University

in partial fulfillment of the requirements for the degree of

MASTER OF SCIENCE
\end{abstract}

December 2011

Major Subject: Petroleum Engineering 
Structural Reliability: Assessing the Condition and Reliability of Casing in Compacting Reservoirs Copyright 2011 Prasongsit Joe Chantose 


\title{
STRUCTURAL RELIABILITY: ASSESSING THE CONDITION AND RELIABILITY OF CASING IN COMPACTING RESERVOIRS
}

\author{
A Thesis \\ by \\ PRASONGSIT JOE CHANTOSE
}

\author{
Submitted to the Office of Graduate Studies of \\ Texas A\&M University \\ in partial fulfillment of the requirements for the degree of \\ MASTER OF SCIENCE
}

\begin{abstract}
Approved by:
Co-Chairs of Committee, Jerome Schubert

Catalin Teodoriu

Committee Member, Paolo Gardoni

Head of Department, Steve Holditch
\end{abstract}

December 2011

Major Subject: Petroleum Engineering 


\begin{abstract}
Structural Reliability: Assessing the Condition and Reliability of Casing in Compacting Reservoirs. (December 2011)

Prasongsit Joe Chantose, B.S., Utah State University

Co-Chairs of Advisory Committee: Dr. Jerome Schubert

Dr. Catalin Teodoriu
\end{abstract}

Casing has a higher risk of failure in a compacting reservoir than in a typical reservoir. Casing fails when reservoir compaction induces compression and shear stresses onto it. They compact as reservoir pressure depletes during production. High compaction reservoirs typically are composed of unconsolidated, overpressured rocks such as chalk, diatomite, and sandstone. Pore pressure depletion increases effective stress, which is the rock matrix stress pushing upward against overburden pressure. Effective stress may exceed rock compressive strength, inducing compaction. Wells in compacting reservoirs risk high failure and deformation rates.

This project introduces the concept of structural reliability to quantify casing failure risks in compacting reservoirs. This research developed probabilistic models for casing capacities using current design methods and a reservoir compaction load using finite-element model simulations. Probabilistic models were used in creating two limitstates functions to predict casing failure: axial yielding and buckling failures. A limitstate function describes the casing condition as the casing experiences a reservoir compaction load. The limit state function is the input in component and system analyses 
for casing fragility and conditional probability of casing failure. Fragilities can predict casing probability of failure as reservoir pressure is depleting. Sensitivity and importance analyses are also performed to determine the importance of parameters affecting the casing reliability.

Applying the knowledge produced from this research to casing design methods can improve design reliabilities and forecast the risk of casing failure in compacting reservoirs. 


\section{DEDICATION}

I dedicate this thesis to my deceased father, Prapas Chantose, who supports me always; my beloved mother, Phatra Adisaraluk; and my family. 


\section{ACKNOWLEDGEMENTS}

I would like to take this opportunity to thank my committee chairs, Dr. Jerome Schubert and Dr. Catalin Teodoriu, for taking me into the group, giving me a project to work on, and guiding me to new ideas to use in this research.

I would like to thank Dr. Paolo Gardoni, my committee member, for taking time to help me incorporate new methods and guiding me through solving the project problem. I would like to thank another committee member, Dr. David Wiltschko, for his patience and guidance.

I want to thank my friends and colleagues for sharing and helping me throughout my years at Texas A\&M University. I would like to acknowledge the financial support from Crisman Institute for funding my research and making it possible for me to achieve my master's degree.

Finally, I thank my mother, father, and family for their encouragement, understanding, and support. 


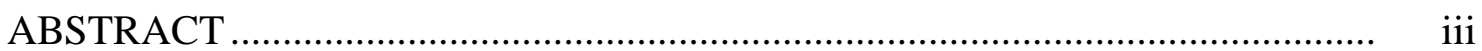

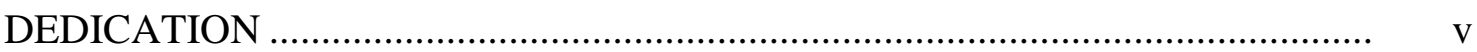

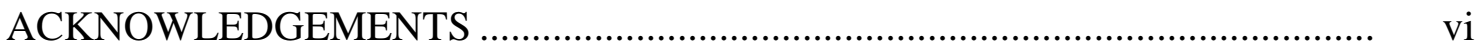

TABLE OF CONTENTS ........................................................................ vii

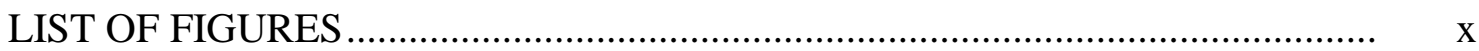

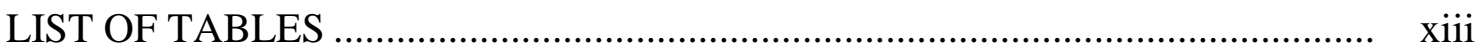

CHAPTER

I INTRODUCTION AND LITERATURE REVIEW ............................ 1

1.1 Background and Objective ........................................................... 1

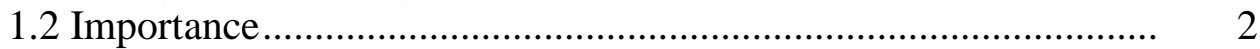

1.3 Literature Review ................................................................. 3

1.4 Proposed Work ....................................................................... 7

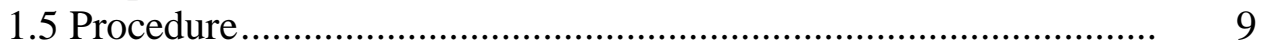

1.6 Structure of Thesis ............................................................... 10

II $\quad$ STRUCTURAL RELIABILITY METHOD AND APPROACH........ 12

2.1 Structural Reliability Approach ................................................. 12

2.2 First Order Reliability Analysis (FORM) ................................... 16

2.3 Use of Standard Normal Space in FORM ................................. 17

2.4 Determination of the Design Point $u^{*}$........................................ 19

2.5 Monte Carlo Simulation ................................................................ 20

2.6 Reliability Analysis on Component Level and System Level....... 20

III $\quad$ PROBABILISTIC MODELS CONTRUCTION ................................. 22

3.1 Introduction ........................................................................ 22

3.2 Probabilistic Capacity Model for Axial Yield Failure ……............ 22 
CHAPTER Page

3.3 Probabilistic Capacity Model for Buckling Failure ..................... 24

3.4 Reservoir Compaction Finite-Element Modeling ...................... 25

3.4.1 Boundary Condition and Model Geometry .................. 26

3.4.2 Analysis Step.................................................. 28

3.4.3 Geostatic Step........................................................ 28

3.4.4 Boundary, Loading, and Initial Condition .................... 29

3.4.5 Result of the Geostatic Step .................................... 31

3.4.6 Soil Step Analysis ................................................... 34

3.4.7 Mesh Convergence Study........................................ 34

3.4.8 Reservoir Compaction Model by Chia (1989) .............. 35

3.4.9 Model Modification.................................................... 38

3.4.10 Experimental Design ............................................... 39

3.5 Probabilistic Demand Model for Reservoir Compaction .............. 40

3.5.1 Deterministic Model Selection.................................... 41

3.5.2 Correction Term for Bias in the Deterministic Model ... 45

3.5.3 Standard Deviation of Model Error............................. 54

IV CASING FRAGILITY ESTIMATES ....................................... 56

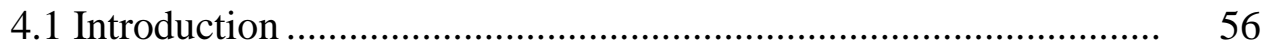

4.2 Fragility Estimate Computation ............................................. 56

4.3 Limit-State Function for Casing Axial Yielding ........................ 57

4.4 Fragility Estimates for Casing Axial Yielding ........................... 59

4.5 Limit-State Function for Casing Buckling ............................... 62

4.6 Fragility Estimates for Casing Buckling .................................... 64

4.7 Casing System Reliability .................................................. 66

$\mathrm{V} \quad$ IMPORTANCE AND SENSITIVITY ANALYSES ........................ 69

5.1 Importance Analysis .............................................................. 69

5.2 Importance Analysis Result and Discussion ........................... 70

5.3 Sensitivity Analysis .......................................................... 73

5.4 Sensitivity Analysis Result and Discussion ............................. 74

VI RESULT DISCUSSION AND APPLICATION ............................ 77

6.1 Casing Failure Mitigation Strategy ......................................... 77

6.2 Structural Reliability Result Discussion .................................. 78 
CHAPTER Page

VII $\quad$ CONCLUSIONS AND FURTHER STUDY …............................ 80

7.1 Conclusions ..................................................................... 80

7.2 Further Study ................................................................... 81

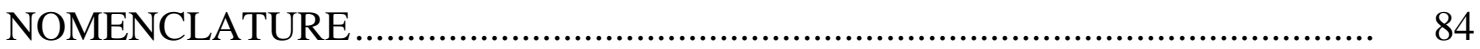

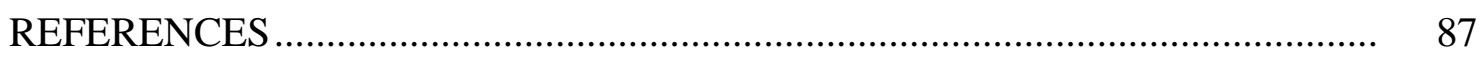

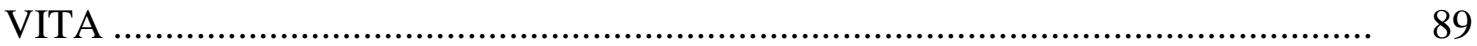




\section{LIST OF FIGURES}

FIGURE

Page

2.1 Probability of failure $\mathrm{p}_{f}$ computation using limit state function $g(x)$ and joint PDF of random variable $x$

2.2 Probability distribution function (PDF) of random variable

2.3 Construction of limit-state function schematic

2.4 FORM approximation of limit state function $G(u)$ in standard normal space

2.5 Use of standard normal space in FORM approximation

3.1 Finite-element model consists of the overburden (top), the reservoir (middle), and the underburden (bottom)

3.2 Magnified view shows casing and cement of the finite element model.

Casing is the left-most column; cement is in the middle; reservoir is on the right.

3.3 Load conditions show pink arrows for overburden load and yellow arrows for element weights

3.4 Formation pressure profile plot. The model was successfully implemented with the input pressure and stress after geostatic step .......

3.5 The model axial deformation result after geostatic step shows small deformation, appears everywhere in the model, with magnitude of $10^{-1}$ to $10^{-4}$

3.6 The pore pressure distribution in the model pore pressure increases with increasing depth. Blue (overburden) is around 5,000 psi. Red (underburden) is around 8,900 psi

3.7 At reservoir depth $(750-800 \mathrm{ft}$. $)$, the effective stress drops drastically because excess pore pressure helps support the formation from overburden stress.

3.8 The modified model meshing. Casing area connected with the reservoir has finer mesh than the reservoirs outer boundary for accuracy. 
FIGURE Page

3.9 Chia's maximum casing axial strain for reservoir R1 is about $2 \%$............................................................. 36

3.10 The modified model maximum casing axial strain is about $1.9 \%$, which is close to Chia's

3.11 Chia's maximum casing axial stress for reservoir R1 is about 14,000 psi..

3.12 The modified maximum casing axial stress is about $14,000 \mathrm{psi}$, which is close to Chia's

3.13 The difference in pore pressure across the reservoir is shown for two methods used in simulation

3.14 Comparison of three deterministic models to simulation results

3.15 Closer look of the comparison illustrates that the deterministic models is accurate in predicting casing axial strain

3.16 Diagnostic plots for Biot constant

3.17 Diagnostic plots for casing grade

3.18 Diagnostic plots for casing outer diameter.

3.19 Diagnostic plots for casing thickness .......

3.20 Diagnostic plots for casing Poisson's ratio 48

3.21 Diagnostic plots for cement Poisson's ratio

3.22 Diagnostic plots for depleted pressure

3.23 Diagnostic plots for casing Young's modulus

3.24 Diagnostic plots for sandstone Poisson's ratio.

3.25 Diagnostic plots for sandstone Young's modulus 
FIGURE $\quad$ Page

3.27 Diagnostic plots for shale porosity ............................................... 52

3.28 Diagnostic plots for shale Poisson's ratio ......................................... 52

3.29 Diagnostic plots for sandstone porosity ........................................... 53

3.30 Diagnostic plots for sandstone Poisson's ratio.................................... 53

4.1 FORM approximation agrees with Monte Carlo simulation results for axial yield failure. ................................................................ 60

4.2 Axial yield fragility estimates decrease in failure probability as casing grade increases ............................................................ 61

4.3 FORM approximation agrees with Monte Carlo simulation result for buckling failure ................................................................... 65

4.4 Buckling fragility decreases as casing outer diameter increases............... 65

4.5 System fragility has the highest probability of failure because

5.1 Model error $\varepsilon$ and formation Young's modulus of elasticity $E_{f}$ have highest effect on casing reliability

5.2 Importance analysis of buckling illustrates that unsupported casing length $L$ is the most important parameter affecting casing reliability ........

5.3 Closer look at importance analysis for buckling mode of failure .............. 73

5.4 Change of interface slippage $S$ is most sensitive to change in fragility for the axial yield mode of failure

5.5 Change of interface slippage $\mathrm{S}$ is most sensitive to change in fragility for the buckling mode of failure. 


\section{LIST OF TABLES}

TABLE Page

3.1 Ranges of input data for parameters in experimental design .................. 40

3.2 MAPE of the deterministic models .................................................... 44

4.1 Input data for parameters in axial yield mode of failure …...................... 58

4.2 Input data for parameters in buckling mode of failure ............................ 64 


\section{CHAPTER I \\ INTRODUCTION AND \\ LITERATURE REVIEW}

\subsection{Background and Objective}

Oil is a valuable commodity today. However, production may stop if the well is damaged or fails as a result of casing deformations, which may result from reservoir compaction during production. Casing damage may interrupt production so repairs can be made, and casing failure can stop production completely. Assessing and predicting casing conditions in developing fields are important to prevent casing failures.

Standard casing designs do not include the reservoir compaction load. Generally, if the reservoir is expected to undergo high compaction, the casing system tends to be overdesigned. The overdesigned casing system adds higher cost to the total project expense. Optimization of the casing design is essential to keep the casing cost minimal and keep the casing functioning properly. Including the reservoir compaction load in the casing designs can ensure the optimum casing designs.

The objective of this research was to develop ways to assess and prediction for casing conditions in reservoirs subject to compaction. To assess and predict casing condition, this research uses the concept of structural reliability to estimate casing fragility. Fragility is the conditional probability of a damaged condition. By estimating

This thesis follows the style of SPE Economics \& Management Journal. 
casing fragility, the knowledge of casing damage conditions under specific reservoir characteristics and depleted pressure are gained.

To achieve the stated objective, the project had the following goals:

1. Assess the capacity of casing for axial yield and buckling failures. Two casing failure modes are high occurrences at the crest of the reservoir, where the highest axial load is expected.

2. Assess the demand from reservoir compaction by creating a finite-element model to simulate the compaction mechanism. The results from modeling were used to choose the best-fit reservoir compaction model.

3. Estimate fragilities of casing subject to reservoir compaction load at the component and system levels. After fragility estimations, importance and sensitivity analyses were performed to pinpoint parameters that greatly influence the casing reliability.

\subsection{Importance}

Present technologies in predicting the magnitude of reservoir compaction and its effect on casing are geomechanical simulation, wellbore 3D simulation, and reservoir 3D simulation. Although simulation can account for many parameters to simulate the closest solutions, simulation results cannot produce exact solutions because of uncertainties that arise in the real world or in making the simulation.

Such uncertainties may be the error in parameter measurements, model error, or some unknown parameters, that cannot be accounted for in the simulation. Thus, the 
simulation results can only give us approximations; they lack the ability to compare the degree of correction to the actual results.

The importance of this research is to introduce an approach that can fill the gap of simulations that cannot account for the uncertainty in the solution.

Structural reliability can optimize the casing design and estimate the condition of the casing for a compacting reservoir. The casing design in compacting reservoir tends to be over-designed to accommodate compaction, this approach can reduce casing cost down the hole. Where the casing has been underdesigned, this approach can extend the project's economic life by preventing failure. The research approach can assess reliability improving the economics and the safety of the design.

It is important to know the casing conditions in the developing field to reduce the number of casing failures, whether by changing production methods or by repairing the wells. Casing conditions are identified by analyzing fragilities, which come from the limit-state functions constructed by probabilistic models. The fragilities explain the damaged condition in terms of probability of failure. The Bayesian method used in generating the probabilistic models in this research allows the models to be applied and updated to fit specifications of other fields with casing failure problems.

\subsection{Literature Review}

Around the beginning of the 1980, when oil fields were being rapidly developed, reservoir compaction was not considered a problem. After 4 to 5 years of production, subsidence began to emerge as a sign of casing failure. Casing deformation and failure 
followed and became problems. Well production stopped. Workover operations were not possible because casings were deformed severely. Some of the fields reported to have high casing failure rates were Ekofisk, Belridge, and Shengli.

Ekofisk is a North Sea chalk basin. High subsidence occurred because of the high-porosity chalk's compaction. More than 90 wells were reported to have casing failure. Yodovich et al. (1988) presented a statistical model that correlated Ekofisk casing failure data, production data, and reservoir data. Using the linear discriminated function given the failure and nonfailure well data, the statistical model was created to forecast the probability of casing failure as function of well inclination and reservoir strain. That probabilistic model can only be applied to Ekofisk field because it was correlated from the casing failure seen from that field.

The Belridge diatomite field located in California experienced casing failure in nearly 1,000 wells. Diatomite high rock compressibility allowed high deformation in the production zone, causing severe damage to the casing in both the reservoir region and the overburden rock formation (Fredich et al. 1998).

Bruno (2001) used 3D wellbore modeling, 3D reservoir modeling, and 2D geomechanical modeling to determine the amount of reservoir deformation at Belridge field. The 2D geomechanical simulation model was used to determine the high compaction zone. The 3D reservoir model focused on simulating the actual formation deformation used in modeling the wellbore to attain casing behavior. The results from Bruno (2001) may be most accurate in simulating casing damage under reservoir compaction. However, the simulation results only apply to one specific field. 
The American Petroleum Institute, (API 1999) studied casing performance to create a design function for casing. They modeled burst, collapse, and pipe body yielding in tension modes of failure in deterministic form. The deterministic formulations give a design value that should exceed the expected loading value times a safety factor value so that casing is ensured not to fail. But deterministic design lacks the ability to quantify safety of the design.

Adams et al. (1993) used structural reliability to quantify risks associated in casing design factors in development and exploration wells, including installation, drilling, and production operations. Adams et al. (1993) used the deterministic casing design published by API to study the safety factor for the capacity strength of casing. The components they studied are loads seen in typical reservoirs. These load components match the components of casing design proposed by API, which include weight, buoyancy, bending, ballooning, and heat. However, compacting reservoirs require specific loading models because these reservoirs do not behave like the typical reservoir where compaction is not a problem.

Fjaer et al. (1992) used a lab experiment to calculate the amount of compaction in terms of axial strain. The experiment was set up to reduce the pressure in the sample core and measure the effect. They proposed an equation explaining the axial strain given the reduced pressure and rock static properties, which are Young's modulus of elasticity and the Poisson ratio. Similarly, Settari (2002), introduced the Biot's constant to the formulation to account for the poroelastic effect in the formation. Ibekwe et al. (2003) applied Settari (2002) formulation for a stiff rock formation and introduced another 
formulation for soft rock. Using these models, Ibekwe et al. (2003) were able to calculate the strain in each reservoir zone and categorize each zone according to the severity of the reservoir compaction. In their model, different casing designs and amount of production are specific for each zone to reduce the risk of casing failure.

Chia et al. (1989) used Abaqus, finite-element simulation software, to simulate the effect of the casing in a compacting reservoir. Their study showed that the axial stresses of the casing exceeded its limit and made it prone to failure. They treated the formation stiffness as linear elastic and the casing as elastoplastic material. The model simulates reservoir compaction using one-phase Darcy flow for two cases: slippage and non-slippage. Slippage at the interface of casing and cement and cement and formation may occur as the reservoir compacts. Chia et al. (1989) showed that slippage could greatly reduce the casing axial strain. The results also show the locations of maximum axial compressive stress and maximum axial compressive strain is at the interface of the reservoir with the overburden and the underburden. The maximum axial compressive strain result is significantly higher than the yield strain of the casing.

Bruno (1990) gives a simple assumption that the formation axial strain is equal to the casing axial strain. If the casing limit is known and assumed equal to the formation strain, this assumption can be used to find maximum depleted reservoir pressure. The critical axial strain for casing steel begins yielding around $0.3 \%$ and ultimately fails in a plastic range of no more than $0.7 \%$. The casing yield strain can be used as a design limit and a company can design the production plan not to exceed the yield strain of the 
casing. Bruno (1990) also introduced a casing buckling failure model. Buckling failure usually occurs when large amount of solid is produced.

Gardoni et al. (2002) used statistical method to produce probabilistic capacity and demand models for bridge components and systems for fragility estimates. Gardoni et al's approach to assess bridge conditions prone to failure from earthquake quantifies the safety of the bridge in terms of probability of failure. The model used the Bayesian updating method, so it can be used for other bridges in other locations by using specific information and knowledge for the specific bridge to update the model. The ultimate result of assessed bridge conditions is a fragility estimate, shown in a cumulative density function, CDF. Gardoni et al. showed the probability of failure increasing from $0 \%$ to $100 \%$, depending on the change of the affected parameter.

\subsection{Proposed Work}

This thesis incorporates statistical methods into the common casing design to account for the uncertainty in formation and casing properties, error in the design model, and error in the measurement of casing.

Casing damage conditions depend on two conditions: the capacity strength of the casing and the demand from the reservoir compaction load. When the capacity is exceeded by the demand, the condition is described as failure. Thus, setting a limit-state function where failure occurs when the limit is exceeded can describe casing conditions. Following the method used in Gardoni (2002), this research creates probabilistic models for the capacity of the casing and loading behavior from reservoir compaction. Using the 
probabilistic models, the fragility can be computed for a well location given the specific field data from the limit-state function.

This work considered two modes of casing failure considering are casing axial yielding and casing buckling. The failure modes mostly occurred at the crest of the reservoir where maximum reservoir deformation takes place. The probabilistic capacity models are taken from standard deterministic design, and the probabilistic demand model is built from the results from simulation. The model simulates reservoir compaction from production, or reduction in pore pressure. Production is simulated as a one-phase fluid flow from the outer reservoir boundary to the casing. Mesh convergence is analyzed for the accuracy of the result with the time used. 14 different models are designed to capture the all casing dimensions. Experimental designs for the simulated cases apply the method of space filled to capture wide range of possibility in input parameters.

Fragility estimates address the probability of casing failure from reservoir compaction by using statistical data given in the oil field and by casing manufacturers. The probability of failure is expressed in a CDF plot. This research analyzed casing failure in component level analysis for one mode of failure, and in system level analysis, either mode of failure could occur. In the component level, this method analyzed fragility estimates for the possibility of only one mode of failure. On the system level, this method analyzed fragility estimates for the possibility for either mode of failure to occur. 
In addition to fragility estimates, importance and sensitivity analyses analyzed the input parameters of the limit-state function for each failure mode. Importance and sensitivity analysis computes the importance and sensitivity of the input parameter to the limit-state function. Importance and sensitivity analyses identify parameter that should be address to reduce the risk of casing failure.

\subsection{Procedure}

The procedures to compute the fragility and estimate the importance and sensitivity parameters are as follows:

1. Construct the probabilistic capacity models for axial yielding and buckling modes of failure.

2. Create finite-element models using Abaqus to compute the strain in casing from reservoir compaction.

3. Experimentally design 70 simulation cases and run the simulation for computing the casing strain for the 70 cases.

4. Use the results from simulations to construct the probabilistic demand model from the best-fit deterministic reservoir compaction strain formulation. The bestmatch formulation is judged by calculating mean absolute percentage error (MAPE) for each deterministic formulation.

5. Create the limit-state function from the created probabilistic models and estimate the fragility at the component level and system levels.

6. Compute the sensitivity and importance measure for the input parameters. 


\subsection{Structure of Thesis}

This thesis is structured in the following manner, beginning with the general introduction chapter, this chapter. The next chapter, Chapter II, describes the structural reliability approach, which uses the statistical methods to account for randomness in the input parameters, uncertainty in the models, model errors, and inaccuracy of the deterministic design. Chapter II explains the theory behind constructing the limit-state function and the method for computing the limit-state function for probability of failure. The two methods for computing the limit-state function are the first-order reliability method (FORM) and Monte Carlo simulation.

Chapter III discusses the procedure for constructing the limit-state function through the probabilistic capacity and demand models. This chapter covers the theory in current deterministic capacity and demand formulation used in constructing the probabilistic models. Chapter III also discusses the procedure and results of the finiteelement models used in creating the demand probabilistic models and the analysis run in the simulation and mesh convergence study. Experimental design cases are shown with description of the theory used in designing the 70 cases. Chapter III covers the strain estimation formulate for reservoir compaction and the procedure for choosing the best formulation using mean absolute percentage error, MAPE.

Chapter IV discussed the results of FORM and Monte Carlo simulation on the limit-state function using the probabilistic models created in Chapter III. By using two methods to solve the limit state function, results can be compared for accuracy. The statistics computational program for finite-element reliability using Matlab (FERUM) 
can compute the limit state function using both FORM and Monte Carlo simulation. The fragility estimate, which is the conditional cumulative probability function, is calculated in this chapter using probability of failure from the component-level and system-level analysis. The results of the component-level and system-level analyses are discussed. Chapter V explains the method and analysis steps in performing the sensitivity and importance analyses. Importance and sensitivity analyses use parts of the results from computing the probability of failure in Chapter IV. Results discussed in this chapter show how sensitive the input parameters are in the probabilistic models and how important the input parameters are in defining the failure condition.

Chapter VI presents the conclusion of my thesis. Further study is suggested in this chapter to improve the accuracy of the results and the quality of probabilistic models to use in the field. 


\section{CHAPTER II}

\section{STRUCTURAL RELIABILITY \\ METHOD AND APPROACH}

\subsection{Structural Reliability Approach}

The structural reliability approach relies on statistical methods to account for uncertainty in the input and for unknown parameters. This approach requires construction of the limit-state function. A limit-state function describes a state at which a capacity model is compared to a demand model. A failure occurs when a demand exceeds a capacity. The limit-state function can be described as shown below.

$$
g(x)=C(x)-D(x),
$$

where $g(x)$ is the limit state function, $C(x)$ is the capacity model, $D(x)$ is the demand or loading model, and $\mathrm{x}$ is a set of random variables associated with the limit-state function such as $x=\left(x_{1}, x_{2}, x_{3}, \ldots, x_{n}\right)$. The failure condition occurs when the limit-state function becomes negative, $g(x) \leq 0$. In general, the failure state begins as the demand model exceeds the capacity model. Thus, a probability of failure can be expressed as:

$$
p_{f}=P(g \leq 0)=\int_{g(x) \leq 0} f(x) d x
$$

where $p_{f}$ is the probability of failure, $f(x)$ is the joint probability distribution function, PDF, of $x$. The probability of failure, $p_{f}$, is the volume underneath the joint PDF, of the starting from surface where $g(x)=0$, to the end of the joint PDF in the direction of $g(x)<$ 0. Fig. 2.1 shows the contour of $f(x)$ plot, the limit state surface where $g(x)=0$, and the volume used in computing the probability of failure. 


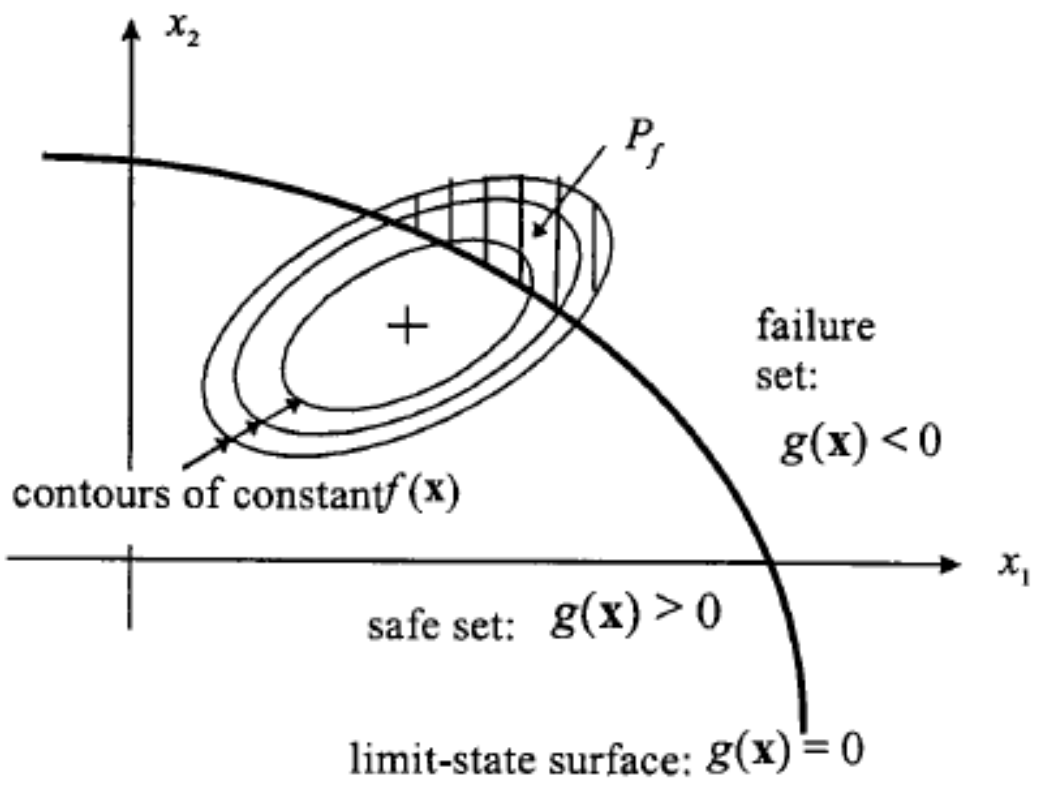

Fig. 2.1-Probability of failure $p_{f}$ computation using limit state function $g(x)$ and joint PDF of random variable $x$

Introducing below is a casing design capacity for burst failure as an example of

this approach.

$$
p_{b}=\frac{1.75 f_{y} t}{D_{o}}
$$

where $p_{b}$ is the casing burst pressure, $f_{y}$ is the casing yield stress, $t$ is the casing thickness, $D_{o}$ is the casing outer diameter. Here, $p_{b}$ represents the maximum burst pressure capacity that the casing is allowed to take. Furthermore, during a production period, the production casing experiences internal pressure required to transport fluid up to surface. The internal fluid pressure represents the demand load to the casing. When the demand exceeds the capacity, failure is likely to occur. 
Using the application of statistical probability, the risk of casing being prone to failure can be quantified. Using the statistical method, all parameters in the design function have their statistic distributions with a mean and a standard deviation. These statistical parameters are called random variables. For example, a casing manufacturer rolls out 2,000 casings with a specific size. If the outer diameter and the thickness are measured for all 2,000 casing, the outer diameter and thickness will vary for each of the casings measured. The plot of measurements against the number of occurrences for 2,000 casings shows the distribution of the measured dimension with a mean and a standard deviation such as in Fig. 2.2.

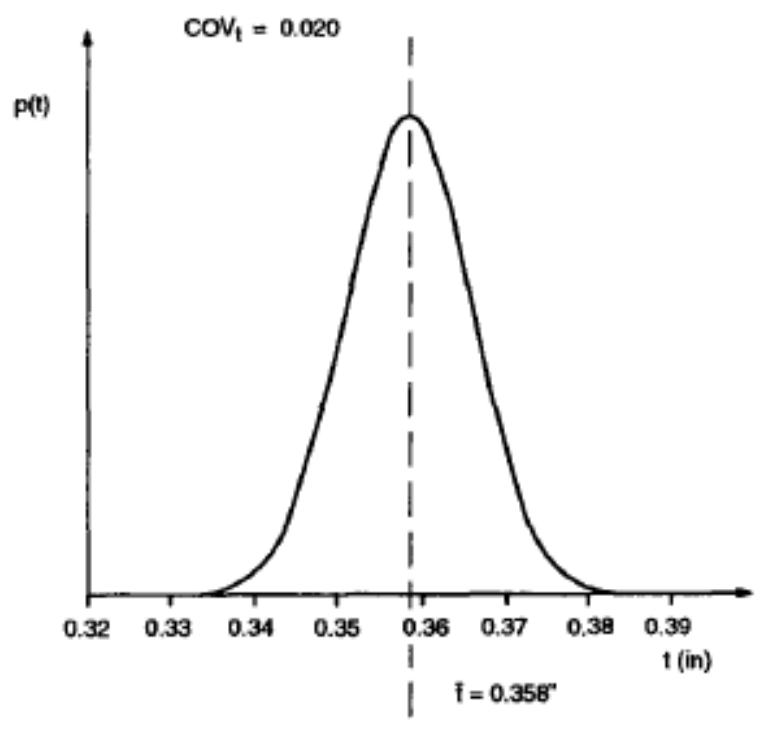

Fig. 2.2—Probability distribution function (PDF) of random variable

Fig. 2.2 shows the probability distribution function (PDF) plot for casing thickness. There are many types of PDFs such as normal, lognormal, uniform, and chisquare distribution. The PDF of thickness in Fig. 2.2 is a normal distribution function. 
Thus, the capacity models and the demand model can be constructed in term of a PDF because each input parameter in the model is a PDF. After the construction of probabilistic capacity models and the probabilistic demand model, they are combined into limit-state functions. Then the limit-state functions can be used to compute the probability of failure. The schematic in Fig. 2.3 shows the construction of a limit-state function by Adams et al. (1993), where he applied structural reliability to a drilling system.
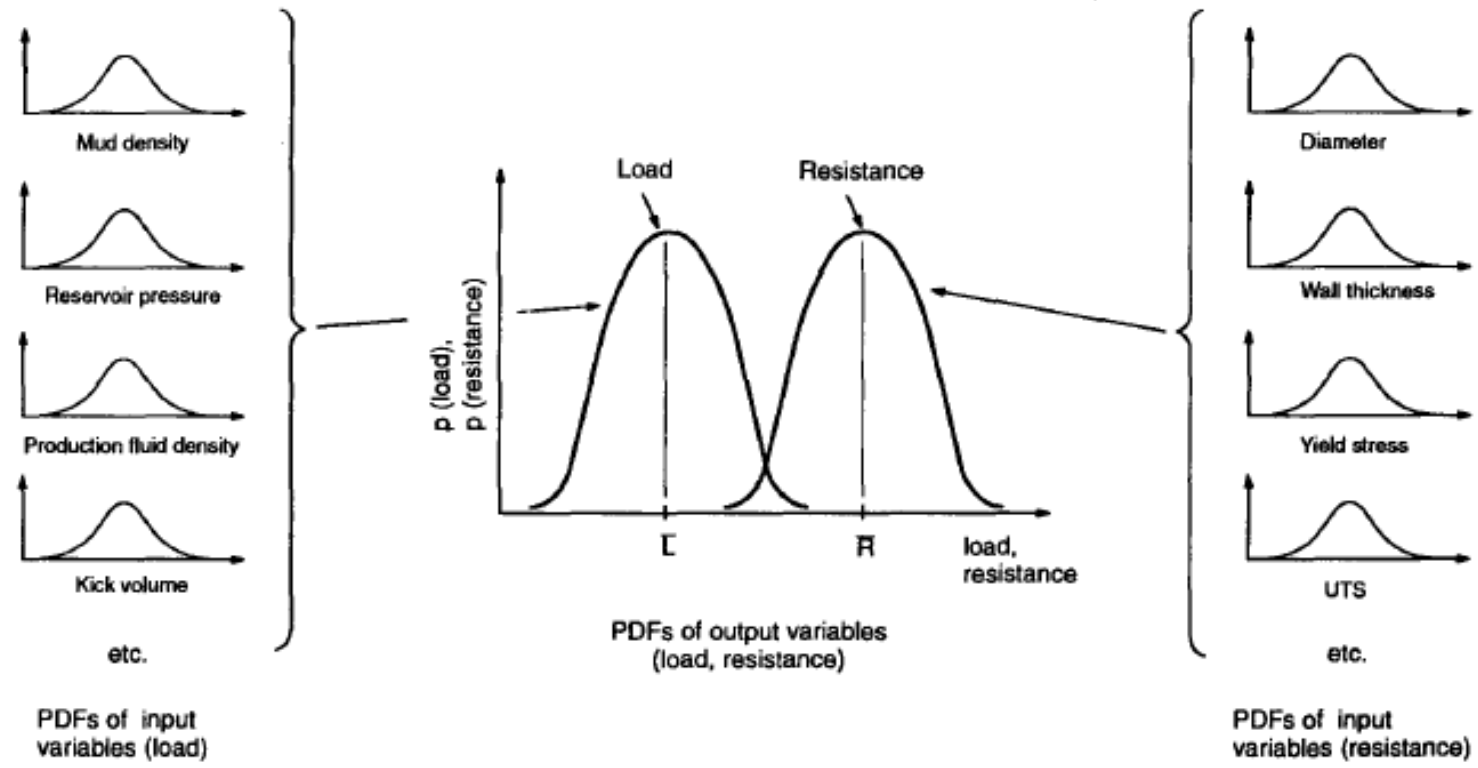

Fig. 2.3-Construction of limit-state function schematic

Several methods can be used to compute the probability of failure or the area in joint PDF $f(x)$ where $g(x)<0$ is shown in Fig. 2.1. Two methods used are the first-order reliability method (FORM) and Monte Carlo simulation. 


\subsection{First Order Reliability Analysis (FORM)}

The FORM method approximates the probability of failure for a limit-state function. The probability of failure is expressed as:

$$
p_{f}=\int_{G(u) \leq 0} \varphi_{n}(u) d u
$$

$G(u)$ expresses the limit-state function in the standard normal space of the associated random variables. $\varphi_{n}(u)$ is the PDF of the random variable $u$ transformed from the limit state function in normal space $f(x)$. The standard normal space and its transformation from normal space are covered in the next section.

Fig. 2.4 shows FORM approximation of the limit-state surface in standard normal space $G(u)=0$.

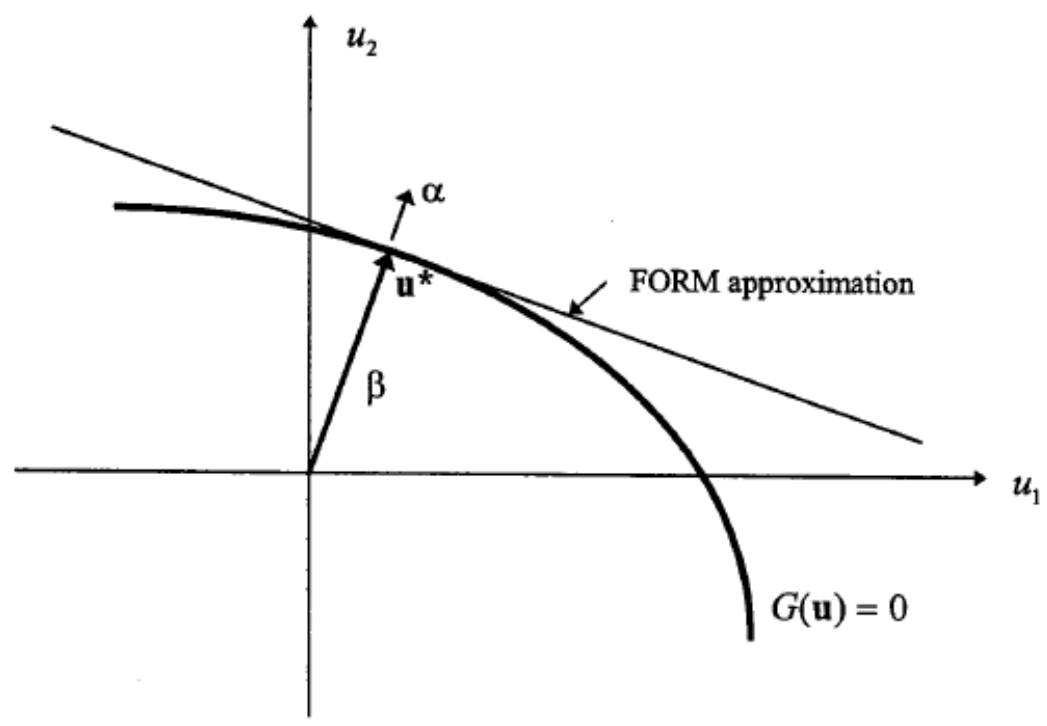

Fig. 2.4-FORM approximation of limit state function $G(u)$ in standard normal space 
By assuming that $G(u)$ is continuously differentiable, the approximation is

written as

$$
G(u) \cong G\left(u^{*}\right)+\nabla G^{T}\left(u-u^{*}\right)
$$

by linearizing the integration boundary. $\nabla G^{T}$ is the gradient vector where $\nabla G^{T}=\left[\partial G / \partial u_{1} \cdots \partial G / \partial u_{n}\right]$. It is in best practice to choose $u^{*}$ that lies on the limit-state surface $G(u)=0$ and closest to the origin. $u^{*}$ is called the "design point" or the "most likely failure point," because its probability of failure is highest.

Using the properties of standard normal space, the probability of failure is $p_{f}=\Phi(-\beta)$ where $\Phi(\cdot)$ is the standard normal cumulative probability function. The property of standard normal space states that $\beta=\alpha^{T} u^{*}$ where $\beta$, reliability index, is the distance from the origin to $u^{*}$ and $\alpha=-\nabla G /\|\nabla G\|$ is the normalized negative gradient vector.

\subsection{Use of Standard Normal Space in FORM}

The standard normal space, which is called $u$ space, has the random variables $u=$ $\left(u_{1}, u_{2}, u_{3}, \ldots, u_{n}\right)$, which have the probability density function

$$
\varphi_{n}(u)=\frac{1}{(2 \pi)^{n / 2}} \exp \left(-\frac{1}{2}\|u\|^{2}\right)
$$

where $\varphi_{n}(u)$ is the standard normal PDF. There are three important properties of the standard normal space to help compute the probability of failure using FORM. First, the standard normal PDF is rotationally symmetrical decaying exponentially with the square 
of the distance from the origin in the radial direction (Gardoni 2009). Second, on a plane $\beta-\alpha^{T} u=0$, defined in terms of its distance $\beta$ from the origin and its unit outbound normal vector $\alpha$, the probability density is maximum at the origin-projection point $u^{*}=\beta \alpha$. It decays exponentially with the square of the distance from that point. Last, the probability content of the half-space $\beta-\alpha^{T} u \leq 0$ is $p_{1}=\Phi(-\beta)$ where $\Phi()$ is the standard normal cumulative probability function. Fig. 2.5 shows the standard normal space use in computing FORM.

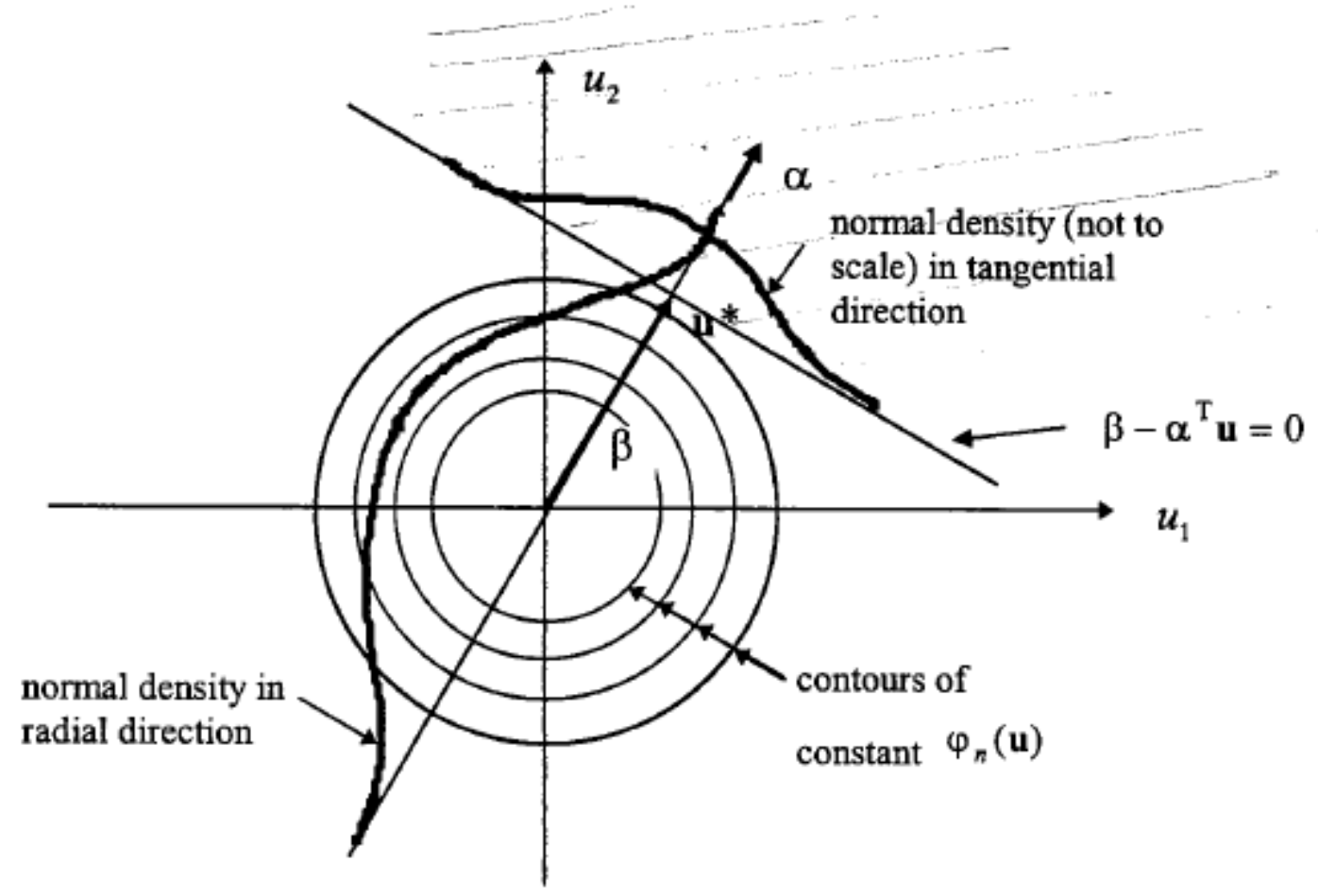

Fig. 2.5-Use of standard normal space in FORM approximation

Normally, the outcome space of the limit-state function's random variables $x=\left(x_{1}, x_{2}, x_{3}, \ldots, x_{n}\right)$ is in normal space. To use FORM, the random variables $x$ in normal 
space require transformation to random variables $u$ in standard normal space using a one-to-one mapping technique. The transformation is written as $u=u(x)$ with the Jacobian matrix $J_{u, x}=\left[\partial u_{i} / \partial x_{j}\right]$. Inversely, the random variable $x$ is $x=x(u)$ and the inverse Jacobian matrix is

$$
J_{u, x}^{-1}=\left[\partial u_{i} / \partial x_{j}\right]=J_{x, u}
$$

Using the one-to-one mapping, the first assumption is random variables $x$ are statically independent non-normal random variables with marginal PDFs $f\left(x_{i}\right)$ and CDFs $F\left(x_{i}\right), i=1,2,3, \ldots, n$. The transformation takes the form

$$
u=\Phi^{-1}\left[F\left(x_{i}\right)\right] \quad i=1,2,3, \ldots, n
$$

where $\Phi^{-1}($.$) is the inverse standard normal cumulative probability function. To solve$ the inverse transform function, the inverted Jacobian diagonal matrix is used as

$$
J_{x, u}=\operatorname{diag}\left[\frac{\varphi\left(u_{i}\right)}{f\left(x_{i}\right)}\right]=J_{u, x}^{-1}
$$

Gardoni (2009) considered this transformation one-to-one as long as $F\left(x_{i}\right)$ is continuous and functions of $x_{i}$ increase strictly.

\subsection{Determination of the Design Point $u^{*}$}

FORM approximation required $u^{*}$ as shows above. Zhang and Der Kiureghian et al. (1995) introduced an improved Hasofer and Lind-Rackwitz and Fiessler (HL-RF) algorithm to find $u^{*}$ closest to the origin for accuracy of FORM. Their procedure is shown below: 
1. Set index $i=1$ and tolerances $\varepsilon_{1}$ and $\varepsilon_{2}\left(\varepsilon_{1}=\varepsilon_{2}=10^{-3}\right.$ is a good choice for most problems). Select an initial point $x_{I}$ (e.g., $\left.x_{I}=M\right)$ and compute $u_{I}=u\left(x_{l}\right)$.

2. Compute $x_{i}=x\left(u_{i}\right)$ (skip this step for $\left.i=1\right), J_{u, x}$ and $J_{x, u}=J_{u, x}{ }^{-1}$ at $x_{i}, G\left(u_{i}\right)=$ $g\left(x_{i}\right)$ and $\nabla G\left(u_{i}\right)^{T}=\nabla g\left(x_{i}\right)^{T} J_{x, u}$.

3. Compute the direction vector $d_{i}=\frac{-G\left(u_{i}\right)+\nabla G\left(u_{i}\right)^{T} u_{i}}{\left\|\nabla G\left(u_{i}\right)\right\|} \frac{\nabla G\left(u_{i}\right)}{\left\|\nabla G\left(u_{i}\right)\right\|}-u_{i}$.

4. Determine the step length $\lambda_{i}=\arg \min _{\lambda}$

\subsection{Monte Carlo Simulation}

Monte Carlo simulation is another method that can be used to compute the probability of failure by simulating each value from the distribution for each random variable. Increasing the number of simulation means increasing the accuracy of the result. However, a large number of simulations requires a large amount of time.

\subsection{Reliability Analysis on Component Level and System Level}

The reliability analysis on a component level involves using a structural reliability approach on a specific failure mode given a capacity and demand model to construct a limit-state function. Thus, the probability of failure for a mode of failure is

$$
p_{f}=P[g(C, D) \leq 0]
$$


where $g(C, D)$ is the limit-state function of a failure mode. The distribution of the limitstate function $\mathrm{g}$ where $g=g(C, D)$ given the $C$ distribution and $D$ distribution can be found. Thus, the probability of failure is written as

$$
p_{f}=P(g \leq 0)=F_{g}(0)
$$

where $F_{g}(0)$ is the cumulative distribution function, $\mathrm{CDF}$.

A system consists of an assembly of components. When a component fails, the system may or may not fail. In this thesis, a system consists of a casing that may fail by axial yielding or buckling. A component-level analysis looks at one state of failure. However, system reliability looks at failure of the system. In this case, the failure in either buckling or axial yielding is considered failure to the system. This type of system reliability is called series system where system fails if any of its components fail.

System reliability explains the event of failure in term of the union between two states of failure. $g_{c}$ is denoted as the limit-state function for axial yielding mode of failure and $g_{b}$ as the limit-state function for the onset of buckling. Thus, the system probability of failure is written as

$$
P\left(F_{y} \cup F_{b}\right)=P\left(g_{y} \leq 0\right)+P\left(g_{b} \leq 0\right)-P\left(g_{y} \leq 0 \cap g_{b} \leq 0\right)
$$

Eq. 2.12 explains system reliability as the union between the event where axial yielding failure occurs $\left(F_{c}\right)$ and event where buckling failure occurs $\left(F_{b}\right)$. The probability that either one of failures will occur is equal to the probability of axial yielding failure plus the probability of buckling failure, minus the probability of axial yielding failure intersecting the probability of buckling failure. 


\section{CHAPTER III}

\section{PROBABILISTIC MODELS \\ CONSTRUCTION}

\subsection{Introduction}

Limit-state functions require probabilistic demand models and probabilistic capacity models. The probabilistic capacity models describe the casing strength necessary to resist the reservoir compaction load. The probabilistic demand model describes the reservoir compaction load on the casing. Reservoir compactions occur as reservoir pressure decrease during production.

Formulations of the probabilistic models consider previous knowledge about the casing and the reservoir behaviors. In probabilistic models, the deterministic term describes the current knowledge about the casing strengths and the deformations from reservoir compaction. This chapter explains the procedure to construct the probabilistic capacity models and the probabilistic demand model. Two probabilistic capacity models covered are axial yielding and buckling failure. The limit-state functions for both failure modes share the same probabilistic demand model, which is covered in this chapter.

\subsection{Probabilistic Capacity Model for Axial Yield Failure}

The state of axial yielding occurs when the casing is loaded during compression until it reaches its yield stress. The casing in the reservoir experiences compressive deformation transfer through the cement from the reservoir. Three layers, consisting of 
casing, cement, and the formation are bonded together. The bonds ensure that the casing deforms the same amount as the reservoir. As a reservoir compacts, deformation is transferred from the formation to the cement to the casing. This causes the casing to compress axially.

An axial yielding failure occurs around the production interval where maximum axial deformation occurs. The axial yield capacity model calculates the maximum strain the casing can resist. Casings are made of steel. Assuming the casing fails in a linear elastic manner, Hook's law can be applied. Thus, the maximum strain is calculated as a function of yield stress and Young's modulus of elasticity of the casing. The casing axial strain is written as

$$
\varepsilon_{c}=\frac{\sigma_{c}}{E_{c}}
$$

$\varepsilon_{c}$ is the axial strain, $\sigma_{c}$ is the yield stress of casing, and $E_{c}$ is the casing Young's modulus of elasticity. Using eq. 3.1, the probabilistic axial yield capacity model $C_{y}(x)$ as

$$
C_{y}(x)=\hat{c}_{y}(x)=\frac{\sigma_{c}}{E_{c}}
$$

$\hat{c}_{y}(x)$ is the deterministic model that account for the failure mechanism. Due to the lack of lab experimental data for the casing compressive yield test, determination of the correction terms for any bias in deterministic model and the standard deviation for model error are not included in this probabilistic model. The correction terms for bias in the 
deterministic model and the standard deviation for model error are described in the probabilistic demand model section later in this chapter.

\subsection{Probabilistic Capacity Model for Buckling Failure}

Buckling is casing instability that results from the axial load in a compacting reservoir and the lack of lateral restrain of the formation to fix the casing in place. Casing buckling usually occurs in the center of the production interval, where vertical strain is maximum. A capacity model is a function of casing properties and formation properties that restrain casing from lateral movement caused by axial stress from the reservoir.

Bruno's (1990) casing buckling failure formulation gives he conservative approximation for minimum buckling load below:

$$
\varepsilon_{b}=\frac{4 \pi^{2} I}{A_{c} L^{2}}
$$

$\varepsilon_{b}$ is the casing strain limit before onset of buckling. $L$ is the unsupported length of casing. $A_{c}$ is the casing cross-sectional area. $I$ is the area moment of inertia of casing. Eq. 3.3 assumes no slips occur at the two interfaces: casing to cement and cement to formation. Eq. 3.4 and 3.5 calculate the area moment of inertia and the casing crosssectional area.

$$
I=\frac{\pi}{64}\left(D_{o}^{4}-\left(D_{o}-2 t\right)^{4}\right)
$$




$$
A_{c}=\frac{\pi}{4}\left(D_{o}^{2}-\left(D_{o}-2 t\right)^{2}\right)
$$

$D_{o}$ is the casing outer diameter. $t$ is the casing thickness.

The above knowledge about casing buckling is used as the deterministic model for the probabilistic buckling model. The probabilistic capacity model for buckling failure $C_{b}(x)$ can be written as shown below.

$$
C_{b}(x)=\hat{c}_{b}(x)=\frac{4 \pi^{2} \frac{\pi}{64}\left(D_{o}^{4}-\left(D_{o}-2 t\right)^{4}\right)}{\frac{\pi}{4}\left(D_{o}{ }^{2}-\left(D_{o}-2 t\right)^{2}\right) L^{2}}
$$

$\hat{c}_{b}(x)$ is the deterministic model term of the probabilistic model.

\subsection{Reservoir Compaction Finite-Element Modeling}

Application of structural reliability requires statistical data for the specific field. Using field data to determine each random variable distribution can reduce uncertainty in the model. However, acquiring field data for this thesis was not possible. The lack of field data in this thesis is compensated by using finite-element model simulation.

Abaqus, a finite-element simulation software, is run to simulate the effect of reservoir compaction on casing. The simulation results are used in creating the

probabilistic demand model. This model design is similar to the model created by Chia (1989), and the results are compared with those results. After calibration, the models are modified a little to capture the effect of depletion pressure. Then the 70 different cases of reservoir compaction simulation are run to capture the effect on casing deformation of 
different depletion pressures. Using the results of 70 simulations to represent casing deformations substitutes for the missing data from the field.

\subsubsection{Boundary Condition and Model Geometry}

The model has three parts: the casing, the cement, and the formation. The elements representing the formation are 8-node axisymmetric quadrilateral, biquadratic displacement, and bilinear pore pressure. The casing and the cement elements are 8-node biquadratic axisymmetric quadrilaterals. Fig. 3.1 shows the whole model in three layers, with the overburden at the top, reservoir in the middle, and underburden in the bottom. At the left side of the model, at the centerline (yellow dotted line), are the casing and cement, which are shown in magnified view in Fig 3.2.

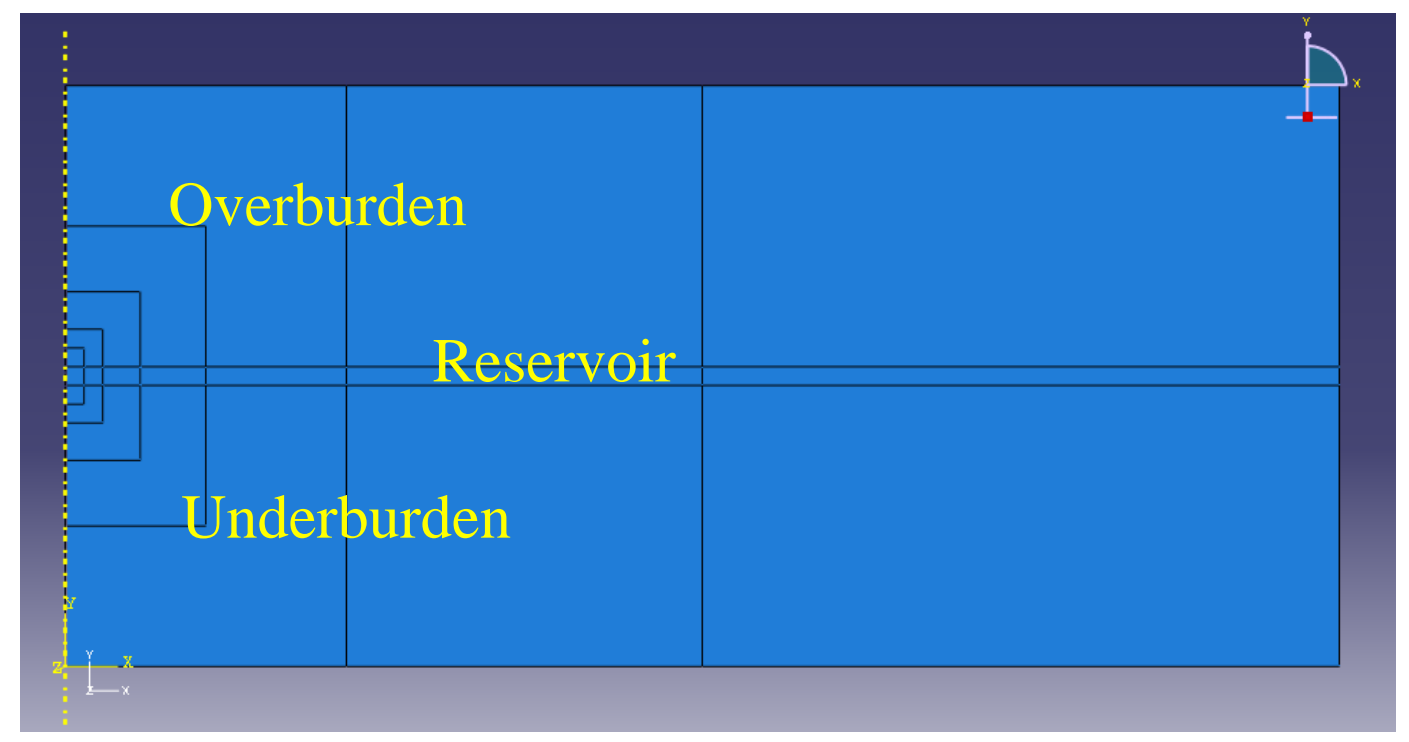

Fig. 3.1-Finite-element model consists of the overburden (top), the reservoir (middle), and the underburden (bottom) 


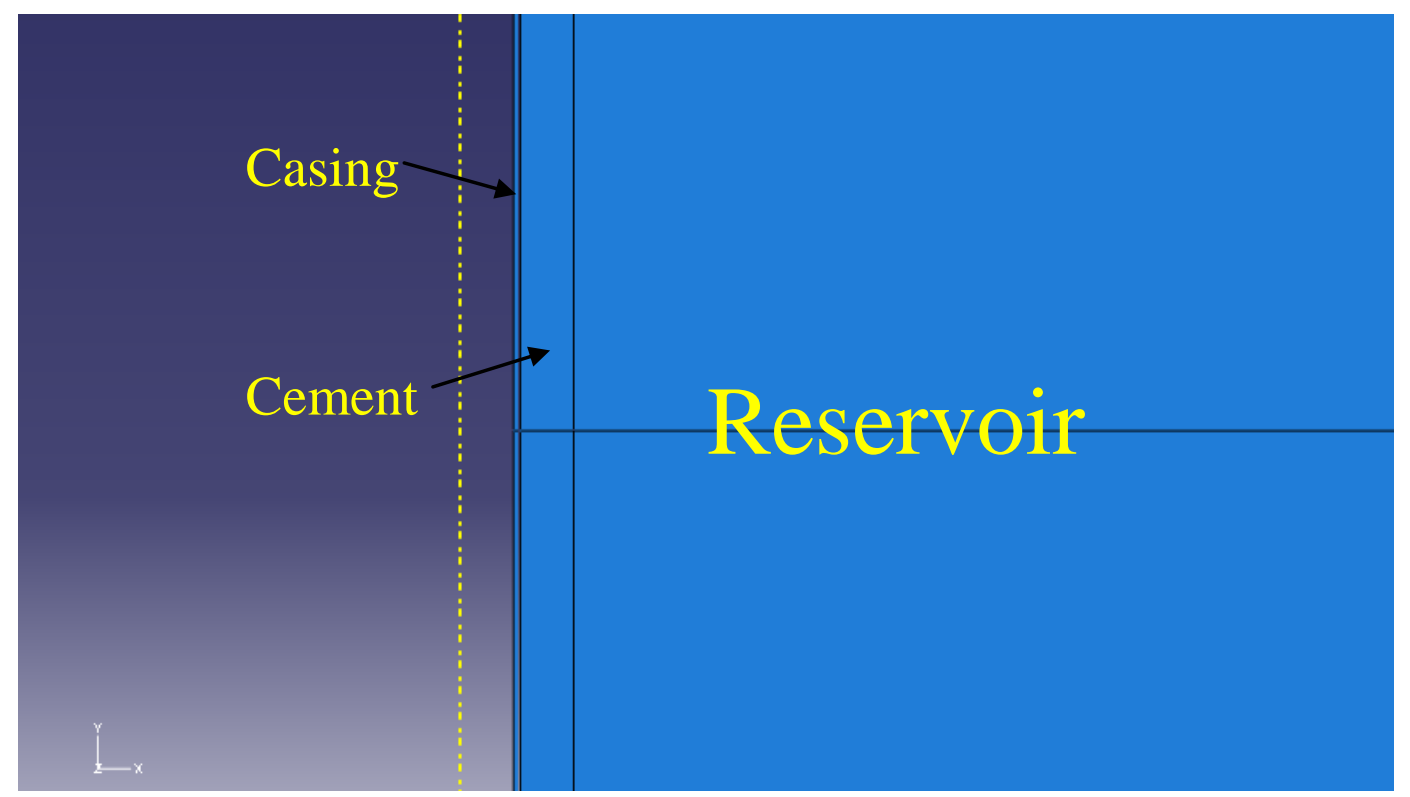

Fig. 3.2-Magnified view shows casing and cement of the finite element model. Casing is the left-most column; cement is in the middle; reservoir is on the right

The elements in the left column represent the casing. The elements in the middle column represent the cement. The elements in the right column are the formation. This model is an axisymmetric model, as shown by the yellow dotted centerline. The axisymmetric model allows the user to analyze the model as a 3D model which requires simpler 2D model input. The axisymmetric model rotates the 2D model geometry input about the axis, the yellow centerline. This model input is chosen because it requires less time to run the analysis. Chia (1989) used a similar model.

The formation is assumed to behave as a linear elastic. The formation material properties consist of permeability, density, Young's modulus of elasticity, and Poisson's ratio. The casing behaves in perfect plasticity mode. The casing has the properties of Young's modulus of elasticity, Poisson's ratio, and yield stress. The cement is assumed 
to behave in elastic mode with Young's modulus of elasticity and Poisson's ratio properties.

\subsubsection{Analysis Step}

The simulations require two analysis steps. The first step is the geostatic step, which allows the model to interact with the boundary conditions to create stress and deformation equilibrium conditions in the formation before production begins. The second step is the soil step, which simulates the production of the fluid in the reservoir. In the soil step, the pore pressure moves from the reservoir boundary to the casing. Thus, the reduction in the reservoir pore pressure simulates the oil production.

\subsubsection{Geostatic Step}

The importance of the geostatic step is to set the model to the input pressure profile of the formation before the oil production. This ensures model accuracy in representing the actual formation.

The geostatic step balances the input formation stresses and the input pore pressure. Abaqus allows users to input the formation stress and the pore pressure profiles according to the model elevation. The geostatic step uses the effective stress, the pore pressure, and the element weights to compute the equilibrium state of the model. It adjusts the model size by displacing each node in the model until the model is in equilibrium for the input stresses, the boundary conditions, and the element weights. The model stress results should be equal to input stresses. 
The goal of geostatic step is to have zero displacement in the model results given the input. Thus, the input of stress and pore pressure should be accurate in comparison with the actual formation data. The model can produce zero displacement easier if the input data is accurate. However, with the field data absent, the model will achieve equilibrium by changing the weight of the elements in the model. The procedure below shows the steps used in achieving zero displacement.

\subsubsection{Boundary, Loading, and Initial Condition}

This section explains the boundary condition in the model. Fig. 3.3 shows the boundary and the loading conditions. The two side boundaries are fixed from displacing in the horizontal direction. The base is fixed from moving in the vertical direction. The top is free to move anywhere. Each element is loaded with gravity, which is shown by yellow arrows pointing down within each element. The top of the model is at the depth of 10,000 ft. The pink arrows represent the overburden pressure pushing downward on the model. 


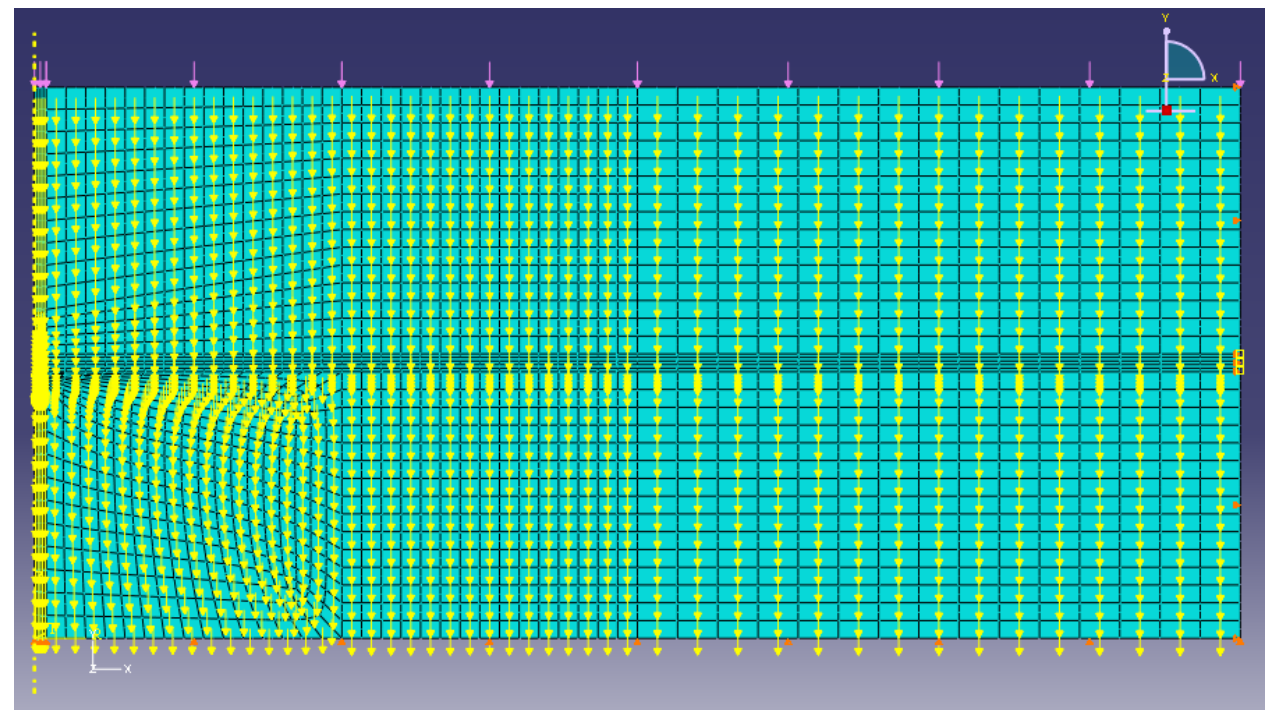

Fig. 3.3 — Load conditions show pink arrows for overburden load and yellow arrows for element weights

For initial conditions, the overburden stress at the top of the model is 10,000 psi. The total stress gradient is $1 \mathrm{psi} / \mathrm{ft}$ from top to base of the model. The effective stress is defined as

$$
\bar{\sigma}=\sigma_{o b}-\rho
$$

$\sigma_{o b}$ is the total stress (overburden stress plus the weight of the formation). $\bar{\sigma}$ is the effective stress. Effective stress is the stress from the rock matrix that pushes against the overburden stress. $\rho$ is the pore pressure. Thus, the total stress is equal to the effective stress plus the pore pressure.

The top of the model has total stress of 10,000 psi. The base has total stress of $11,550 \mathrm{psi}$. The overburden stress in the formation increases linearly by $1 \mathrm{psi} / \mathrm{ft}$. The height of the model is $1,550 \mathrm{ft}$. The initial pore pressure is 5,000 psi at the top to 8,900 psi at the base. The reservoir represents the transition zone, or the zone of excess 
pressure from the oil production zone. In the reservoir, pore pressure rises from 5,275 psi to 8,525 psi. Fig. 3.4 shows the pore pressure and the total stress plots against the formation depth.

In order to reach this initial condition with zero displacement after the geostatic step, the applied overburden pressure and weight of each element is changed. The simulation run the different overburden pressure and the weight of the formation inputs until the deformation reaches zero. With this pressure and weight, the model can accurately represent a deepwater reservoir.

\subsubsection{Result of the Geostatic Step}

The displacement result is shown in Fig. 3.5. The displacement result is not quite zero. However, it is less than 1 in. and in the magnitude of -1 to -2 . Spending time to find the loading values for the smallest displacement does not change the result much.

Fig. 3.6 shows the model pore pressure distribution, which follows the pore pressure profile in Fig. 3.4. The reservoir lay in the excess pore pressure zone, where the pore pressure raises from 5,275 psi to 8,525 psi. Effective stress increases with depth

(Fig. 3.7), but when it reaches the excess pore pressure zone, it decreases largely. This is because the excess pore pressure in this zone helps relieve the effective stress from carrying the total stress. 


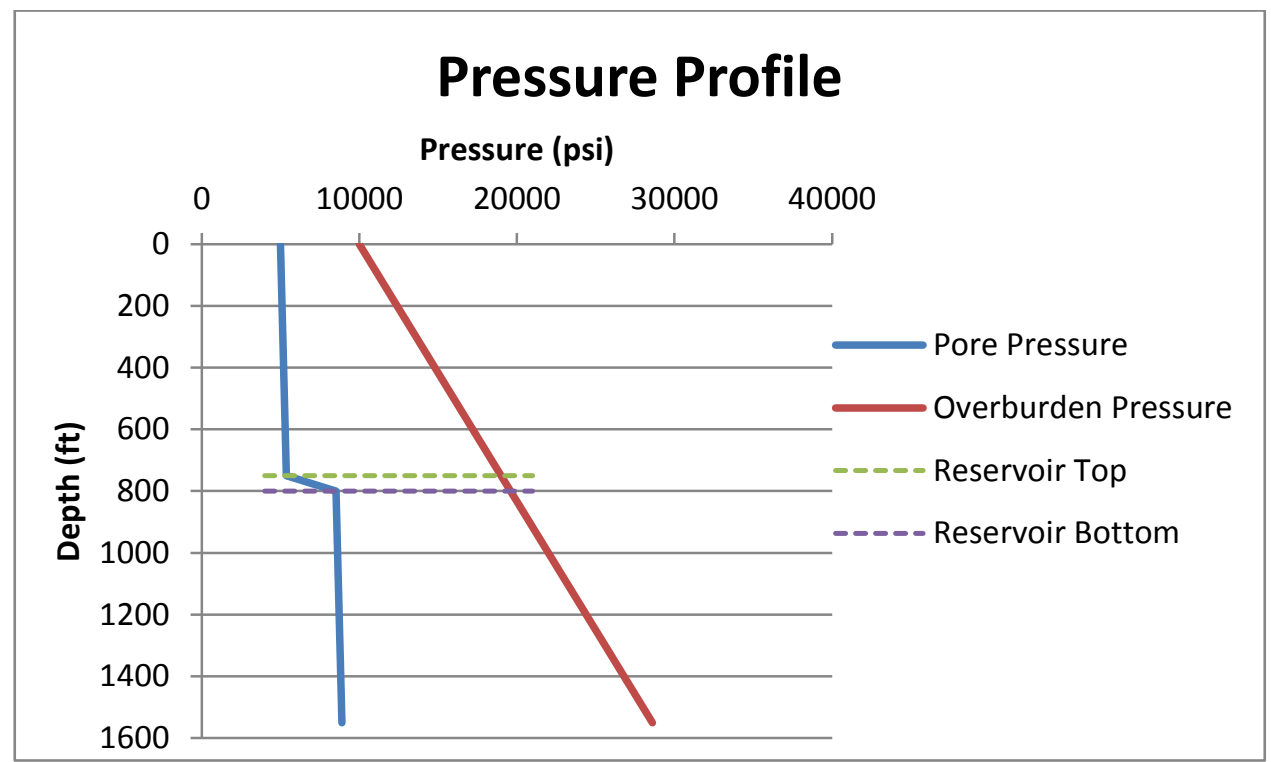

Fig. 3.4-Formation pressure profile plot. The model was successfully implemented with the input pressure and stress after geostatic step

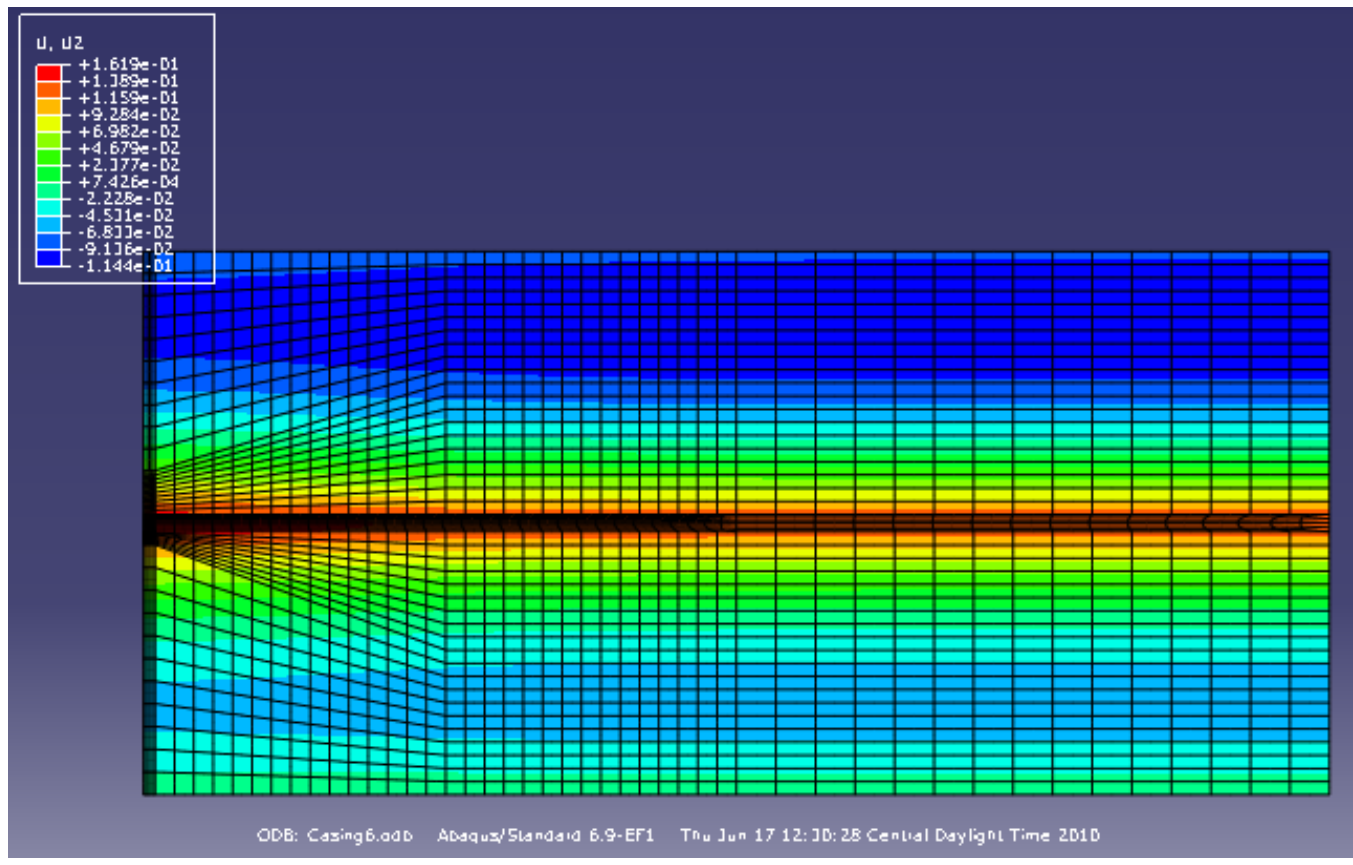

Fig. 3.5-The model axial deformation result after geostatic step shows small deformation, appears everywhere in the model, with magnitude of $10^{-1}$ to $10^{-4}$ 


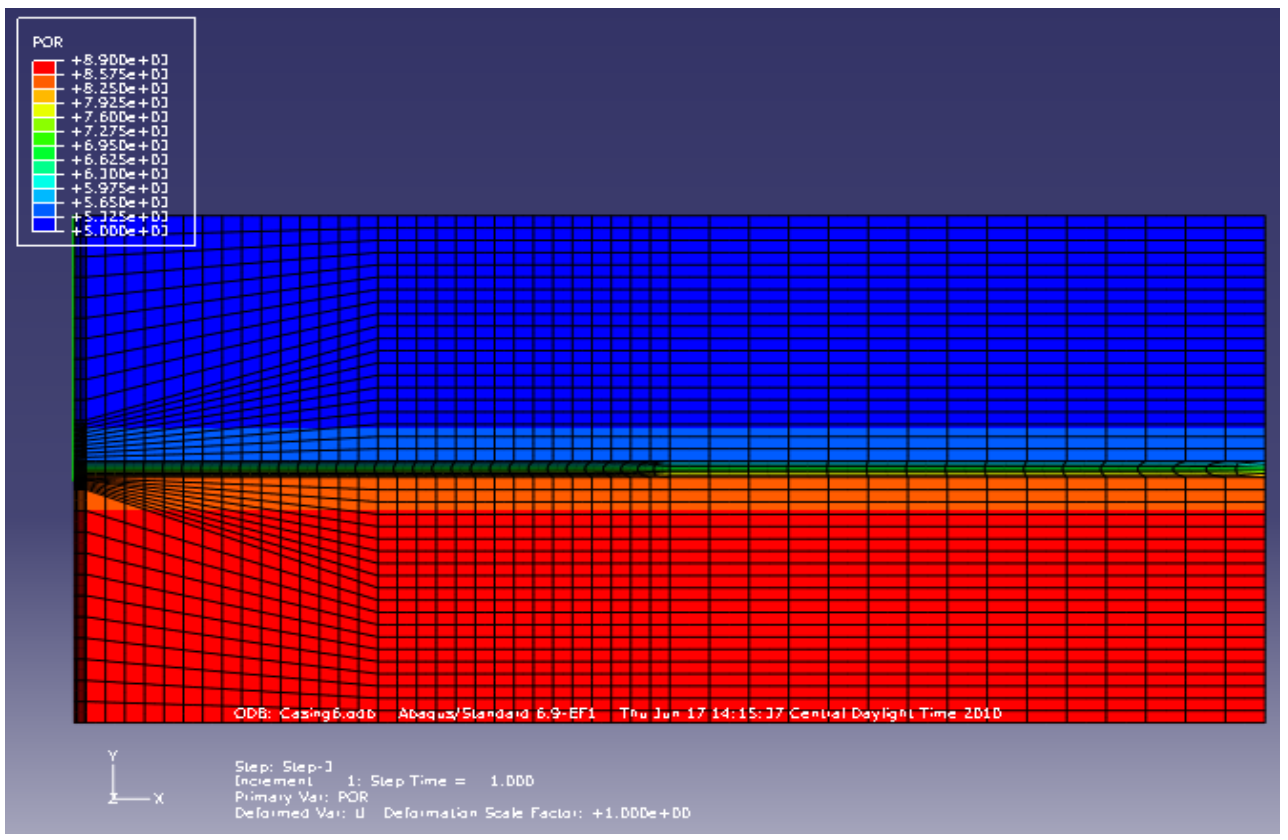

Fig. 3.6 - The pore pressure distribution in the model pore pressure increases with increasing depth. Blue (overburden) is around 5,000 psi. Red (underburden) is around 8,900 psi

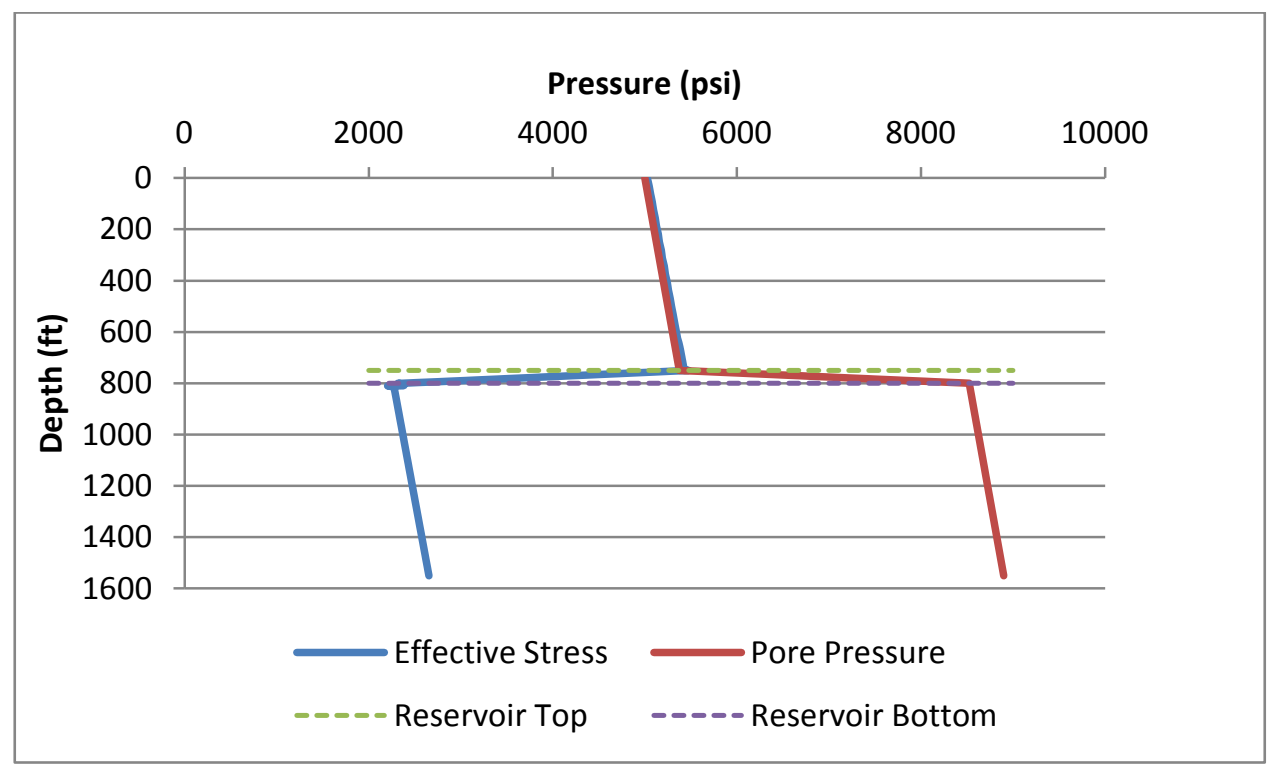

Fig. 3.7-At reservoir depth $(750-800 \mathrm{ft}$.), the effective stress drops drastically because excess pore pressure helps support the formation from overburden stress 


\subsubsection{Soil Step Analysis}

Soil step analysis models the fluid movement from the reservoir boundary to the casing. Soil step simulates oil production by specifying boundary conditions for the pore pressure. After the model reaches an equilibrium state, the boundary condition at the casing is set to a lower pressure than the reservoir pressure to create a movement in the pore pressure, simulating the production. Mesh convergence is studied to determine the result convergence and the time needed for running the simulation.

\subsubsection{Mesh Convergence Study}

Fig. 3.8 shows the meshing of the model. Elements of the casing and cement are noticeably finer than the outer reservoir boundary elements. The casing, the cement, and the formation are modeled with different materials. Finer mesh is needed at the area of interest for accuracy in the results. In this simulation, the casing in the reservoir zone is expected to have the maximum compaction strain. The goal is to increase the number of elements for the casing region that connects the reservoir until the strain result converges. The optimized total was 11,400 elements with reasonable computation time. 


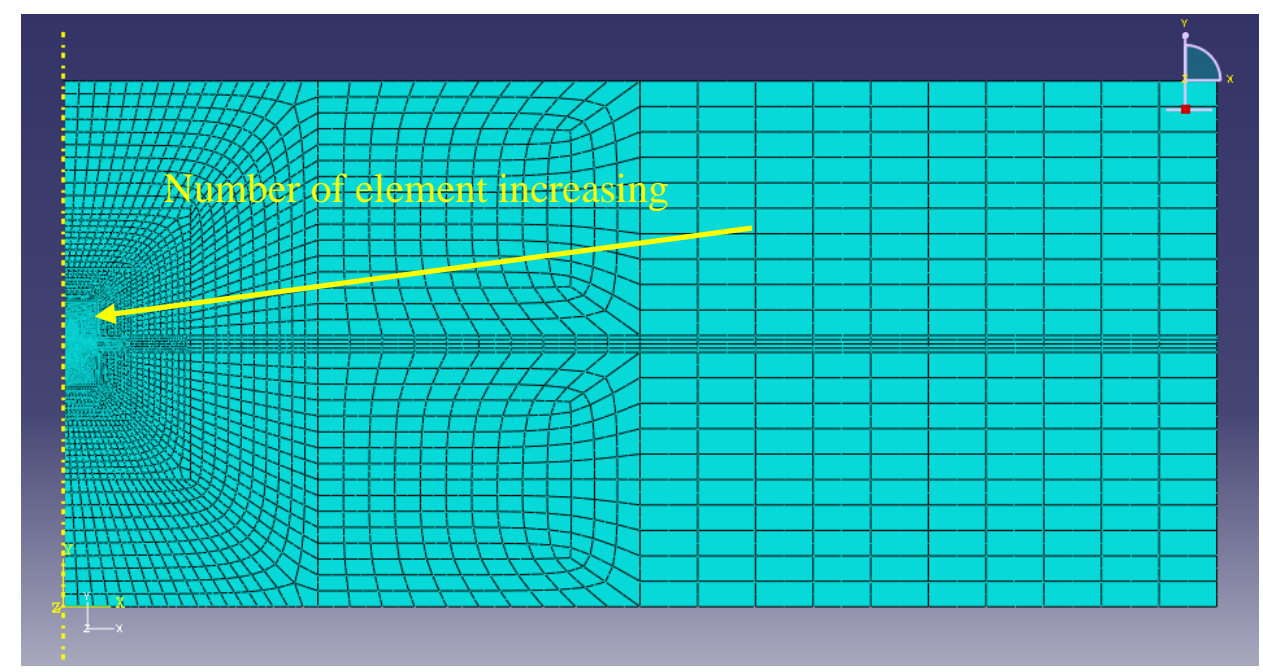

Fig. 3.8 - The modified model meshing. Casing area connected with the reservoir has finer mesh than the reservoirs outer boundary for accuracy

\subsubsection{Reservoir Compaction Model by Chia (1989)}

To validate the model, the results are compared to a model created by Chia (1989). Fig. 3.9 shows Chia's the axial casing strain according to depth. The highlighted region represents the reservoir region. $\mathrm{R} 1$ has the height of $50 \mathrm{ft}$, which is the same height as the modified model. The $\mathrm{R} 1$ reservoir has a production rate of 1,200 B/D. R2 and R3 have heights of $25 \mathrm{ft}$ and production rates of $600 \mathrm{~B} / \mathrm{D}$. Model results are compared to the R1 reservoir for model validation. Fig. 3.10 shows the result of model axial casing strain. The behavior of casing axial strain is a little different from Chia's model. However, the maximum axial casing strain is quite close. Chia's maximum casing strain is about $2 \%$; the modified model maximum casing strain is about $1.9 \%$. The difference in the result may come from computer processing power and size of mesh used. 


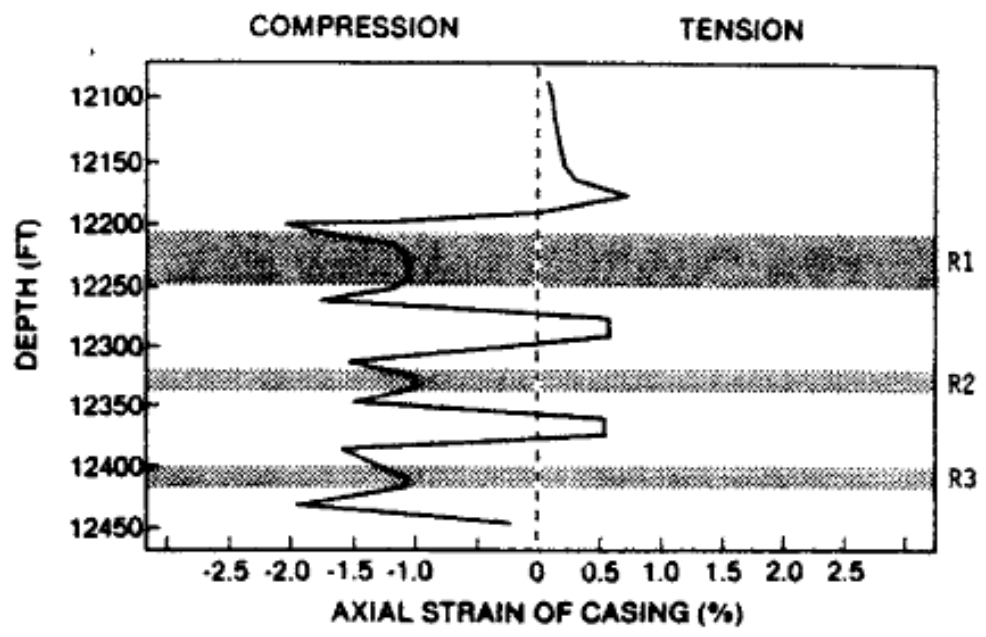

Fig. 3.9-Chia's (1989) maximum casing axial strain for reservoir R1 is about $2 \%$

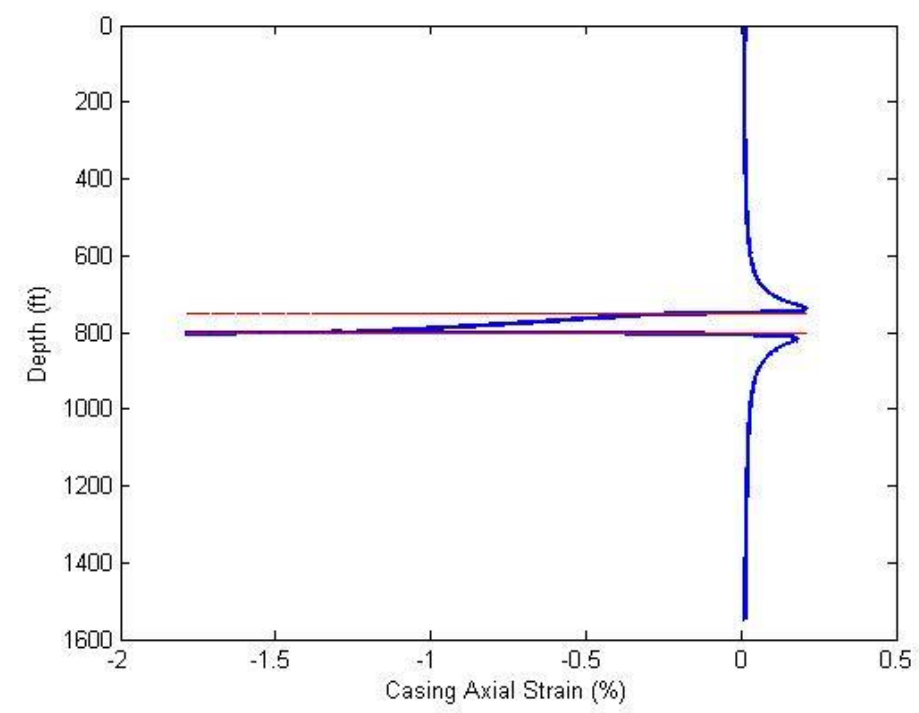

Fig. 3.10 - The modified model maximum casing axial strain is about $1.9 \%$, which is close to Chia's

Fig. 3.11 shows the axial casing stress result from Chia's model. Comparing R1 results to the modified model results shows that the axial stress behaves in the same manner and the model results are within range of Chia's. The difference between the modified model is axial stress and Chia's stress is that the modified model starts in 
compression where Chia's axial stress starts in tension. The modified model axial stress starts in compression because of the overburden load at the top of the model.

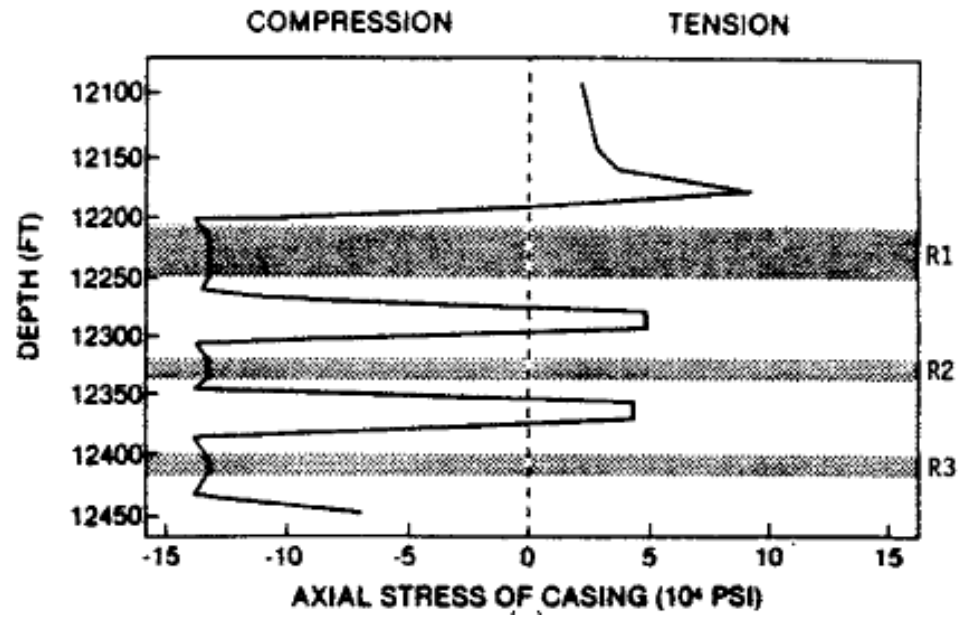

Fig. 3.11 - Chia's maximum casing axial stress for reservoir $R 1$ is about 14,000 psi

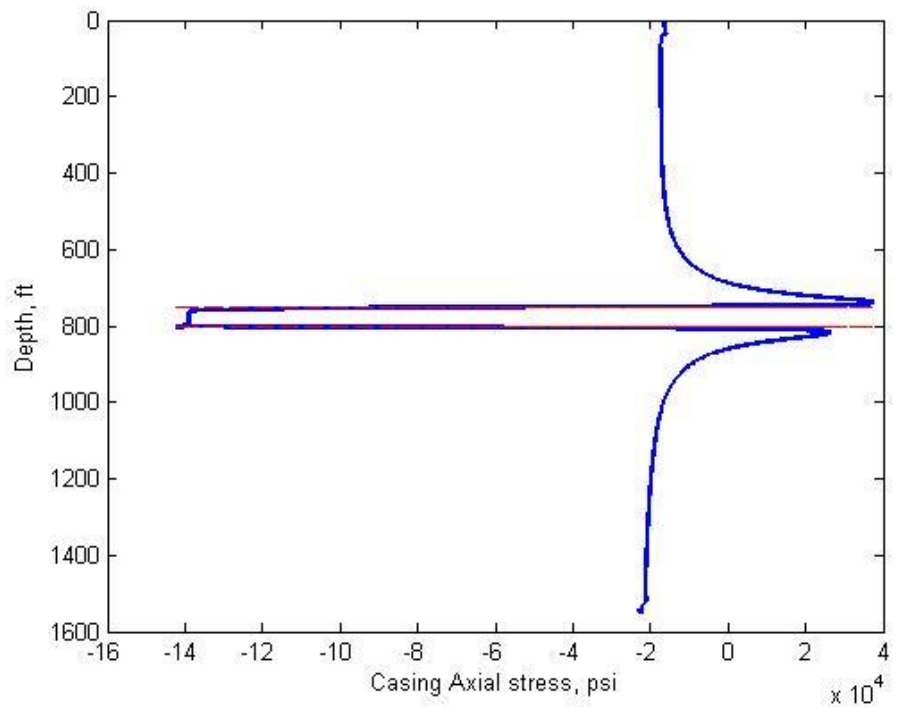

Fig. 3.12 - The modified maximum casing axial stress is about 14,000 psi, which is close to Chia's 


\subsubsection{Model Modification}

The reservoir compaction model was successfully created and validated by Chia's (1989) model. However, this model does not account well for pressures in the reservoir.

Abaqus does not allow users to input the drawdown or the depletion pressure data. Only the reservoir depletion pressure can be accounted for accurately using Abaqus. This is because the permeability input in Abaqus controls both the permeability of the formation in darcies and the production rate in volume/time, but not just the permeability.

Using soil step and specifying the pore pressure boundary at the casing, a pore pressure movement is simulated across the reservoir. If permeability input for Chia's model is used, the pore pressure across the reservoir shows the drawdown effect. If a higher permeability value is used, the reservoir pressure become constant across the reservoir. The reservoir pressure is also equal to the specified pressure at the casing. This method accounts for the change in reservoir pressure easily and accurately.

Fig. 3.13 compares Chia's plot of pore pressure vs. the reservoir radius compare to the modified model used in this thesis. For both methods, a wellbore pressure around the perforation is specified with 2,200 psi. The pressure at the radius of the reservoir is reduced from the original at 8,500 psi to around 6,800 psi for Chia's (1989) model and 2,200 for the modified model. In Chia's model, the oil produced is from around the wellbore with a little bit in the outer reservoir radius, and drawdown pressure affects the casing producing axial strain around $1.8 \%$ (Fig. 3.10). 


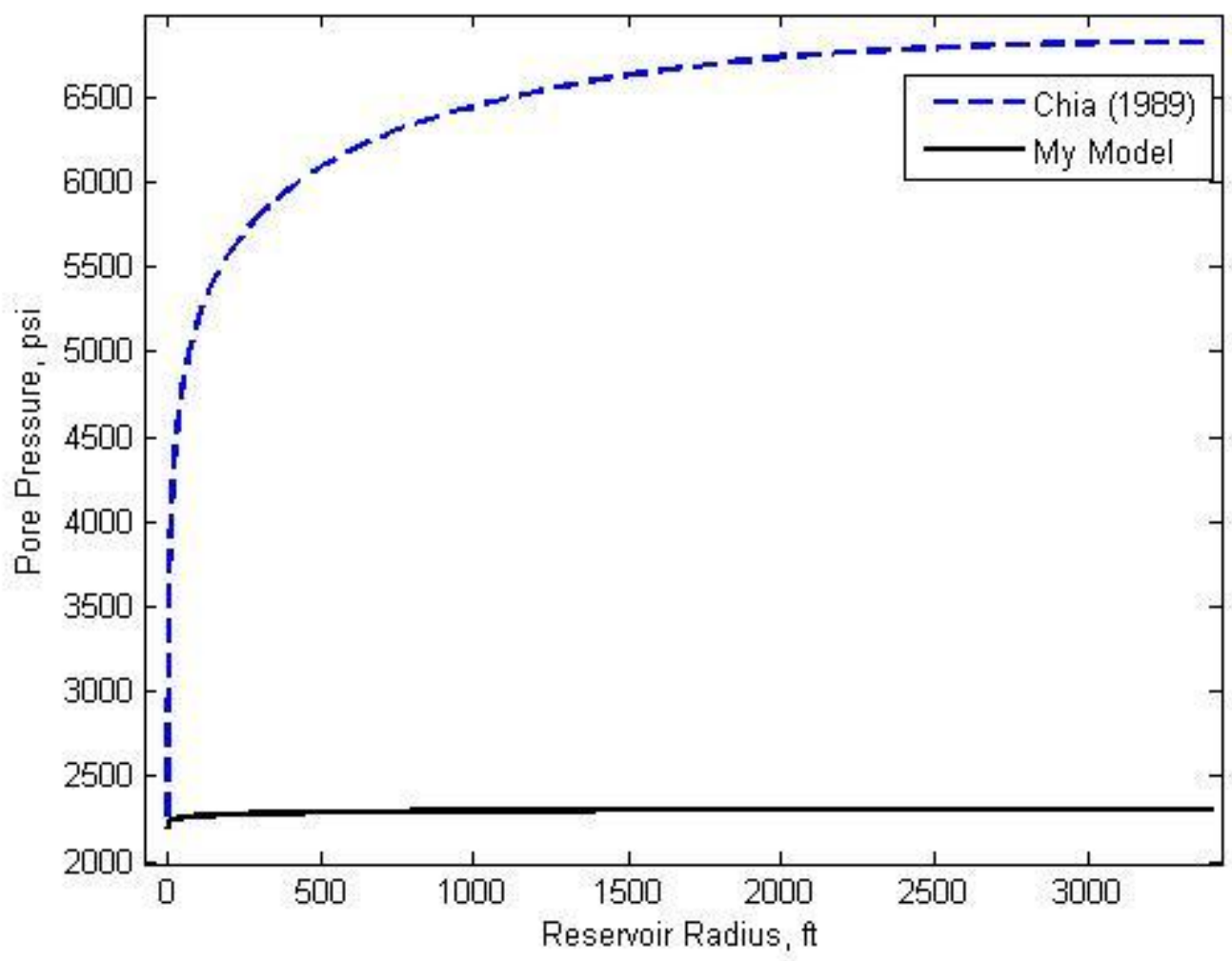

Fig. 3.13 - The difference in pore pressure across the reservoir is shown for two methods used in simulation

\subsubsection{Experimental Design}

Experimental design is introduced to design the value for each parameter input to run in Abaqus. WIth Statistical Toolbox, additional toolbox in Matlab, the simulation cases are designed for 70 different cases. Table 3.1 shows the range of parameters used for the experimental design. The design style is the space-filling design style, which is best when not much information about the model is known. It is best used in cases that call for a whole range of results from a given range of inputs. This is because the spacefilling design maximizes all possible occurrences with the given parameter ranges. 
Table 3.1 - Ranges of input data for parameters in experimental design

\begin{tabular}{lcc}
\hline Variable & Symbol & Range \\
\hline Reservoir Young's & $\mathrm{E}_{\mathrm{r}}$ & $14,500-4,350,000$ \\
Modulus of Elasticity (psi) & $v_{\mathrm{r}}$ & $0.05-0.35$ \\
Reservoir Poisson ratio & $\varphi_{\mathrm{r}}$ & $3-40$ \\
Reservoir Porosity (\%) & & \\
Cement Young's & $\mathrm{E}_{\mathrm{ce}}$ & $1,740,000-2,610,000$ \\
Modulus of Elasticity (psi) & $v_{\mathrm{ce}}$ & $0.20-0.33$ \\
Cement Poisson ratio & $\sigma_{\mathrm{c}}$ & $40,000-110,000$ \\
${ }^{\mathrm{a}}$ Casing Yield Stress (psi) & & \\
Casing Young's & $\mathrm{E}_{\mathrm{c}}$ & $28,300,000-30,000,000$ \\
Modulus of Elasticity (psi) & $v_{\mathrm{c}}$ & $0.27-0.30$ \\
Casing Poisson ratio & $\mathrm{OD}$ & $4.5-20$ \\
${ }^{\mathrm{b}}$ Casing Outer Diameter (inches) & $\mathrm{T}$ & $0.25-0.635$ \\
${ }^{\mathrm{c}}$ Casing Thickness (inches) & $\mathrm{dP}$ & $2200-8500$ \\
Depletion Pressure (psi) & & $58,000-10,000,000$ \\
Shale Young's & $\mathrm{E}_{\mathrm{s}}$ & $0-0.30$ \\
Modulus of Elasticity (psi) & $v_{\mathrm{s}}$ & $3-40$ \\
Shale Poisson ratio & $\varphi_{\mathrm{r}}$ & \\
Shale Porosity (\%) &
\end{tabular}

${ }^{\mathrm{a}}$ Discrete variable with values of 40,$000 ; 55,000 ; 75,000 ; 80,000 ; 90,000$; 95,000; 110,000.

${ }^{\mathrm{b}}$ Discrete variable with values of $4.5,5.0,5.5,6.625,7.0,7.625,8.625$, 9.625, 10.75, 11.75, 13.375,16, 18.625, 20

${ }^{\mathrm{c}}$ Discrete variable with values of $0.244,0.25,0.352,0.375,0.395,0.43$, $0.435,0.45,0.48,0.489,0.5,0.54,0.557,0.635$

\subsection{Probabilistic Demand Model for Reservoir Compaction}

The probabilistic demand model represents reservoir compaction behavior load on the casing. The probabilistic demand model has the general form of 


$$
D_{c}(x, \Theta)=\hat{d}_{c}(x)+\gamma\left(x, \theta_{c}\right)+\sigma_{c} \varepsilon_{c}
$$

$\hat{d}_{c}(x)$ is the deterministic model, which account for the current reservoir compaction approximation method. $\gamma_{c}\left(x, \theta_{c}\right)$ is the model correction term for any bias that the deterministic design has, compared to the actual occurring results, or in this case the simulation results. The model correction term is expressed in terms of $x$ variable and $\theta_{c}$ , unknown parameters. $\sigma_{c}$ is the standard deviation of the model error. $\varepsilon_{c}$ is a random variable with zero mean and unit variance. The rest of this chapter will explain the process of constructing each term in the probabilistic demand model by determining each of the terms in the probabilistic model.

\subsubsection{Deterministic Model Selection}

From the literature review, three deterministic models that approximate the magnitude of reservoir compaction are the Settari (2003) model, the Fjaer (1998) lab experiment correlation model, and the soft rock model by Ibekwe et al. (2003). Fjaer 
(1998) model is based on lab experiments where sandstone was put into a confining pressure and pore pressure. The experiment started by loading the sandstone sample with constant confining pressure. The pore pressure was reduced and then the deformation of the sample was recorded. The sandstone strain is written as

$$
\varepsilon_{z}=\frac{1-v_{s}-2 v_{s}{ }^{2}}{\left(1-v_{s}\right) E_{s}} \Delta P,
$$

$v_{s}$ is the sandstone Poisson ratio, $E_{s}$ is the sandstone Young's modulus of elasticity, and $\Delta P$ is the change in pore pressure. The Settari (2003) model used Fjaer's (1998) model but also included $\alpha$, Biot's constant or poroelastic constant, to account for the actual pore fluid behavior in rock.

$$
\varepsilon_{z}=\left[\frac{\alpha\left(1-v_{s}-2 v_{s}^{2}\right)}{\left(1-v_{s}\right)}\right] \frac{\Delta P}{E_{s}}
$$

Last, in the model proposed in Ibekwe et al. (2003) for a soft rock, the vertical formation strain is written as

$$
\varepsilon_{z}=\frac{\left(1+v_{s}\right)}{\left(1-v_{s}\right) E_{s}} \Delta P
$$

Ibekwe et al. (2003) used Settari's (2003) model for stiff rock in the formation. To choose the best-fit deterministic model for simulation results, the three models are compared (Figs. 3.14 and 3.15) with the simulation result. 


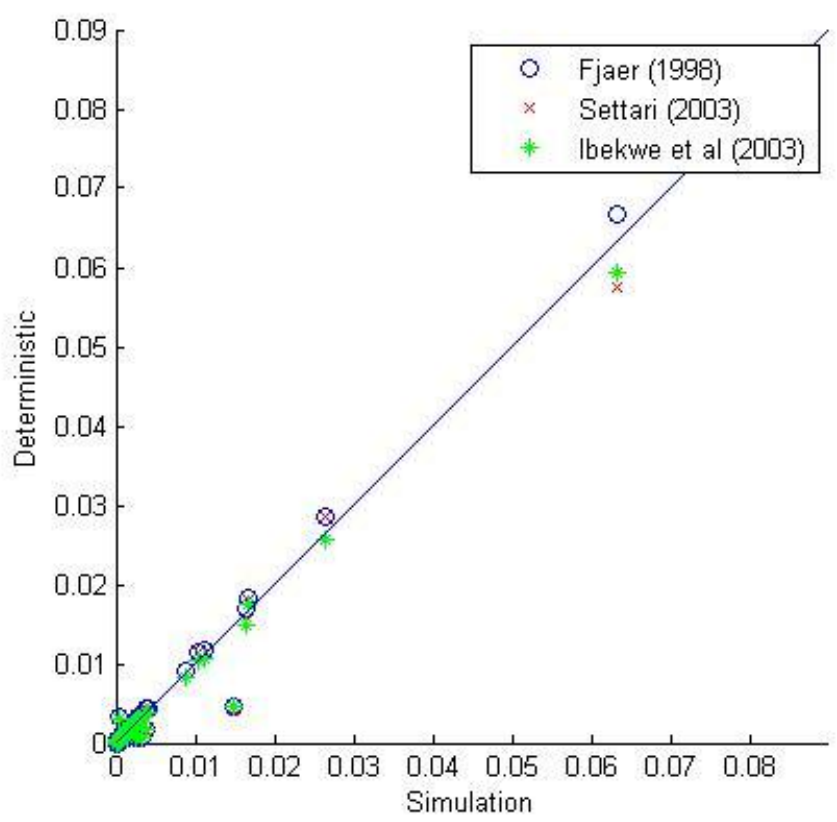

Fig. 3.14-Comparison of three deterministic models to simulation results

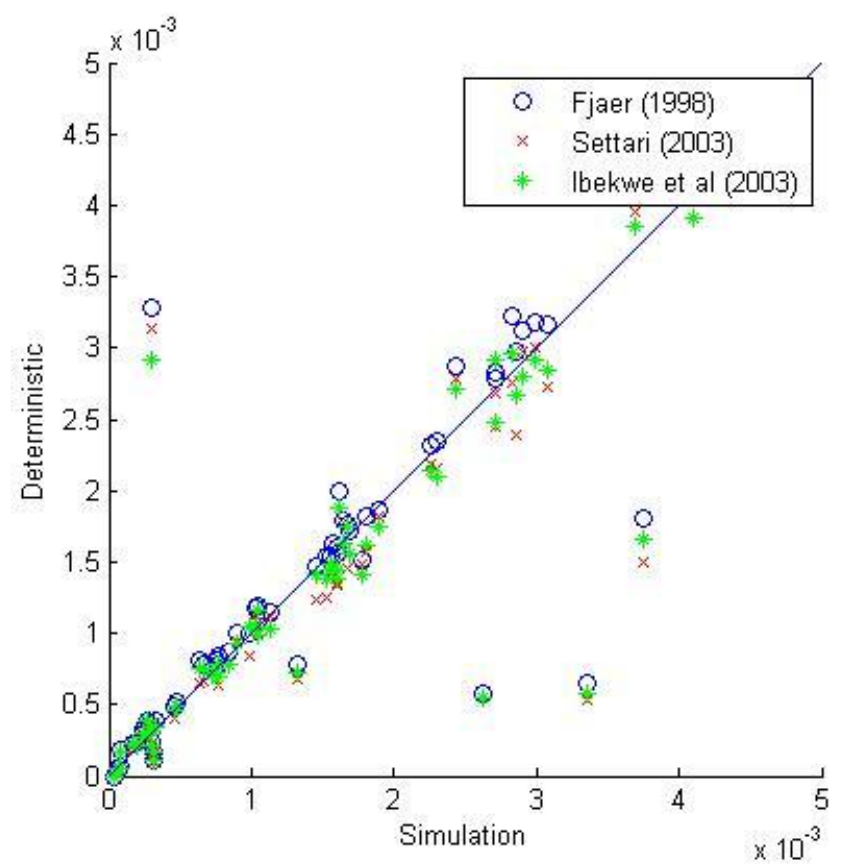

Fig. 3.15-Closer look of the comparison illustrates that the deterministic models is accurate in predicting casing axial strain 
Figs. 3.14 and 3.15 show that all three models agree with the result of the simulation. The 1:1 reference lines are plotted on both figures to compare the deterministic model results with the simulation, which is the actual results. Points lying along the 1:1 line mean that the deterministic model approximation is equal to the actual results. However, a graphical figure does not show how exactly those points lie on the 1:1 lines. To find the best-fit model for the deterministic term in the probabilistic model, mean absolute percentage error, MAPE, is used. The lowest error provided by MAPE computation is the best-fit model. The MAPE computational formulation is show as

$$
M A P E=\frac{1}{n} \sum_{i=1}^{n}\left|\frac{A_{i}-F_{i}}{A_{i}}\right|,
$$

where $n$ is the total number of simulation, $A_{i}$ is the actual data, which is the each simulation result, and $F_{i}$ is the predicted value from each of the model shown above.

\section{Table 3.2- MAPE of the deterministic models}

\begin{tabular}{lc}
\hline Deterministic Model & MAPE \\
\hline Fjaer (1998) & $15.40 \%$ \\
Settari (2003) & $15.10 \%$ \\
Ibekwe et al (2003) & $14.30 \%$ \\
\hline
\end{tabular}

Table 3.2 shows the MAPE results, confiming the Ibekwe et al. (2003) model is best-fit for the deterministic term with the lowest error in the probabilistic model. Thus, the deterministic model is written as 


$$
\hat{d}_{c}(x)=\frac{\left(1+v_{s}\right)}{\left(1-v_{s}\right) E_{s}} \Delta P,
$$

where the three parameters $E, v$, and $\Delta P$ are random variables with lognormal distribution.

\subsubsection{Correction Term for Bias in the Deterministic Model}

The deterministic model cannot fully represent the simulation results. The correction term should correct any bias that the deterministic model has on the simulation results, which represent the actual field results. Graphically, Fig. 3.15 shows that the deterministic model does not have any bias compared to the simulation results because the points are close on the 1:1 reference line. The correction term for bias in the deterministic model cannot be determined graphically. To determine accurately the correction term for bias in the deterministic model, diagnostic plots for each parameter in the simulation are used. The diagnostic plot shows the effect of a parameter on the differences between the simulation result and the deterministic model. Figs. 3.16 to 3.30 show the diagnostic plots for different parameters.

If a parameter has any bias on the deterministic model, the diagnostic plot would show a trend line. As shown from the diagnostic plots below, the parameter values are mostly zero as the values for the differences in the simulation results and deterministic model increase. Thus, the deterministic model is unbiased. This term is excluded from the probabilistic demand model. However, $\theta_{1}$, a constant parameter to account for 
uncertainty in the deterministic model, is included into the probabilistic model to make it a linear model. $\theta_{l}$ is an unknown model parameter.

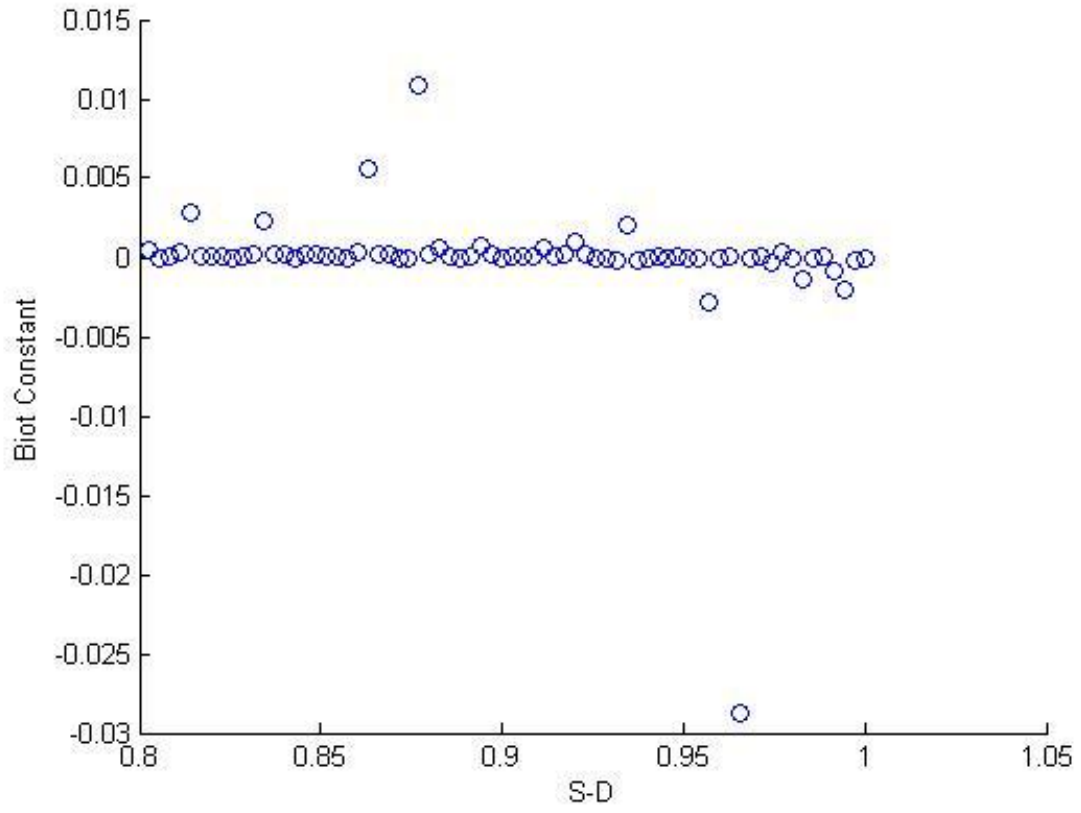

Fig. 3.16-Diagnostic plots for Biot constant 


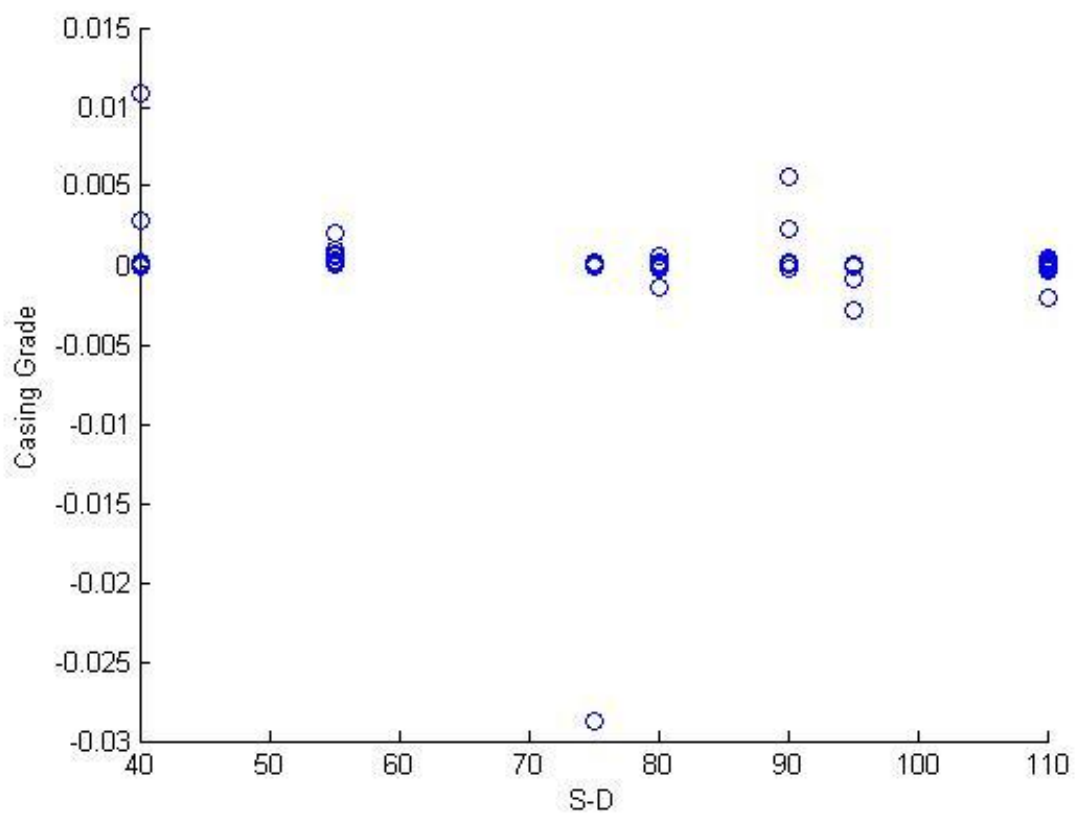

Fig. 3.17-Diagnostic plots for casing grade

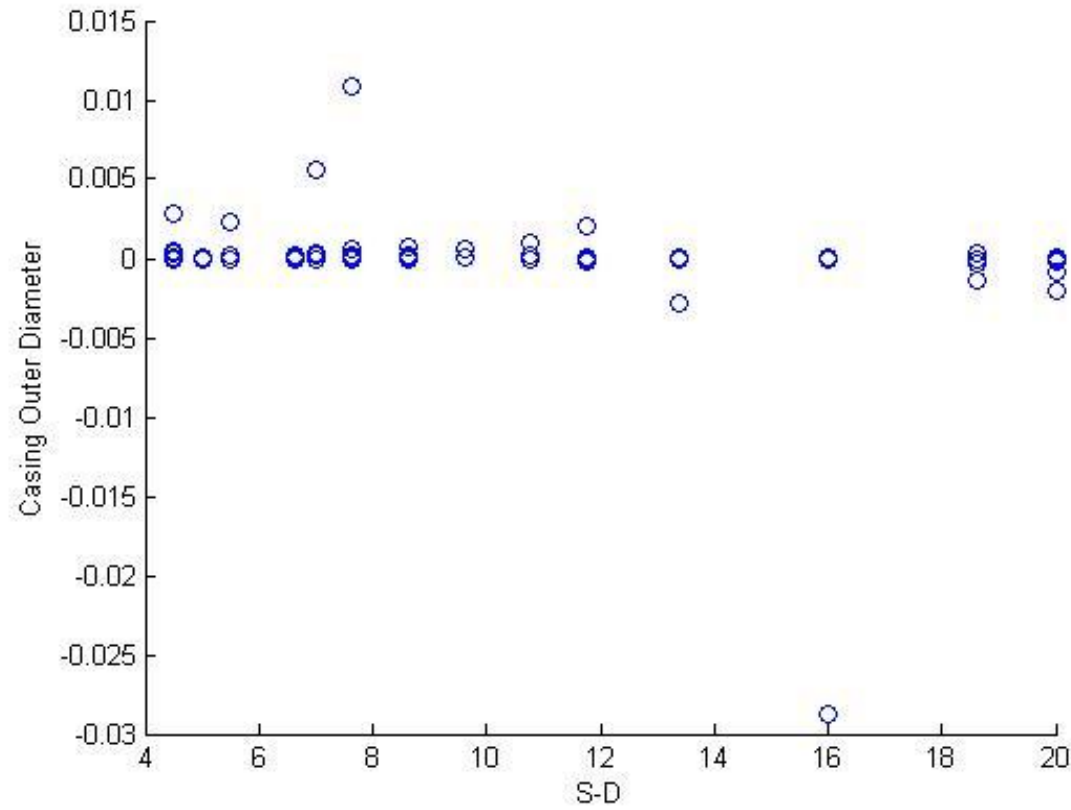

Fig. 3.18 - Diagnostic plots for casing outer diameter 


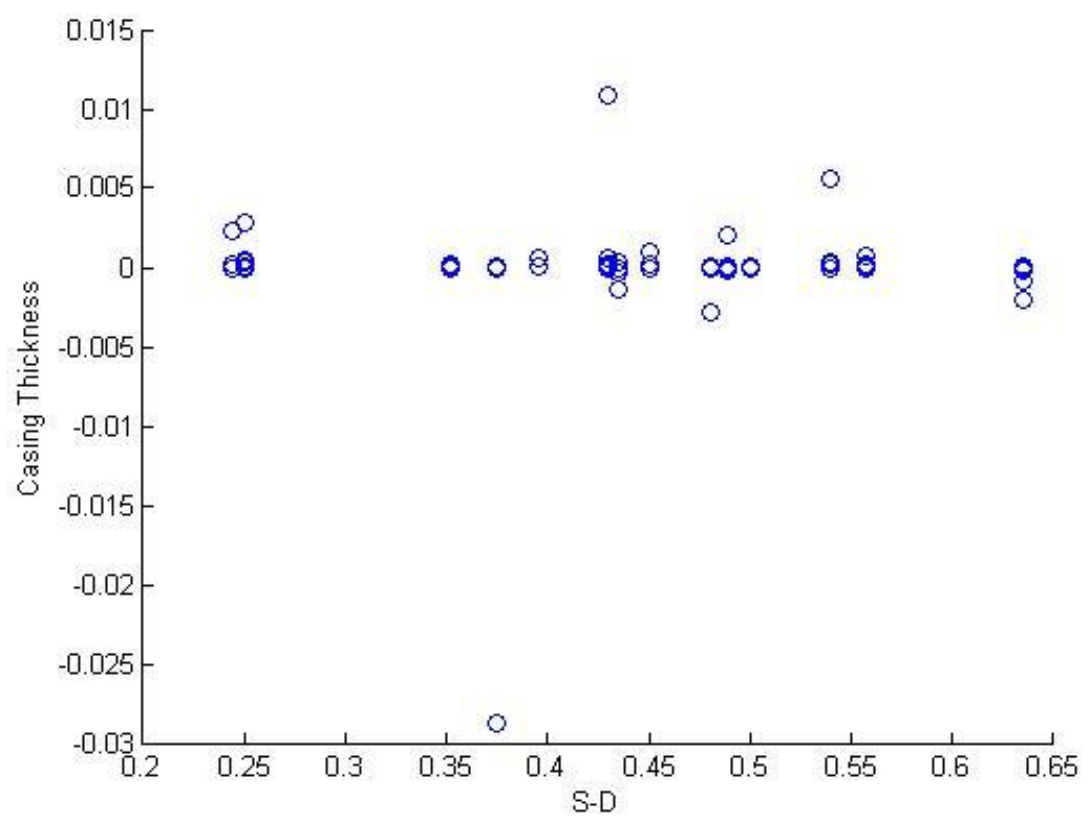

Fig. 3.19—Diagnostic plots for casing thickness

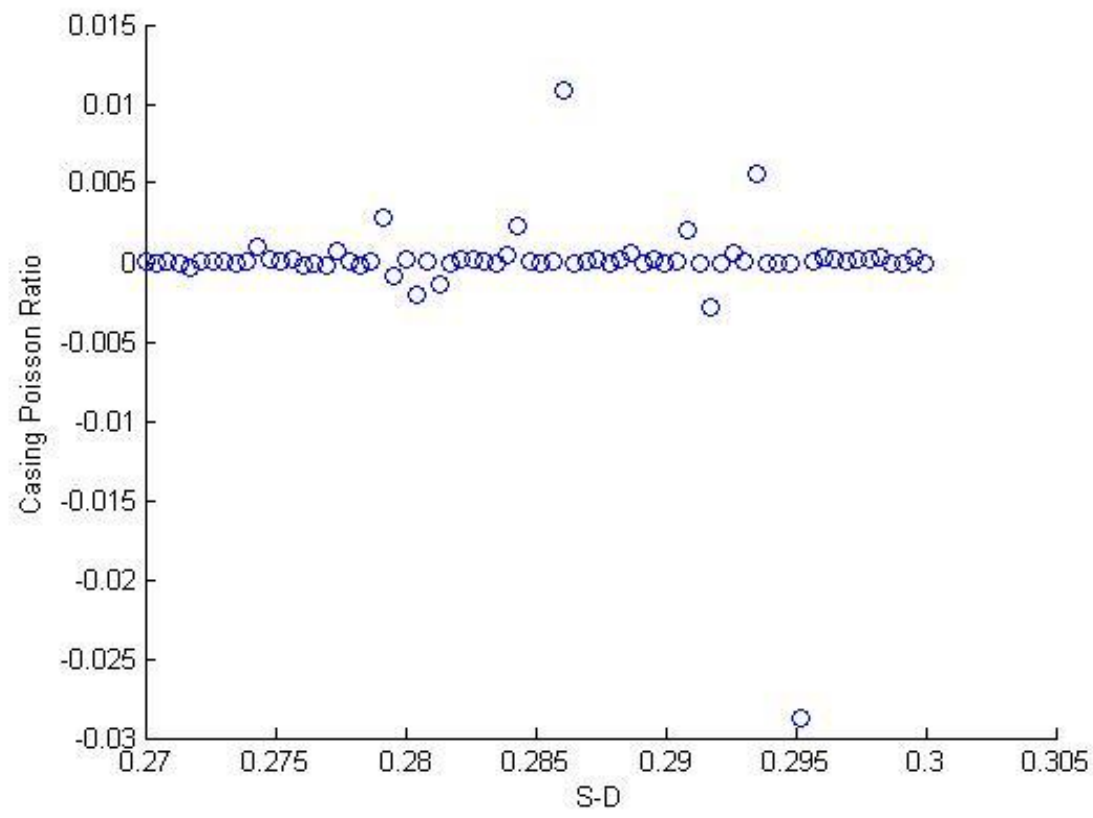

Fig. 3.20-Diagnostic plots for casing Poisson's ratio 


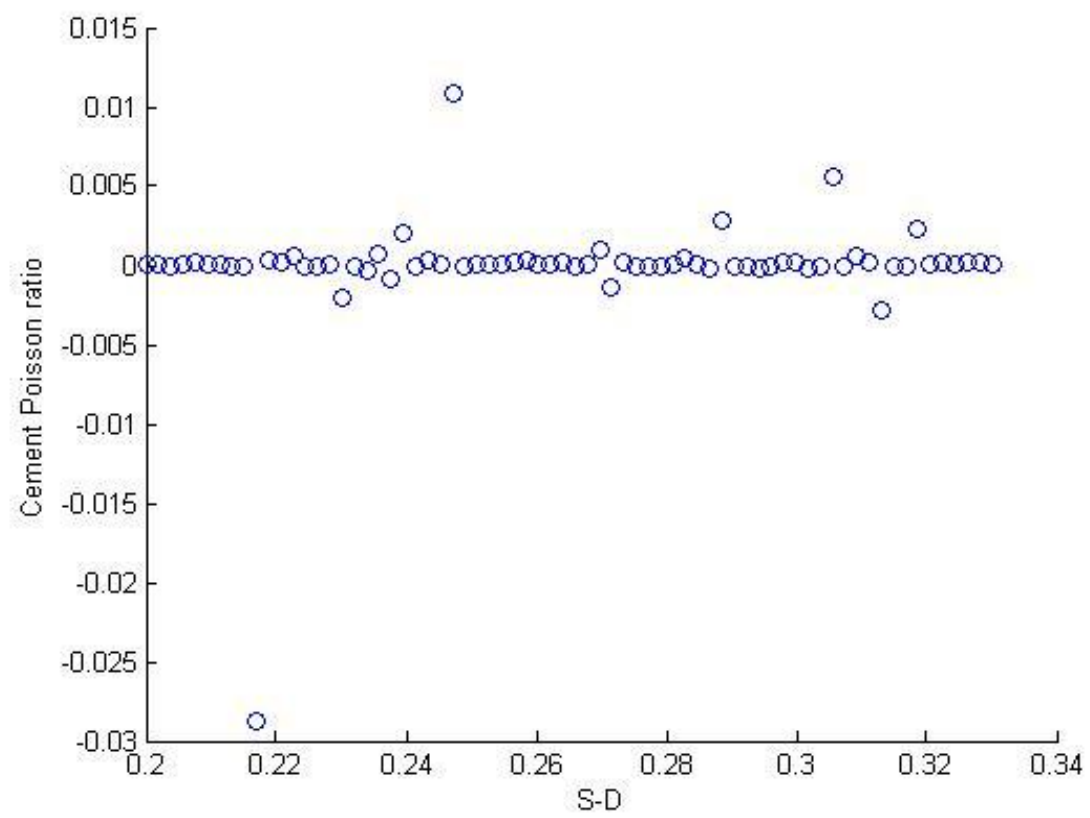

Fig. 3.21-Diagnostic plots for cement Poisson's ratio

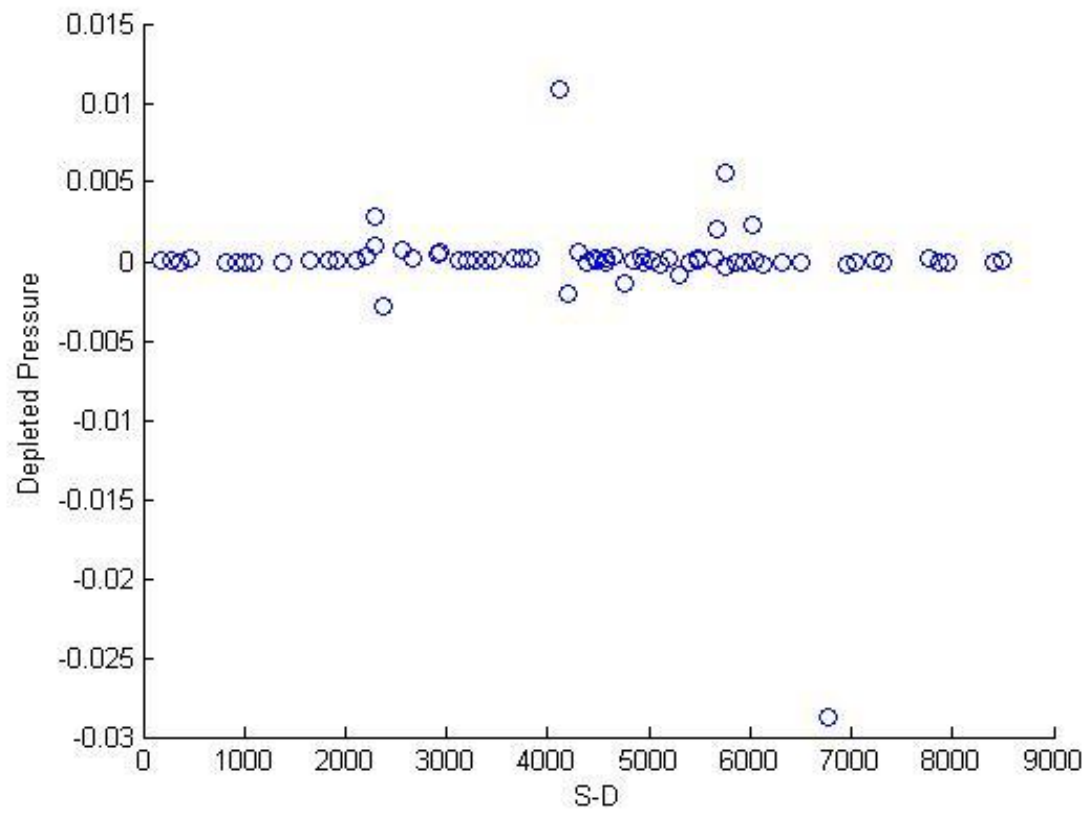

Fig. 3.22-Diagnostic plots for depleted pressure 


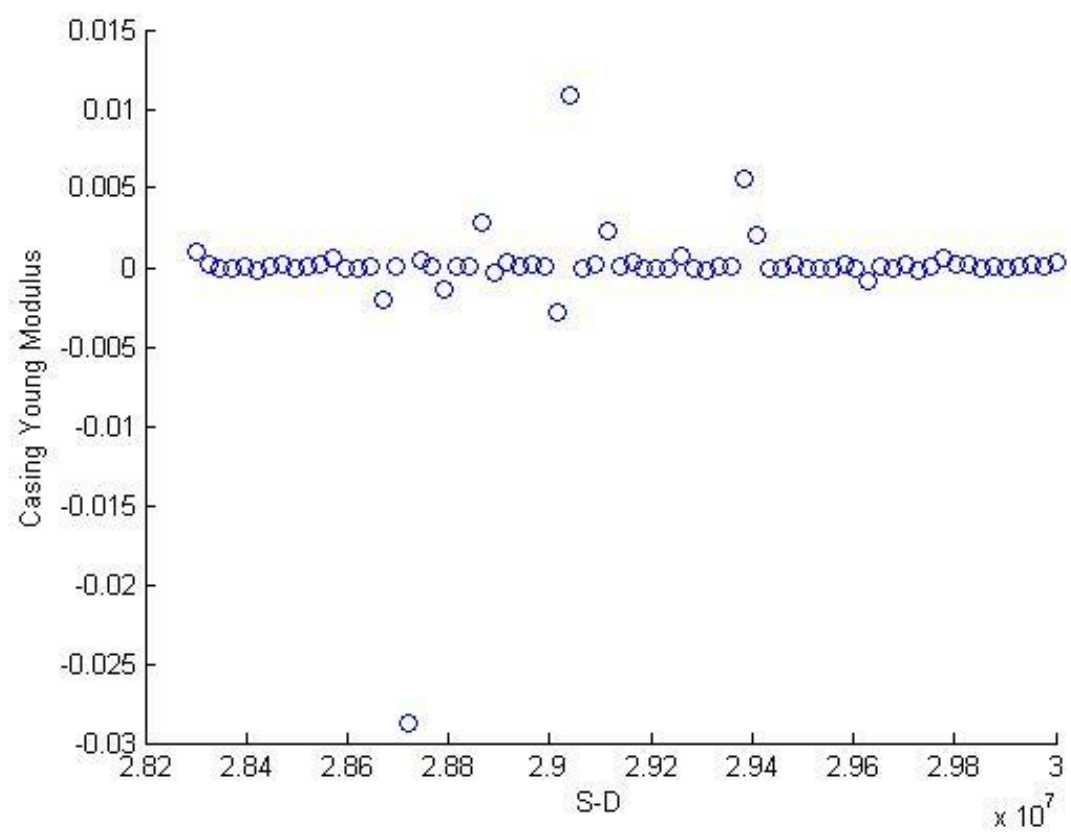

Fig. 3.23 - Diagnostic plots for casing Young's modulus

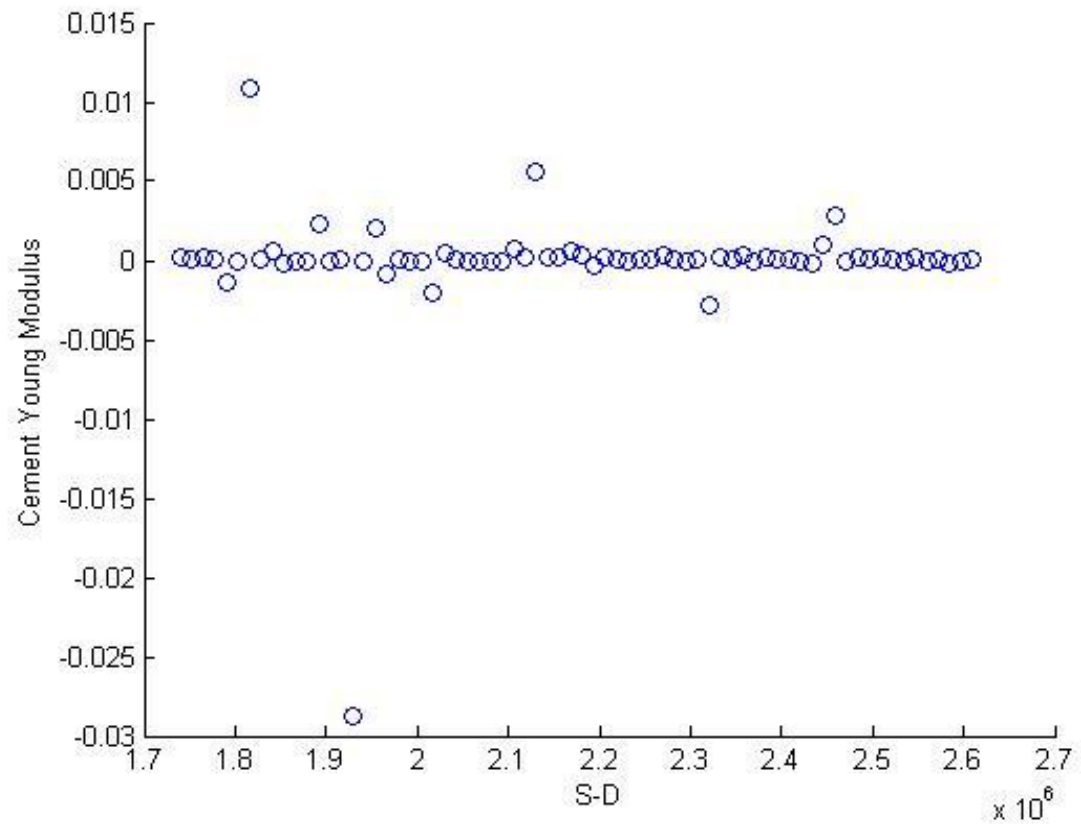

Fig. 3.24-Diagnostic plots for sandstone Poisson's ratio 


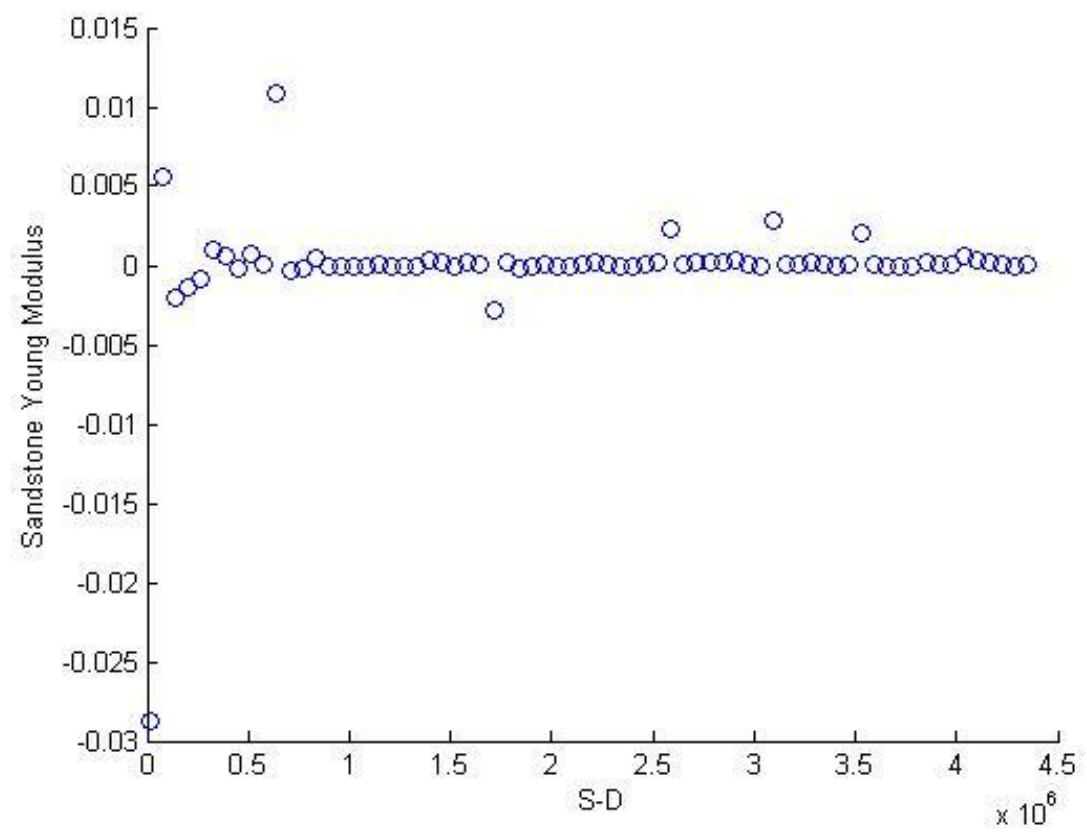

Fig. 3.25-Diagnostic plots for sandstone Young's modulus

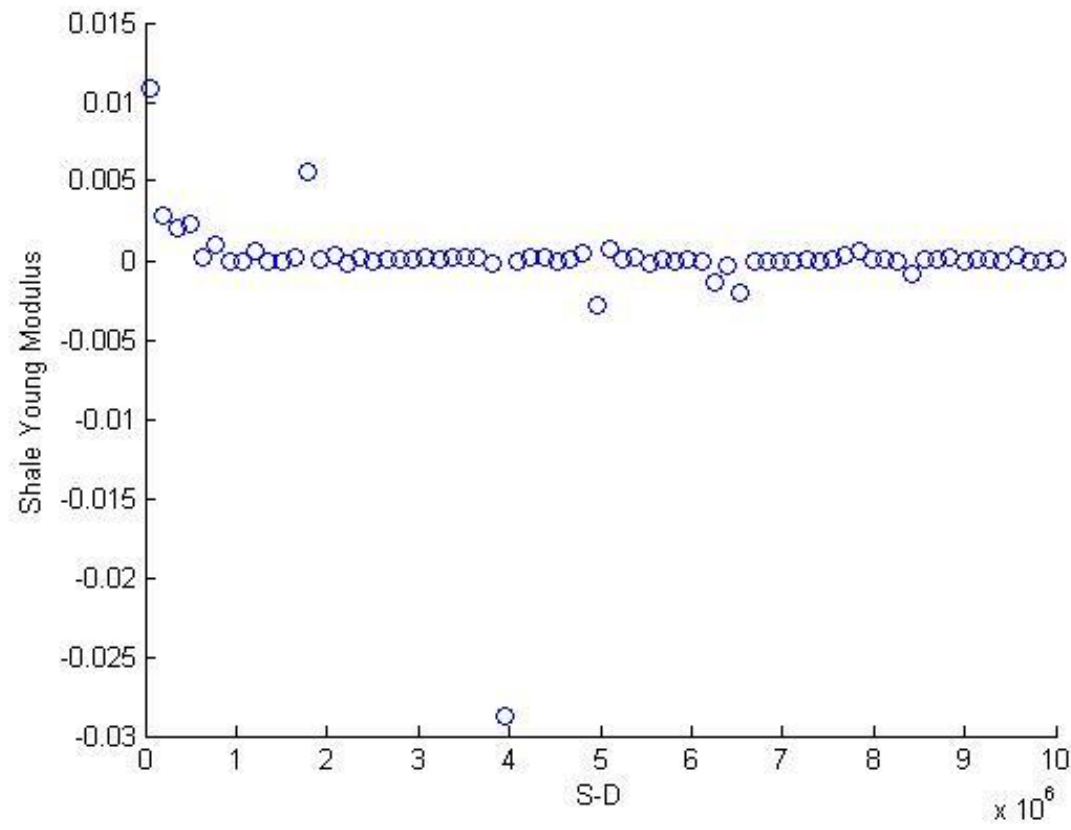

Fig. 3.26-Diagnostic plots for shale Young's modulus 


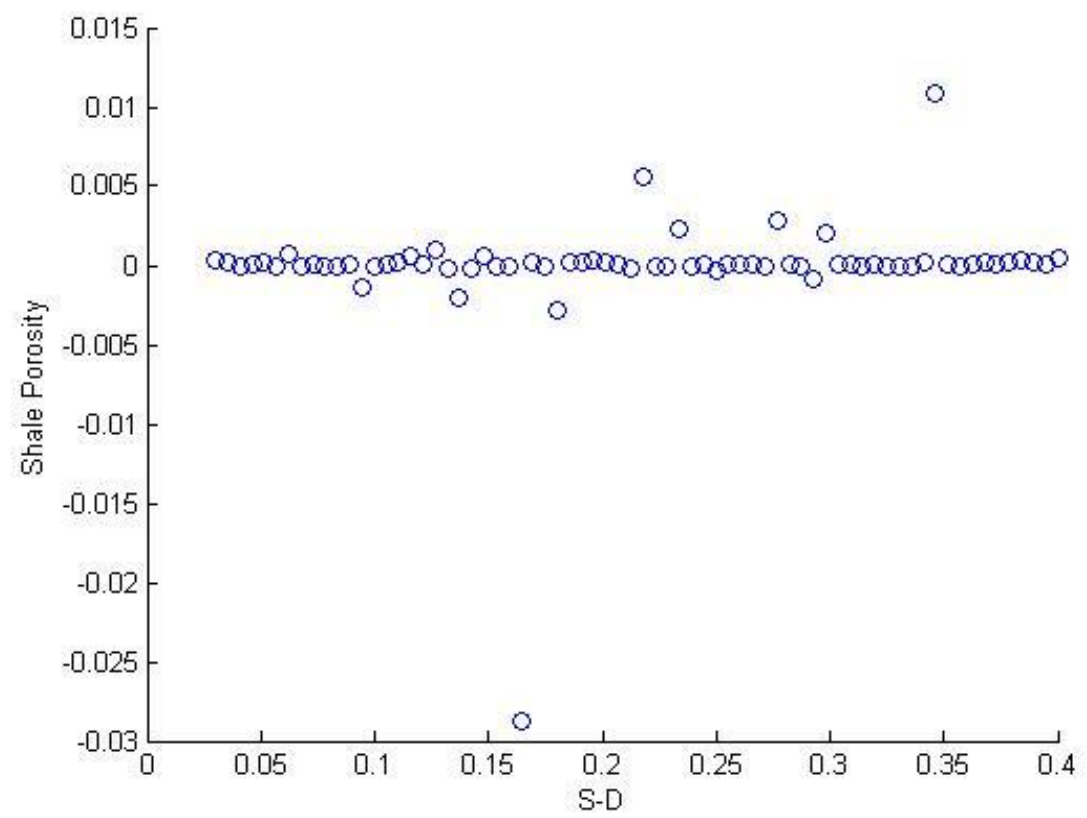

Fig. 3.27-Diagnostic plots for shale porosity

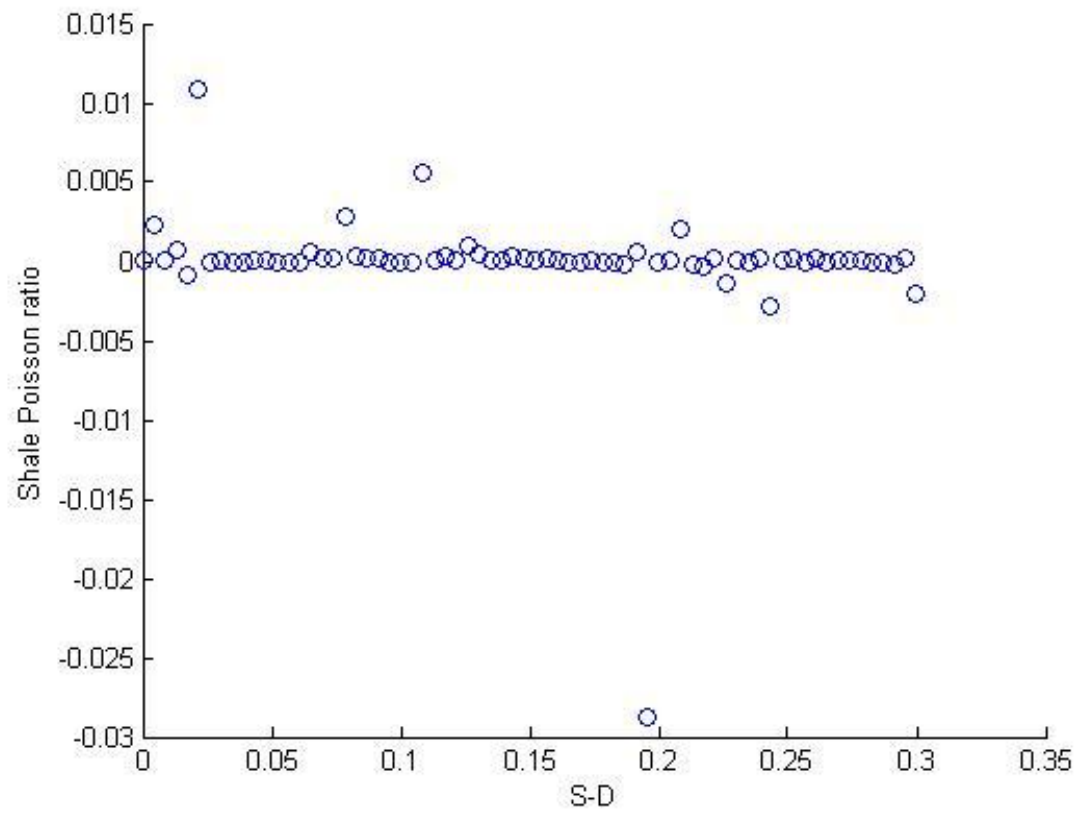

Fig. 3.28 - Diagnostic plots for shale Poisson's ratio 


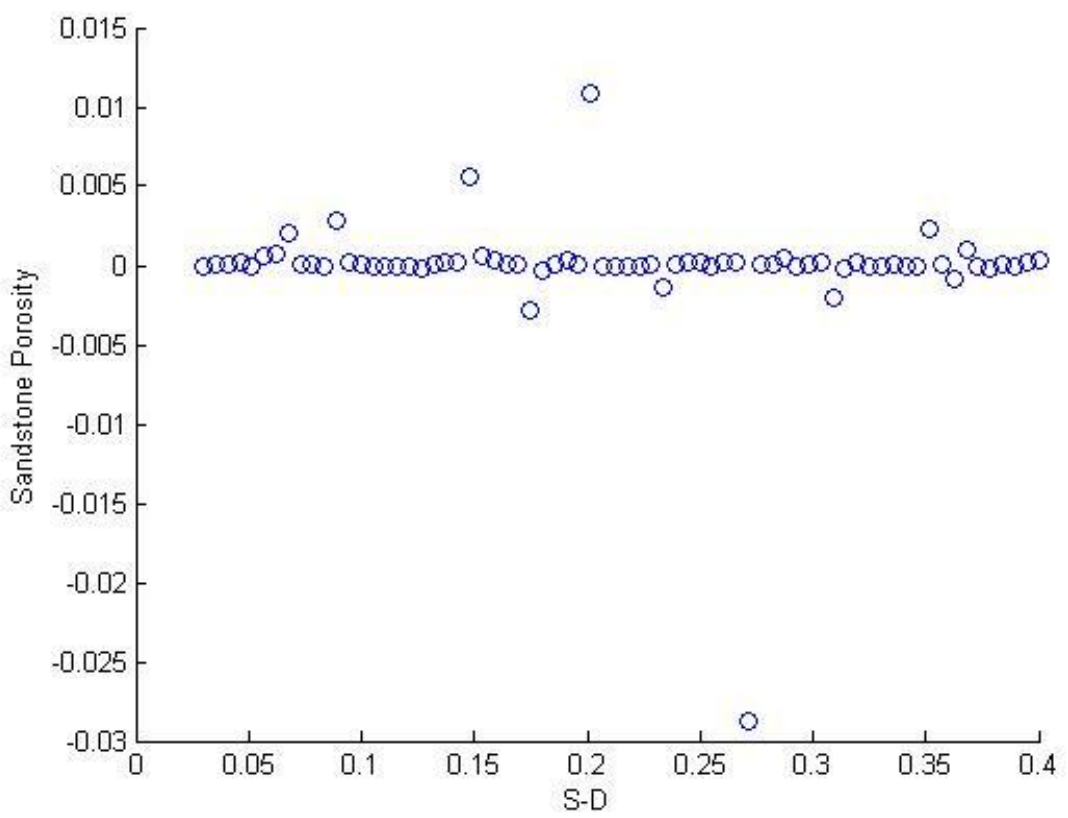

Fig. 3.29-Diagnostic plots for sandstone porosity

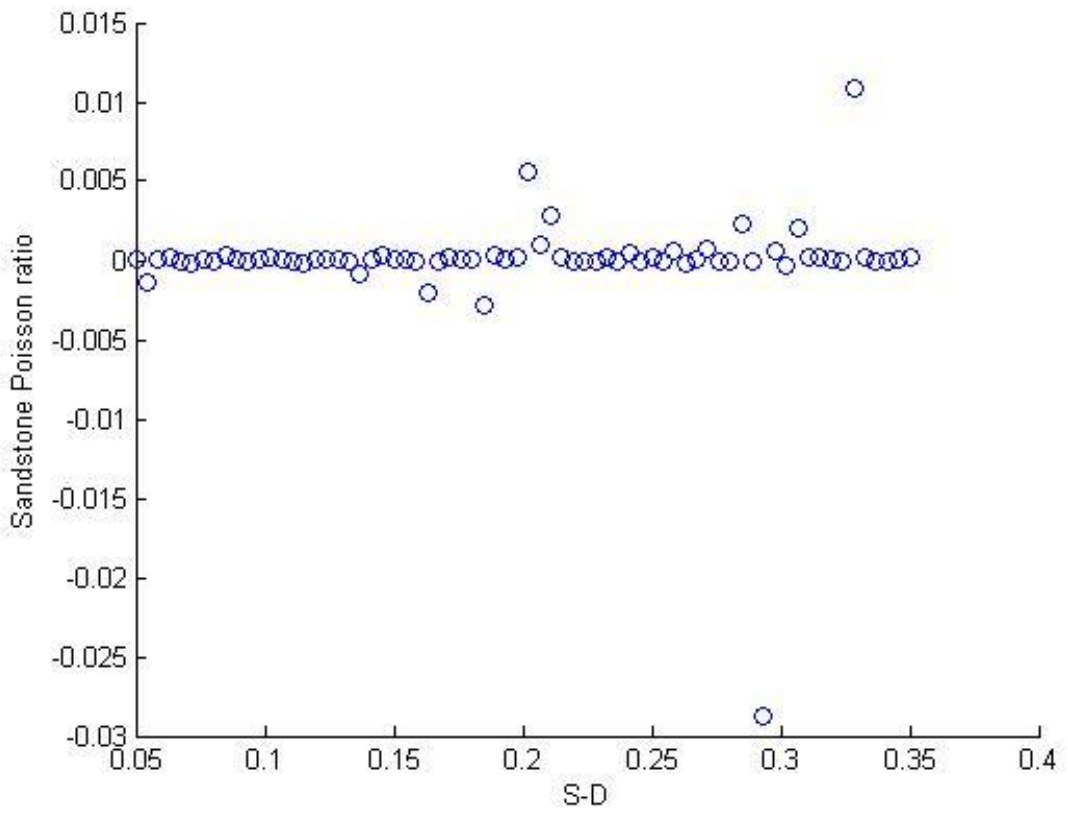

Fig. 3.30 - Diagnostic plots for sandstone Poisson's ratio 


\subsubsection{Standard Deviation of Model Error}

The probabilistic demand model is written as linear model where the original form is

$$
Y=H \theta+\sigma \varepsilon
$$

and each parameter is a vector matrix axs shown below.

$$
\left[\begin{array}{c}
Y_{1} \\
\vdots \\
Y_{i} \\
\vdots \\
Y_{n}
\end{array}\right]=\left[\begin{array}{ccc}
H_{11} & \cdots & H_{k 1} \\
\vdots & & \vdots \\
H_{1 i} & \cdots & H_{k i} \\
\vdots & & \vdots \\
H_{1 n} & \cdots & H_{k n}
\end{array}\right]\left[\begin{array}{c}
\theta_{1} \\
\vdots \\
\theta_{k}
\end{array}\right]+\sigma\left[\begin{array}{c}
\varepsilon_{1} \\
\vdots \\
\varepsilon_{i} \\
\vdots \\
\varepsilon_{n}
\end{array}\right]
$$

The probabilistic demand model is written as

$$
D_{d}(x, \Theta)=\hat{d}_{d}(x)+\theta_{1}+\sigma_{d} \varepsilon_{d}
$$

Linear regression analysis is performed to determine $\sigma_{d}$, the standard deviation of the model error and $\theta_{1}$, the unknown model parameter. $Y$ is represented as the simulation result strains minus the deterministic model strains. The $H$ matrix is represented as $1 \times 64$ matrixes, with a total of 70 results from simulations. However, six results are not accurate. They do not take into account. $\varepsilon_{\mathrm{d}}$ is the model error which has a normal distribution with a mean of zero and a unit standard deviation.

According to Gardoni (2002), $\theta_{l}$ has a t distribution, $t_{k}\left(\hat{\theta}, s^{2}\left(H^{\prime} H\right)^{-1}, \eta\right)$ and $\sigma_{c}$ has an inverse chi square distribution, $\eta s^{2} \chi^{-2} . \theta_{1}$ has the mean and variance of $\hat{\theta}$ and $\eta s^{2}\left(H^{\prime} H\right)^{-1} /(\eta-2) . \sigma_{c}$ has the mean and variance of $\eta s^{2} /(\eta-2)$ and $2 \eta^{2} s^{4} /\left[(\eta-2)^{2}(\eta-4)\right]$ 
Giving all the terms in the probabilistic demand model, the probabilistic demand model is written as

$$
D_{c}(x, \Theta)=\left(\frac{1+v_{f}}{E_{f}}\right) \Delta P+\theta_{1}+\sigma_{d} \varepsilon_{d}
$$




\section{CHAPTER IV}

\section{CASING FRAGILITY ESTIMATES}

\subsection{Introduction}

In the previous chapter, the probabilistic capacity models and the probabilistic demand model were created for two modes of casing failure, which are axial yielding and buckling. In this chapter, the probabilistic models are used to construct the limit state functions. To show the application of structural reliability, the input values and distribution are assumed for a specific field. The input parameters are the Young's modulus of elasticity and Poisson's ratio. It is recommended to acquire actual field data for accurate results for a specific field.

\subsection{Fragility Estimate Computation}

FERUM, a computative program using MATLAB, was used in computing the

reliability index and probability of failure for given capacity and loading models for both compression and buckling failure. The first-order reliability method (FORM) and Monte Carlo simulation were used to compute reliability index $(\beta$, beta). The purpose of performing two computations is because FORM required less computation time than Monte Carlo simulation. However, FORM is an approximation; it does not produce as accurate results as Monte Carlo simulation. Monte Carlo simulation requires a large amount of time to compute the result. 


\subsection{Limit-State Function for Casing Axial Yielding}

The limit-state function describes the condition state for the casing. The limitstate function is written as

$$
g(x)=C(x)-D(x)
$$

where $C(x)$ is the probabilistic capacity model. $D(x)$ is the probabilistic demand model. In Chapter III, both capacity and demand probabilistic models were consructed. The probabilistic capacity model describes the axial yielding strain limit of the casing. The probabilistic demand model describes the reservoir deformation strain caused by depleting the reservoir pressure.

The assumption for the axial yielding limit-state function is that the strain of the reservoir equals the strain in casing deformation. However, in the field, slippage may have occurred at the formation-cement and cement-casing interfaces. The slippage random variable is included in the limit-state function to account for this effect. Chia and Bradley (1986) showed that slippage could occur to reduce casing deformation by $30 \%$ to $40 \%$. The slippage variable is included into the demand model to reduce the reservoir compaction strain. The failure state occurs when the casing begins yielding. The limitstate function takes the form of

$$
g_{y}(x, \Theta)=\frac{\sigma_{c}}{E_{c}}-\left[\left(\frac{1+v_{f}}{E_{f}}\right) S \Delta P+\theta_{1}+\sigma_{d} \varepsilon_{d}\right]
$$

All the parameters are random variables with distributions, means, and standard deviations, Table 4.1. 
Table 4.1 — Input data for parameters in axial yield mode of failure

\begin{tabular}{lcccc}
\hline & & & & Standard \\
Random Variable & Symbol & Distribution & Mean & Deviation \\
\hline Reservoir Young's Modulus of & & & & \\
Elasticity (psi) & Ef & Lognormal & 300000 & 50000 \\
Reservoir Poisson ratio & vf & Lognormal & 0.22 & 0.043 \\
Casing Yield Stress (psi) & $\sigma c$ & Lognormal & 103550 & 2278.1 \\
Casing Young's Modulus of & & & & \\
Elasticity (psi) & Ec & Lognormal & $30,000,000$ & $1,050,000$ \\
Slippage & $\mathrm{S}$ & Lognormal & 0.65 & 0.05 \\
Depletion Pressure (psi) & $\Delta \mathrm{P}$ & Lognormal & 1000 & 30 \\
Unknown Parameter & $\theta_{1}$ & Normal & $1.09 \mathrm{E}-04$ & $1.03 \mathrm{E}-04$ \\
Standard Deviation of Model & & & & \\
Error & $\sigma_{\mathrm{d}}$ & Lognormal & $8.25 \mathrm{E}-04$ & $3.54 \mathrm{E}-04$ \\
\hline
\end{tabular}

Adams et al. (1993) assumed that the casing yield stress, casing Young's modulus of elasticity, and pore pressure distributions were normal distributions. In this study, most of the random variables are assumed lognormal because their actual values cannot be negative. In Chapter III, $\sigma_{d}$ has inverse chi square distribution and $\theta_{l}$ has $t$ distribution as explained in the previous chapter. However, $\sigma_{d}$ is assumed lognormal distribution and $\theta_{1}$ is assumed a normal distribution. The reason is that FERUM does not implement an inverse chi square distribution and $t$ distribution input into the program. Apparently, lognormal distribution has similar behavior as inverse chi square distribution and normal distribution is similar to $t$ distribution for high values of degree 
of freedom, $\eta$, according to Gardoni et al. (2002). $\varepsilon_{d}$ is a normal distribution with zero mean and unit standard deviation.

A correlation matrix, which accounts for the relationship between random variables, is required for input. Another assumption made is that all random variables are statistically independent, which means they have no relation to each other. Thus, the correlation matrix is unit diagonal and zero. Assuming random variables are statistically independent may not be correct for the input variables, casing thickness may relate to casing diameter when they are rolled. Further study is required to determine the relation between the random variables for the input correlation matrix.

\subsection{Fragility Estimates for Casing Axial Yielding}

Chapter II shows the method used in solving the limit-state functions for probability of failure. A combination of probability of failure at different depletion pressure with the limit-state functions generates the fragility of casing risk to axial yield. Fragility is the conditional probability of casing failure. Fig. 4.1 shows the comparison between FORM and Monte Carlo simulation as a check for the results. The results from the two methods show agreement, which indicates that FORM results are accurate. 


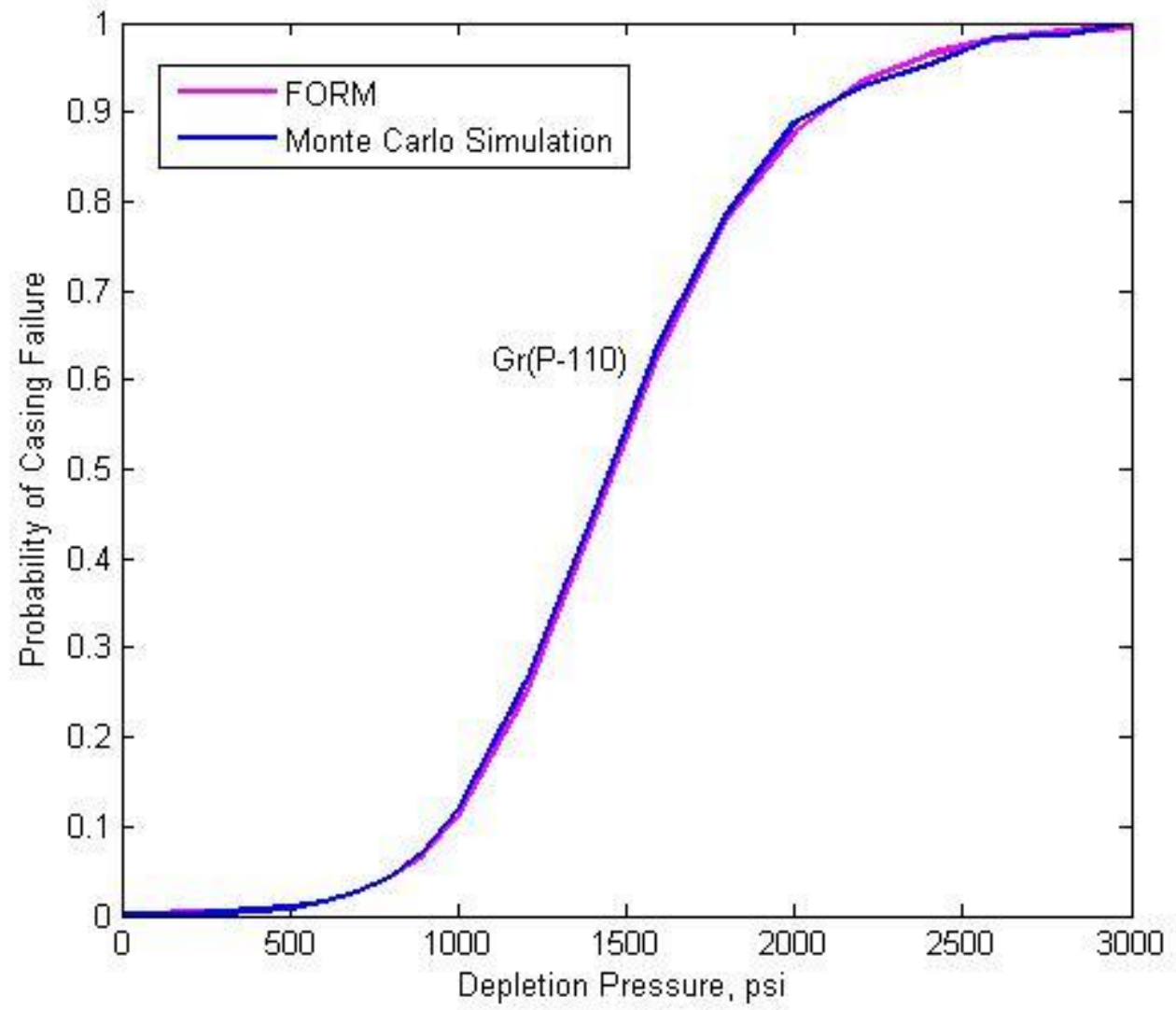

Fig. 4.1-FORM approximation agrees with Monte Carlo simulation results for axial yield failure

Using the FORM method to calculate the probability of casing failure, casing fragilities are estimated and shown in Fig. 4.2. The fragility estimate is shown as a function of increasing depleted reservoir pressure for different casing grade. The input casing grade is from Adams et al. (1993), who uses 0.022 for the coefficient of variation for the casing grade. The coefficient of variation is the mean divided by the standard deviation. Thus, calculation for the standard deviation for each casing grade is possible. 


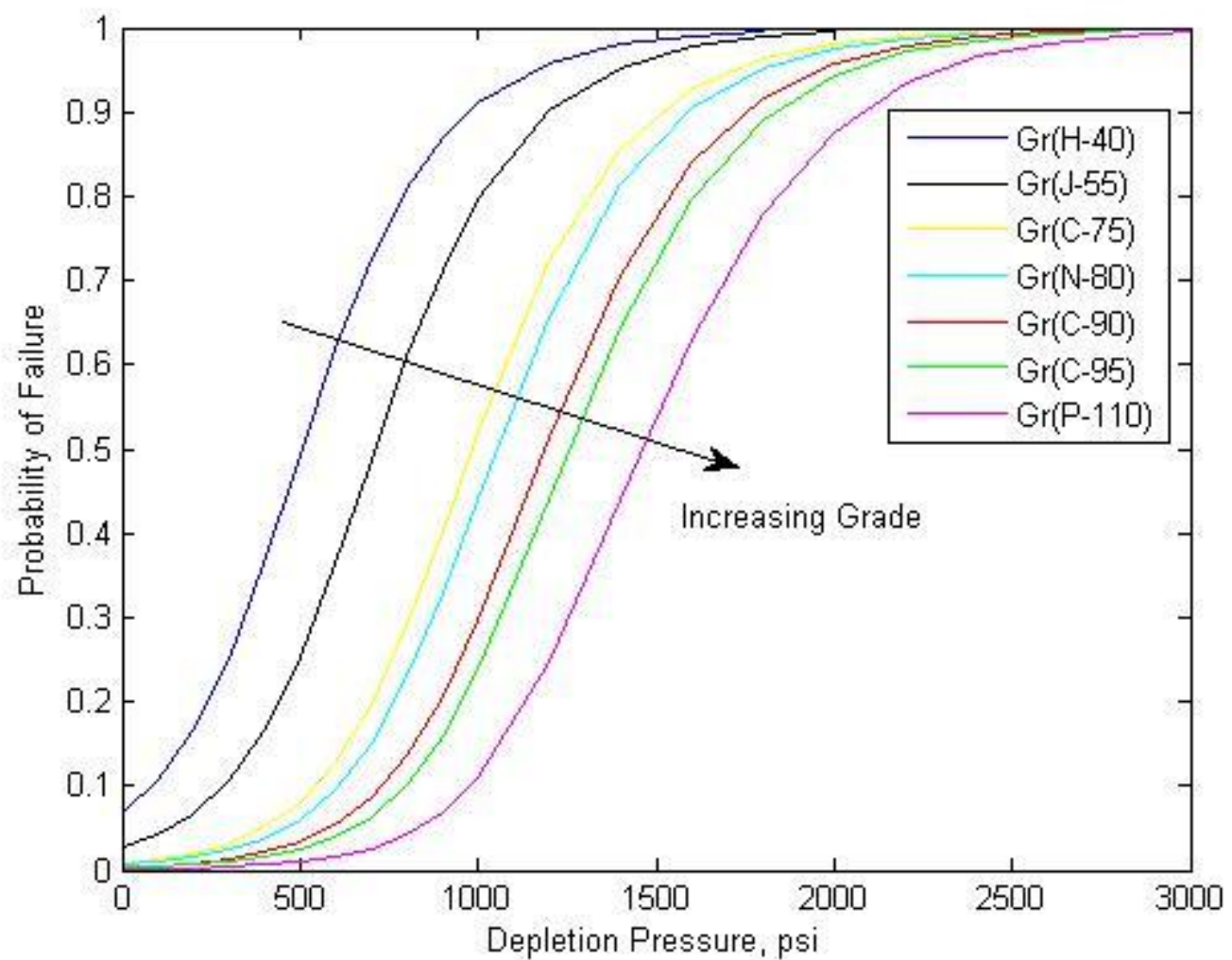

Fig. 4.2 — Axial yield fragility estimates decrease in failure probability as casing grade increases

The result shows the decrease in probability of failure as the casing grade increases; higher casing grade is recommended for completion in a high-risk reservoir compaction field. Reservoir depletion pressure of about 1,500 psi can cause Grade P-110 casing to have a $50 \%$ probability of yielding. For $100 \%$ yielding, the depletion pressure is around 3,000 psi.

Casing yielding is not the ultimate casing failure. Production casing may continue to be used after yielding, but it is prone to collapse if the formation radial stress increases. Furthermore, Grade $\mathrm{H}-40$ casing has the lowest yield stress. At the beginning of production, it risks failure because of the standard deviation of the model error term. 


\subsection{Limit-State Function for Casing Buckling}

Casing buckling occurs when the casing sees no lateral support after loss of cement. For the buckling limit-state function, the same demand model as for the axial yielding limit-state function is used, though the simulations representing reservoir compaction include cement in the model. The assumption is made that casing deformation is still equal to the reservoir deformation with and without cement.

Usually, cement is lost during the solid production process caused by high differential pressure near the wellbore. However, cement remains above and under the production zone. The cement above and below the production zone can translate the reservoir deformation to casing. This deformation causes buckling in the production interval.

From Chapter III, a probabilistic demand model and a probabilistic capacity model for casing buckling were constructed. The probabilistic capacity model is written as

$$
C_{b}(x)=\hat{c}_{b}(x)=\varepsilon_{b}=\frac{4 \pi^{2}\left[\frac{\pi}{64}\left(D_{0}{ }^{4}-\left(D_{o}-2 t\right)^{4}\right)\right]}{\left[\frac{\pi}{4}\left(D_{o}{ }^{2}-\left(D_{o}-2 t\right)^{2}\right)\right] L^{2}}
$$

where $\varepsilon_{b}$ is the casing strain limit for buckling, $D_{o}$ is the casing outer diameter, $t$ is the casing thickness, and $L$ is the unsupported length of casing downhole. The probabilistic capacity model has only the deterministic model term. Further studies and data are needed to construct a model bias correction term and the standard deviation of model error term. 
The buckling capacity model assumes that the cement is absent starting at the beginning of production. However, in an actual production well, the cement is present at the start of production. After periods of production, the cement may be produced with the solid particles from the formation due to near wellbore drawdown pressure. The absence of cement takes away casing lateral support. Further study is needed to incorporate the solid production process into the capacity model to compute the unsupported casing length, $L$.

Combining the capacity and demand models, the limit-state function for buckling failure is written as

$$
g_{b}(x, \Theta)=\frac{4 \pi^{2}\left\{\frac{\pi}{64}\left[D_{o}{ }^{4}-\left(D_{o}-2 t\right)^{4}\right]\right\}}{\left\{\frac{\pi}{4}\left[D_{o}^{2}-\left(D_{o}-2 t\right)^{2}\right]\right\} L^{2}}-\left[\left(\frac{1+v_{f}}{E_{f}}\right) S \Delta P+\theta_{1}+\sigma_{d} \varepsilon_{d}\right]
$$

All random variables are assumed statistically independent. Table 4.2 shows the input distribution, mean, and standard deviation for each parameter. 
Table 4.2 - Input data for parameters in buckling mode of failure

\begin{tabular}{lcccc}
\hline Random Variable & Symbol & Distribution & Mean & $\begin{array}{c}\text { Standard } \\
\text { Deviation }\end{array}$ \\
\hline Reservoir Young's Modulus of & & & & \\
Elasticity (psi) & Ef & Lognormal & 300000 & 50000 \\
Reservoir Poisson ratio & $\mathrm{Nf}$ & Lognormal & 0.22 & 0.043 \\
Casing Outer Diameter (inches) & $\mathrm{OD}$ & Lognormal & 4.5 & 0.0032 \\
Casing Thickness (inches) & $\mathrm{T}$ & Lognormal & 0.287 & 0.00054 \\
Unsupported Casing Length & & & & \\
(inches) & $\mathrm{L}$ & Lognormal & 25 & 10 \\
Depletion Pressure (psi) & $\Delta \mathrm{P}$ & Lognormal & 1000 & 30 \\
Unknown Parameter & $\theta_{1}$ & Normal & $1.09 \mathrm{E}-04$ & $1.03 \mathrm{E}-04$ \\
Standard Deviation of Model & & & & $3.54 \mathrm{E}-04$ \\
Error & $\sigma_{\mathrm{d}}$ & Lognormal & $8.25 \mathrm{E}-04$ & \\
\hline
\end{tabular}

Outer diameter $D_{o}$ and thickness $t$ are specified with the mean and standard deviation for each $\mathrm{D}_{\mathrm{o}}$ range from 4.5 in. to $20 \mathrm{in}$. The unsupported length is assumed constant for all the cases.

\subsection{Fragility Estimates for Casing Buckling}

To check the FORM result for the buckling limit-state function, the Monte Carlo simulation is performed. Fig. 4.3 shows that a FORM result agrees with the Monte Carlo simulation result. 


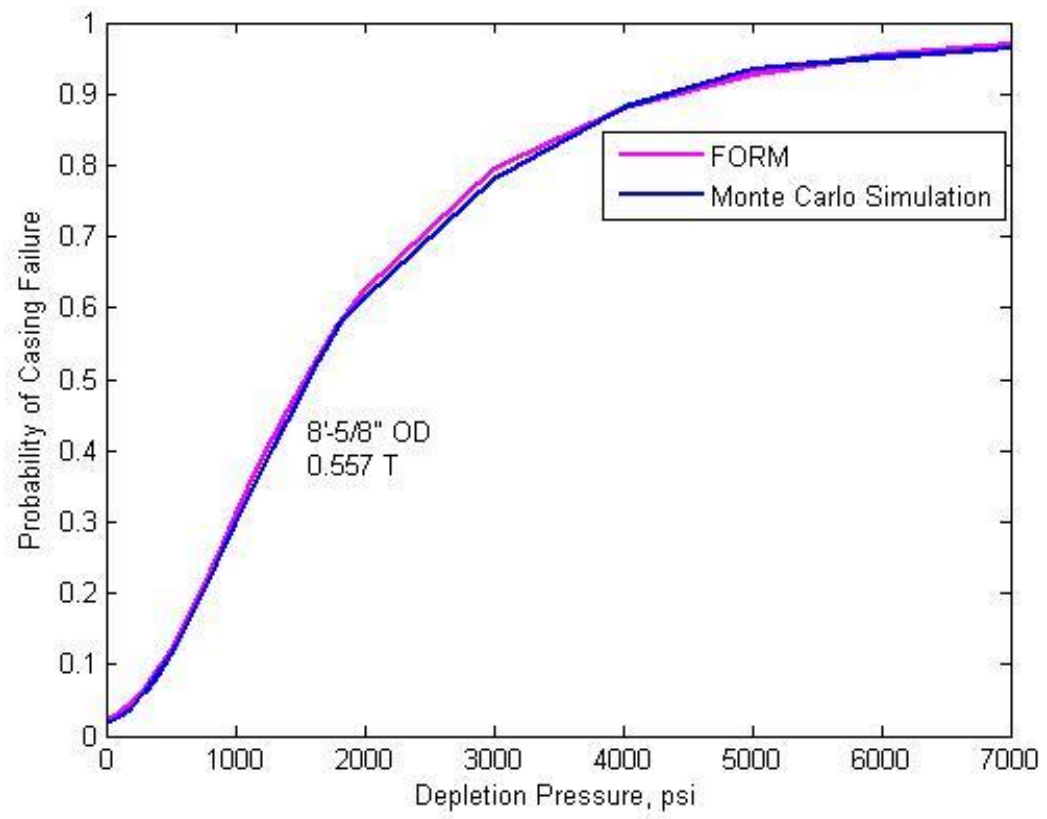

Fig. 4.3-FORM approximation agrees with Monte Carlo simulation result for buckling failure

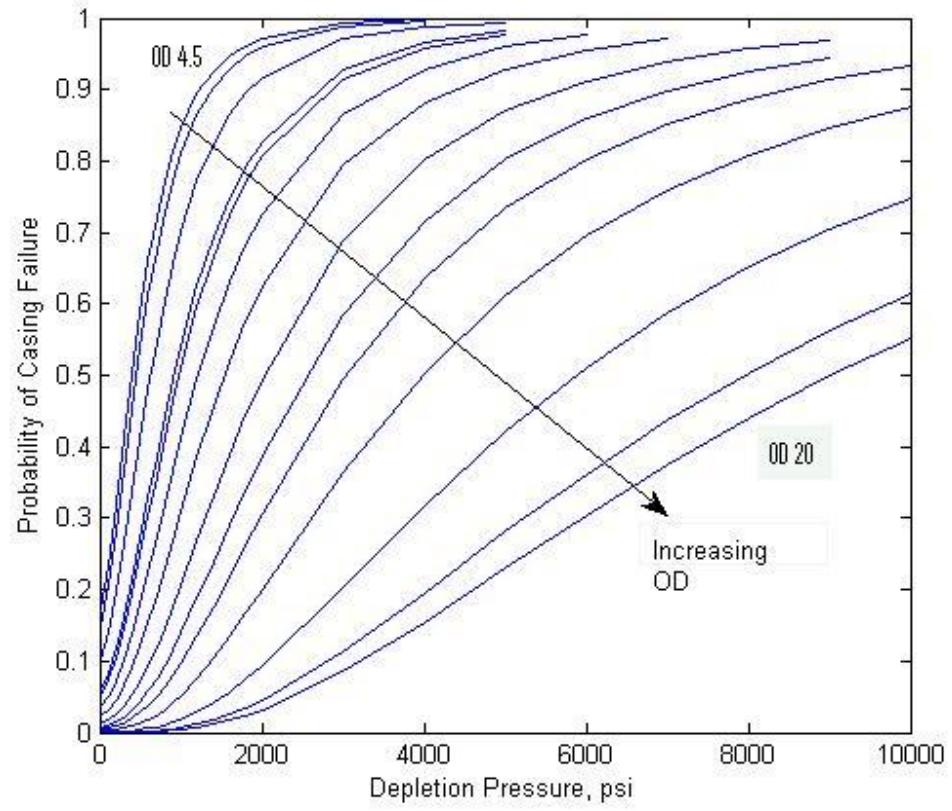

Fig. 4.4-Buckling fragility decreases as casing outer diameter increases 
Fig. 4.4 shows the fragility estimate for casing buckling for each outer diameter and thickness. Fragility estimates of casing buckling failure shows that increasing the outer diameter reduces the risk of casing buckling. For a 4-1/2 in. OD, it takes around 1,000 psi of depleted pressure to assure casing buckling.

High compaction reservoirs require large casing diameter. However, as today's production scenarios face tough challenges from the deeper sources with high pressure and high temperature, choosing large production casing sizes are limited.

Structural reliability for component reliability of casing in compacting reservoir is a tool for assessing casing condition and predicting future conditions. Fragilities, results based on axial yielding and buckling, can help estimate casing failure risk associated with the amount of production.

\subsection{Casing System Reliability}

With the results for component reliability, they can be compared and combined to analyze the system reliability. Using the method explained in Chapter II, the results of system reliability prone to any mode of failure is computed and shown in Fig. 4.5.

Computation of system reliability requires the results from component reliability as shown

$$
P\left(F_{y} \cup F_{b}\right)=P\left(g_{y} \leq 0\right)+P\left(g_{b} \leq 0\right)-P\left(g_{y} \leq 0 \cap g_{b} \leq 0\right)
$$

Fig. 4.5 shows the differences between system reliability and component reliabilities for a P-110 casing grade with outer diameter of 7-5/8 in. 


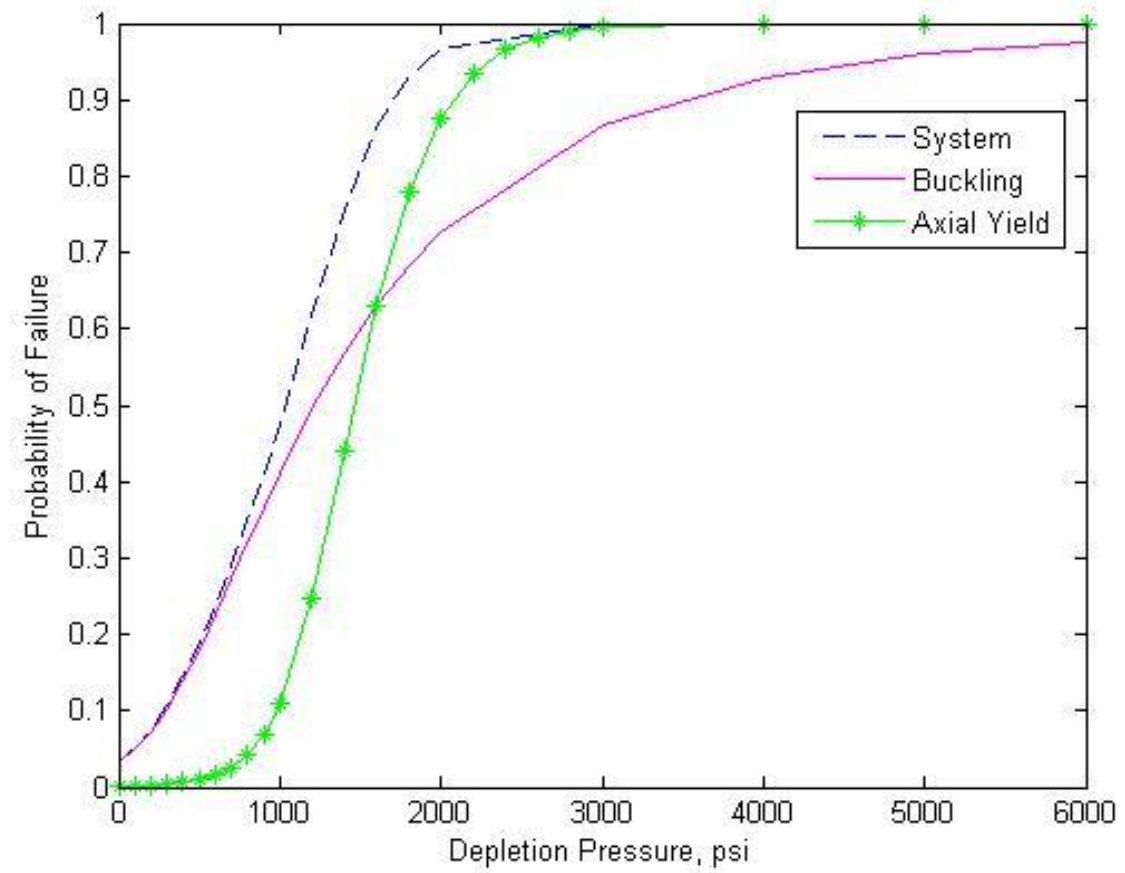

Fig. 4.5-System fragility has the highest probability of failure because either axial yield or buckling could occur

The system fragility has the highest probability of failure because either mode of failure may occur. The two limit-state functions do not contain any reduction variable. Both failures could occur as the reservoir pressure depletes. The system fragility follows the buckling fragility at the beginning, where buckling risk a higher probability of failure. At the end, it merges with axial yield fragility.

System reliability analysis computes the results by combining the results at the component level for axial yielding and buckling. Using the same demand models for both failures, casing sees the same load but it could behave in axial yielding or buckling modes. Comparison between axial yield and buckling fragilities shows that casing is 
more like to buckle at the beginning of production. Axial yielding is more likely to happen toward the end.

The reason for buckling to occur at the beginning of production is the slenderness ratio, $L / r$. The slenderness ratio is the unsupported length divided by the radius of gyration of the casing. Usually for a low value of slenderness ratio (a short, unsupported length with a large diameter), axial yielding is likely to occur first. However, the system reliability result shows that buckling occurs first. Thus, the slenderness ratio consists of unsupported casing length $L$, outer diameter $D_{o}$, and thickness $t$ large enough to cause buckling before casing can yield. 


\section{CHAPTER V}

\section{IMPORTANCE AND SENSITIVITY}

\section{ANALYSES}

\subsection{Importance Analysis}

Importance analysis measures the effect of uncertainty in random variable distributions toward probability of failure. In addition to calculating the casing fragility, FORM approximation gives results for importance analysis of each failure mode. Importance analysis measures how much each random parameter in the limit-state function affects the probability of failure.

From FORM computation, the results $\beta$, the reliability index, and $u^{*}$, design point is obtained. Importance analysis starts by shifting the distribution of each random variable $u_{i}$ by small amount $\varepsilon$; the corresponding change in $\beta$ is

$$
\Delta \beta=\left[\frac{\partial \beta}{\partial u_{1}}+\frac{\partial \beta}{\partial u_{2}}+\cdots+\frac{\partial \beta}{\partial u_{n}}\right](-\varepsilon)
$$

Because $\beta$ is in standard normal space, $\varepsilon$ shifts the $\beta$ coordinate system by vector $e=[-\varepsilon$ $-\varepsilon \ldots-\varepsilon]^{T}$. Thus, the change in $\beta$ is

$$
\Delta \beta=\nabla_{u^{*}} \beta^{T} e
$$

where $\nabla_{u^{*}} \beta$ is the gradient vector of $\beta$ with respect to the coordinates at the design point. The gradient vector $\nabla_{u^{*}} \beta$ is written as 


$$
\nabla_{u^{*}} \beta=\operatorname{sgn}(\beta) \frac{u^{*}}{\left\|u^{*}\right\|}=\alpha
$$

where $\alpha$, gradient vector, is the unit vector at the design point directed towards the failure set. Thus $\alpha$ is the importance measure of the random variables $u$ if the random variables $x$ in normal space is statistically independent, as assumed.

The algebraic sign of $\alpha$ describes random variable $u$ as a demand variable or a capacity variable. Positive $\alpha_{i}$ corresponds to a demand random variable $x_{i}$. Negative $\alpha_{i}$ corresponds to a capacity variable $x_{i}$. In interpreting of the results in importance analysis, as the values of positive $\alpha$ increase, the probability of failure increases. As the values of negative $\alpha$ increase, the probability of failure increase. Thus, importance measures tell us how important the random variable distributions are as the probability of failure increases in fragility estimates.

\subsection{Importance Analysis Result and Discussion}

Importance analysis shows the effect of uncertainty in random variable distributions toward probability of failure. Fig. 5.1 illustrates the importance vector $\alpha$ of the random variables in axial yielding mode as a function of reservoir depletion pressure. The plot is for Grade P-110 casing, which is mostly used in high-compaction reservoirs. 


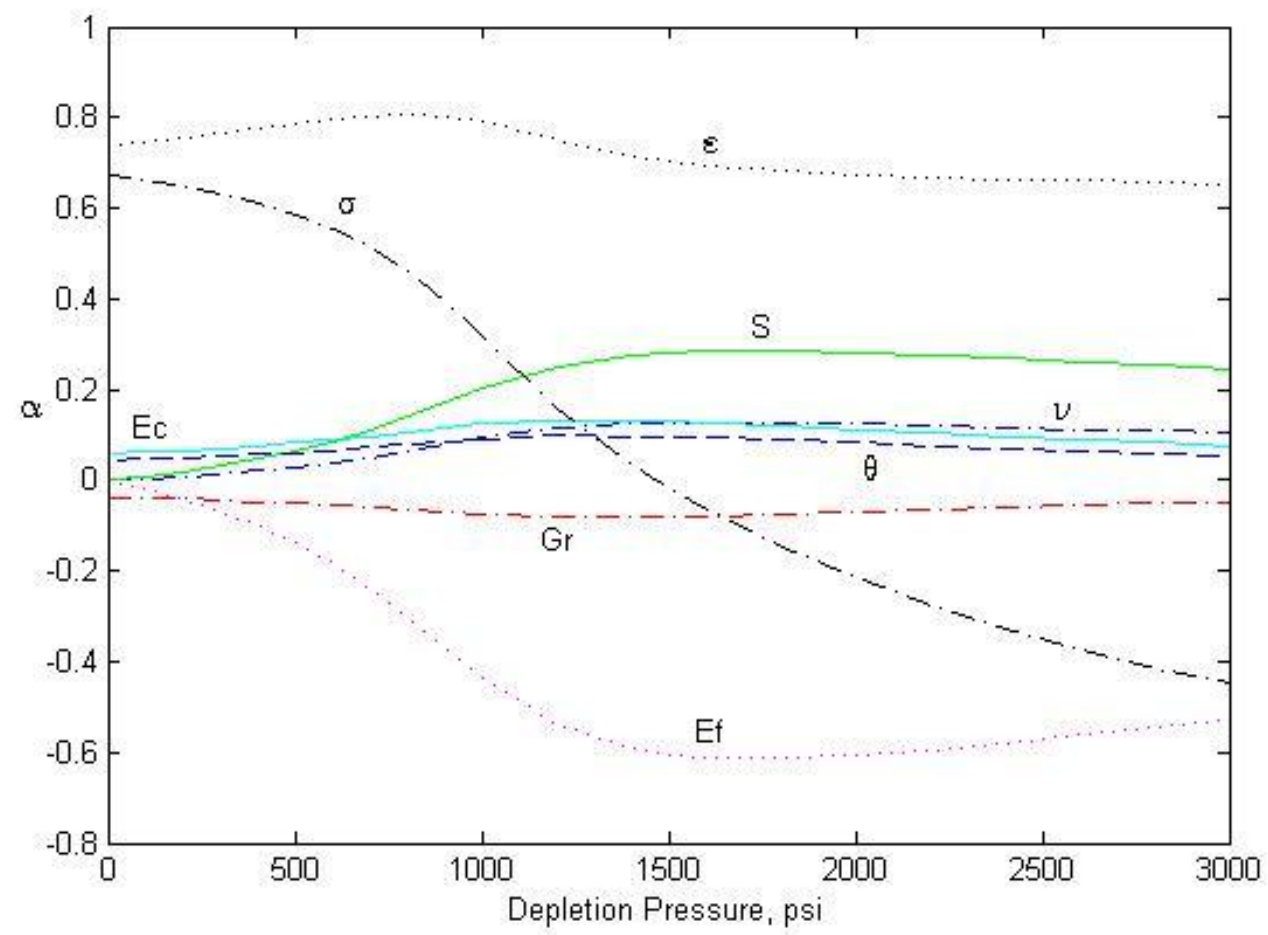

Fig. 5.1-Model error $\varepsilon$ and formation Young's modulus of elasticity $E_{f}$ have highest effect on casing reliability

In axial yield mode, the $\varepsilon$ and formation Young's modulus of elasticity $E_{f}$ are two most important random variables. A high positive value of the model error $\varepsilon$ indicates that $\varepsilon$ is a "demand" variable; it remains constant over the production period. The formation Young's modulus of elasticity $E_{f}$ increases in negative value as production increases. This indicates that the formation Young's modulus of elasticity $E_{f}$ has a high effect on probability of failure as production increases.

For buckling failure, Fig. 5.2 shows importance measures for a 6-5/8-in. outer diameter casing with a 0.557 -in. thickness. Unsupported casing length $L$ and formation Young's modulus of elasticity $E_{f}$ are the most important variables. The importance 
results match Bruno's (1990) theory, which stresses the importance of having good cement placement to reduce the risk of buckling failure. In addition, the unsupported casing length $L$ has higher values than the interface slippage $S$. This shows that it is more important to control the cement placement and solids production than to place ductile cement to reduce casing deformation.

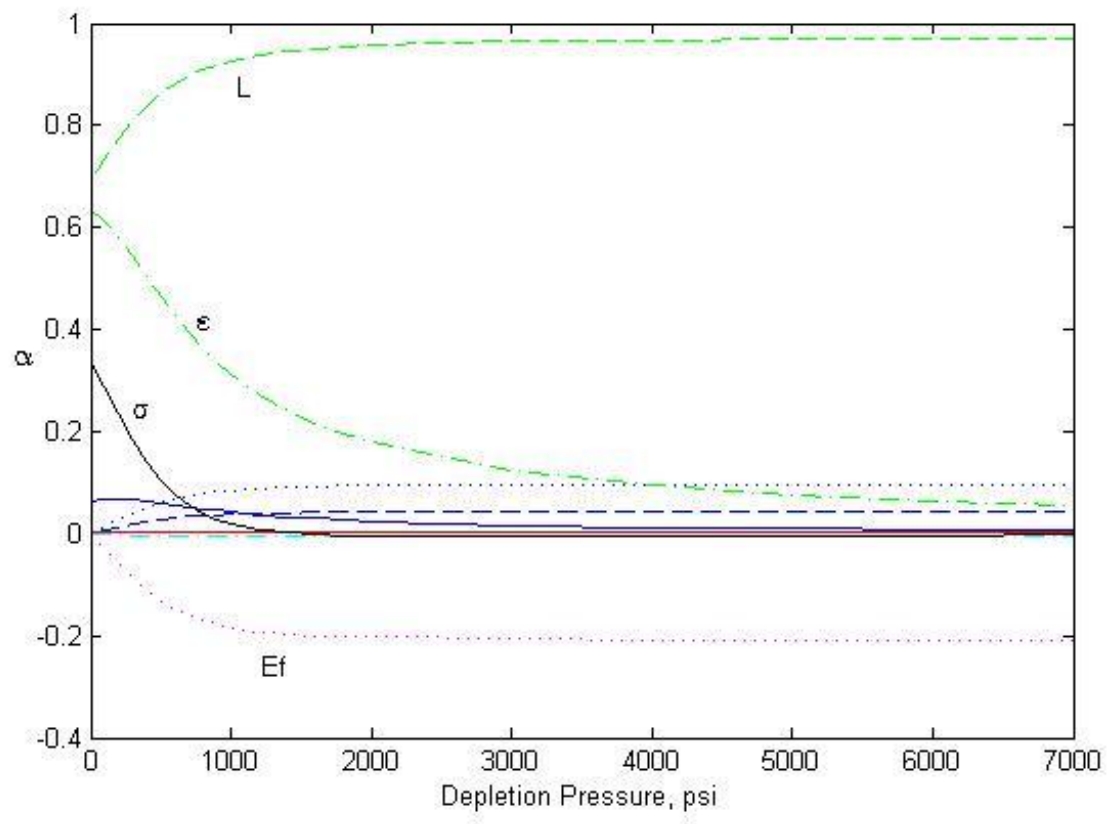

Fig. 5.2-Importance analysis of buckling illustrates that unsupported casing length $L$ is the most important parameter affecting casing reliability

Fig. 5.3 is the zoom of Fig. 5.2. The importance order of random variables illustrates that the model error $\varepsilon$ and model standard deviation $\sigma$ are more important than formation Young's modulus of elasticity $E_{f}$. 


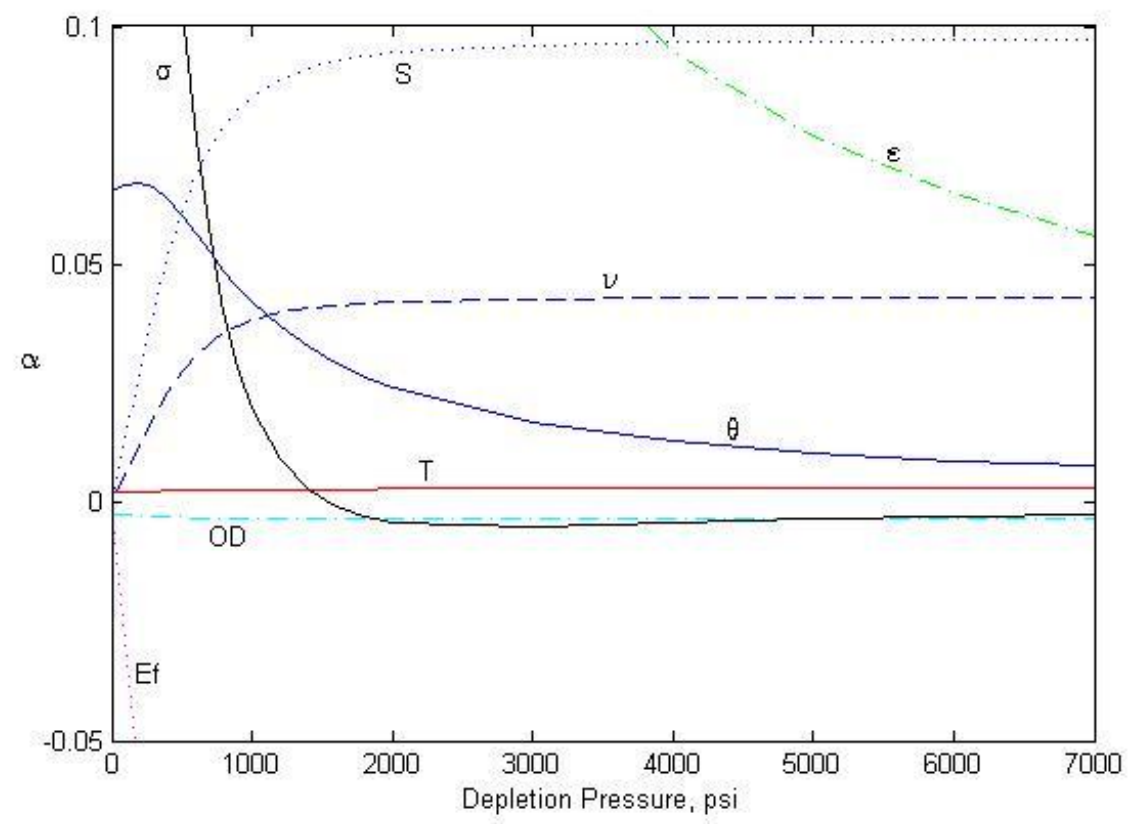

Fig. 5.3 - Closer looks at importance analysis for buckling mode of failure

Comparing importance analyses between axial yielding and buckling modes shows that the random variable in buckling is a higher contributor to failure than axial yielding. However, in axial yielding the Young's modulus of elasticity $E_{f}$ and the interface slippage $S$ are more important than in buckling. Giving the results, the unsupported casing length $L$, the Young's modulus of elasticity $E_{f}$, and the interface slippage $S$ are most important contributors to the system of casing failure.

\subsection{Sensitivity Analysis}

Sensitivity measures analyzed how sensitive the reliability of the components is to the change in parameters used in computing the probability of failure. The sensitivity of the reliability is measured with respect to changes in the input random variables. It is 
useful for an easy evaluation of the change of the fragility for a given change of the design of the structure. In optimizing the design, the derivative of failure probability $p_{f}$ is expressed as

$$
\nabla_{(\mathrm{x} 0, \Theta)} \mathrm{p}_{\mathrm{f}}=-\varphi(\beta) \nabla_{(\mathrm{x} 0, \Theta)} \beta
$$

where $\varphi(\beta)$ is the standard normal PDF, and $\nabla_{(x 0, \Theta)} \beta$ is the gradient vector of reliability index $\beta$ with respect to parameter $x 0$ and $\Theta$. The parameter $\Theta$ denotes the set of distribution parameters: means, standard deviations, and correlation coefficients. The parameter $x 0$ is the vector of deterministic parameters in the limit-state function.

In sensitivity measures, model error $\varepsilon$, standard deviation of model error $\sigma$, and unknown parameter $\theta$ are left out. The gradient vector $\nabla_{(x 0, \Theta)} \beta$ and reliability index $\beta$ are obtained from the first order reliability method (FORM) using the method by Hohenbichler and Rackwitz (1986) and Bjerager and Krenk (1989). Unlike the importance analysis, ranking of the variables is not possible because of the difference in units.

\subsection{Sensitivity Analysis Result and Discussion}

The sensitivity analysis measures the change in probability of failure with respect to the change in model parameters. Thus, random variables in sensitivity measure cannot be compared in order like the importance analysis because differences in units. However, sensitivity plots of each random variable give insight on failure mechanism. The sensitivity measures plot in term of the reliability index (beta) sensitivity with respect to the mean value of the distribution parameters. Fig. $\mathbf{5 . 4}$ shows the 
sensitivity of the casing grade P-110 for axial yield. The change of the interface slippage $S$ and the formation Poisson's ratio $v$ can greatly affect the fragility of the casing axial yielding failure. At 1,500 psi of depleted pressure, the sensitivity measure of the interface slippage $\mathrm{S}$ is about 2.3 . We can take the sensitivity measure times any change in the interface slippage $S$ and add it to the original reliability index to find the new reliability index.

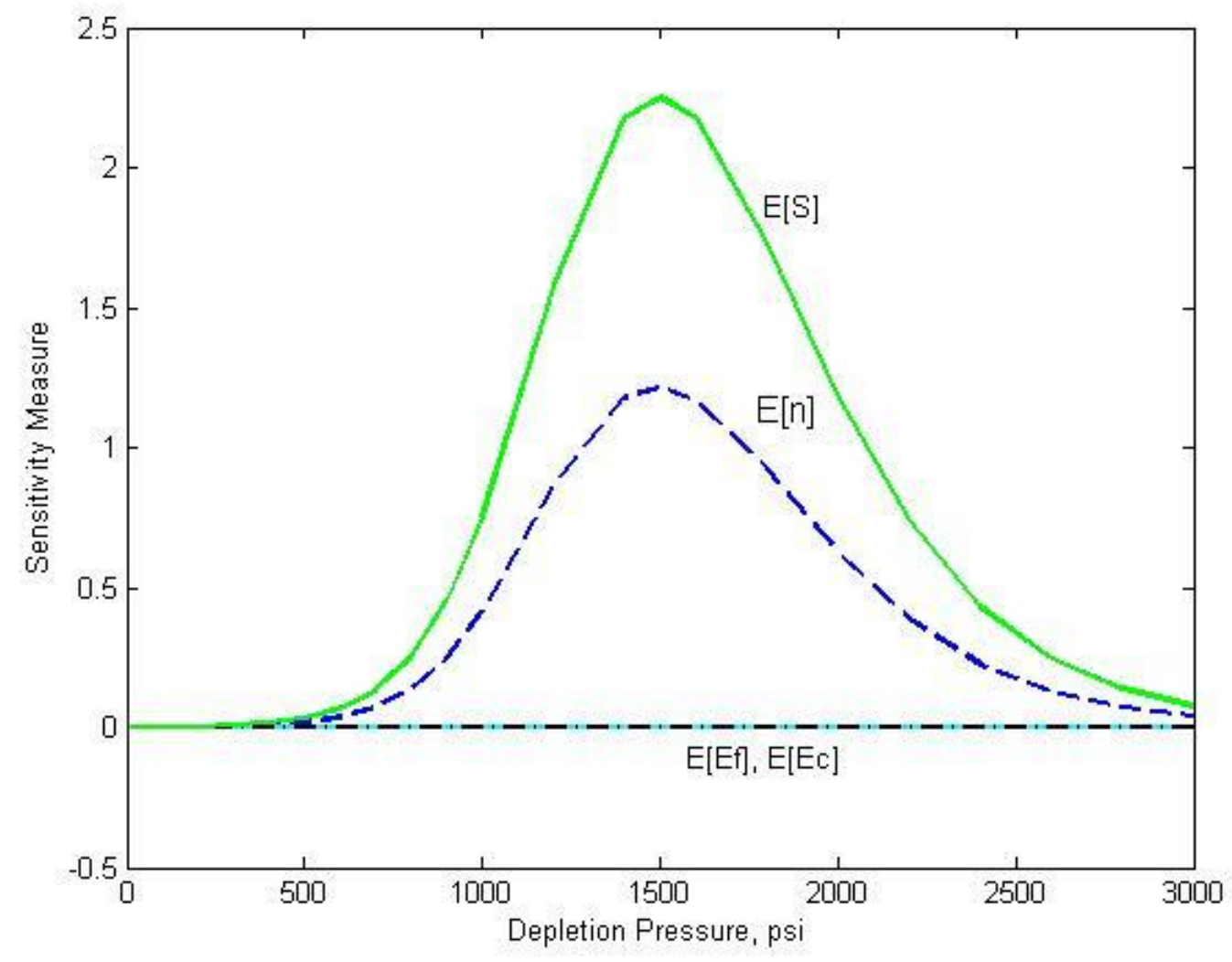

Fig. 5.4-Change of interface slippage $S$ is most sensitive to change in fragility for the axial yield mode of failure 
Sensitivity analysis of buckling failure illustrates that interface slippage $S$ is most sensitive. Increasing the unit of interface slippage $S$ can increase the casing reliability to buckling. In the field, this can be done by using ductile cement. This way the deformation from the formation is absorbed by the cement, which can reduce the deformation in casing. Furthermore, it expects to see that the unsupported casing length $L$ variable did not have a high sensitivity measure. The assumption for buckling failure is that the casing is already unsupported at the beginning of production. This is the reason that the sensitivity of unsupported casing length is not high.

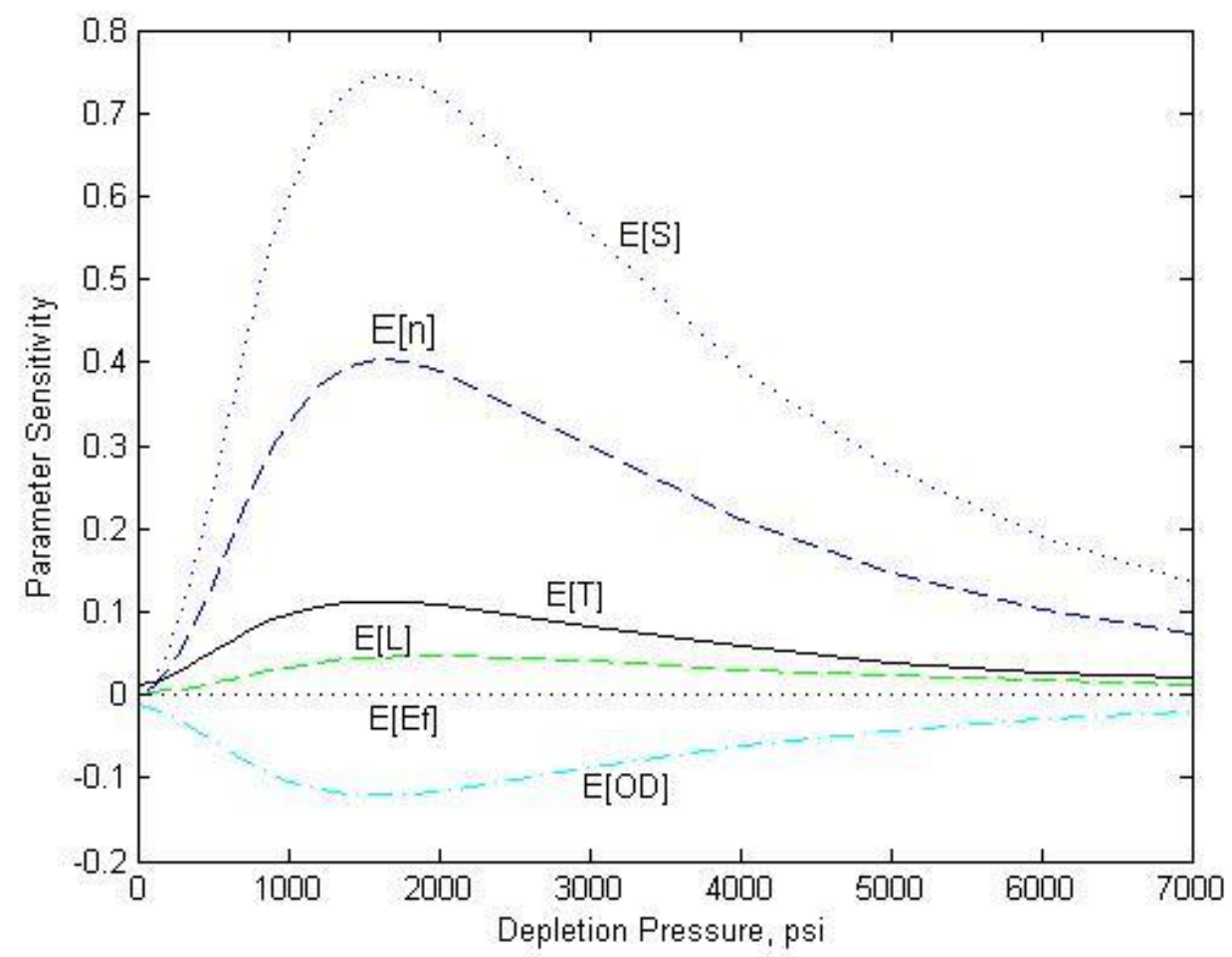

Fig. 5.5-Change of interface slippage $S$ is most sensitive to change in fragility for the buckling mode of failure 


\section{CHAPTER VI}

\section{RESULT DISCUSSION AND APPLICATION}

\subsection{Casing Failure Mitigation Strategy}

After subsidence occurs, casing failures or damages are likely to follow. However, aftering subsidence has occurred, it is already too late. At this point, casing may already have been damaged. Therefore, the first strategy against casing failure is to study reservoirs and surrounding formations. Reservoir planning using information from the geologist and geomechanical models helps identify high compaction zones. Avoiding drilling and producing from these zones can prevent casing from failure.

If production from a high-compaction zone is necessary, structural reliability can be used to predict future casing failure risk from the amount of production. Structural reliability can also be applied to developing fields to determine the casing's risk of failure by assessing reservoir pressure from when the well started producing to the present. Also, by setting the maximum failure risk, a company can produce to the identified reservoir pressure before beginning workover operation to repair and maintain casing conditions. Another method to reduce failure risk is to inject water into nearby wells to keep reservoir pressure from reaching the reservoir pressure associated with the set maximum casing failure risk. 


\subsection{Structural Reliability Result Discussion}

This section discusses effects of the results on decision making of when to start injecting water or to begin workover operations. First, the fragilities in Fig. 4.2 and Fig. 4.4 have shown that using a large-diameter casing with high casing grade in a compaction zone can extend casing life. With large diameter and high casing grade, the casing has more capacity to resist compaction load. However, putting large-diameter casing into the production zone may not be possible because of challenges in producing from deeper reservoirs, where a casing system requires a very large-diameter conductor and surface casing to carry the total weight from other casing downhole. Depending on the number of casing strings, the choice of the production casing may be limited. Thus, using high casing grades for production casing may be the choice to increase casing resistance to compaction load. Even though using large diameter casing may not be possible, another choice to increase casing system resistance is by ensuring good cement placement in the production zone. The importance analysis result for buckling failure in Fig. 5.2 shows that the unsupported casing length $L$ has a high effect on the probability of failure. Thus, if a good cement placement is ensured thoroughout the life of the well, the risk of casing buckling is lowered.

Comparison between axial yielding and buckling in Fig. 4.5 shows that casing buckling is more likely to occur at the beginning of a production period. Yielding is more likely to occur later into the production period. However, the buckling model use the input PDF of unsupported casing length $L$ and $50 \mathrm{ft}$ reservoir height. Changing reservoir height to smaller than $50 \mathrm{ft}$ and changing the PDF to one associated with 
possible cement loss can decrease the probability of buckling to be lesser than the probability of yielding from the start to the end of production.

Times to failure are associated with the production rate, well planning, well location, and reservoir management. Geomechanical modeling of formations and well production can assist the user in effectively computing the failure location and time.

When depletion pressure reaches $100 \%$ probability of axial yielding, the casing begins to yield. Yielded casing is still capable of delivering oil to the surface; just as when the buckling fragility reaches $100 \%$, the casing has only begun to buckle and the well can continue to produce. The buckling fragility does not account for the severity of buckling condition. However, for both modes of failure, at this point the casing is damaged. Continuation of production can lead to ultimate failure such as casing collapse or severe deformation obstructing workover tools. Casing repairs to strengthen the casing or water injection to increase pore pressure in the reservoir should definitely start at this point. It may be worthy to send a downhole camera to check casing conditions at depletion pressure, where the probability of failure is $50 \%$. If the casing has already yielded or buckled at the depletion pressure of $50 \%$ failure probability, continuing production until depletion pressure reaches $100 \%$ failure probability can fail the well. 


\section{CHAPTER VII}

\section{CONCLUSIONS AND FURTHER STUDY}

\subsection{Conclusions}

1. The application of structural reliability in the field of petroleum engineering can assist the user in making better decisions knowing the risk taking. Structural reliability can predict and assess casing conditions given static field data and casing data. It can account for the uncertainty in the input data to compute failure probability and to construct the fragility estimates of casing conditions.

2. A fragility estimate is the conditional probability of casing condition according to reservoir pressure reduction from production. The fragility shows that casing may undergo axial yielding even if reservoir pressure reduction from the assumed reservoir properties is low. Grade P-110 casing has a 100\% probability of casing axial yielding around a depleted pressure of 3,000 psi. Although axial yielded casing may still able to produce, its stress resistance is altered and it is prone to collapse under the stress around the wellbore.

3. Using the assumption made for buckling failure where the lateral support is absent from the start of production, casing risks buckling in the beginning of the production period. However, in reality, casing buckling depends highly on how much the well produces solids such as cement and the surrounding rock formation. Solids production can take away the lateral support casing needs to prevent buckling. 
4. System reliability estimates fragility for system failure. System failure represents any mode of failure that can occur in a system. System fragility has the highest probability of failure among the component reliabilities. The reason is that system fragility computes the failure case where either mode of failure, axial yield or buckling, could occur.

5. Sensitivity analysis describes the effect of the change in parameters to the change in fragility. For both modes of failure, the change in interface slippage $S$ parameter has the highest effect on the change of fragility. In the field, cement type controls the interface slippage. Using ductile cement in a compacting reservoir can reduce the risk of casing failure. Ductile cement has the property to deform easier than regular cement. Thus, the cement may absorb some of formation deformation before transferring it to the casing.

6. Importance analysis describes which parameter is the important contributor to fragility. For axial yielding, the casing model error term $\varepsilon$ and the formation Young's modulus of elasticity $E_{f}$ are the most important. For buckling, the unsupported casing length $L$ is the most important.

\subsection{Further Study}

To improve the results and quality of the probabilistic models, field data is needed. Analyzing field data for a specific field will reduce the uncertainty in the probabilistic demand models. Necessary field data are data related to casing failure occurrences such as failed casing specifications and formation parameters including 
Young's modulus of elasticity, Poisson ratio, and depletion pressure. Matching the reliability results with the actual failure occurrences can estimate the model's accuracy. High-accuracy models may require few adjustment and calibration.

Lab experiment data could assist in data collection for the capacity models of the casing. So far, casing specification data that have been collected from a casing manufacturer. Random variables of the casing parameters were studied by Adams et al. (1993). However, casing compressive lab experiments on axial yielding are needed to find the actual yielding casing strain from compression forces. The actual casing strain can be used to find the model error in the capacity model. In addition, detection of the bias in the deterministic model can be done using the lab experimental results. Addition of the error term and the collection of the bias of the deterministic model can improve the accuracy of the probabilistic model results.

Performing 3D reservoir modeling for reservoir compaction instead of the 2D model used in this research can compute more accurate deformation results. However, $3 \mathrm{D}$ reservoir modeling requires high technology computers to run simulations. The costs of these computers are very high.

Generally, two modes of failure occur at the crest of the reservoir and at the production interval where maximum reservoir deformation occur. However, additional probabilistic model construction is necessary to better account for casing failure at all of the field locations, including the overburden rock formation and the field's outer radius. The additional modes of failure are shear, tension, and collapse failures. Several methods that could assist in constructing these models are 3D wellbore modeling for casing 
capacity, 3D reservoir modeling for formation deformation demand, and lab experiments to account for better uncertainty of the formation and casing parameters.

Application of structural reliability has a wide range of application, which can be applied to different problems in the field of petroleum engineering. 


\section{NOMENCLATURE}

$g$

C

D

$x$

$p_{f}$

$p_{b}$

$f_{y}$

$t$

$D_{o}$

$\varphi_{n}$

$u$

$u^{*}$

$\nabla \mathrm{G}^{\mathrm{T}}$

$\Phi$

$\beta$

$\alpha$

$J$

F

$F_{c}$

$F_{b}$
Limit-state function

Capacity model

Demand model

Random variable

Probability of failure

Casing burst pressure

Casing yield stress

Casing thickness

Casing outer diameter

Probability density function in standard normal space

Random variable in standard normal space

Design point

Gradient vector

Standard normal cumulative probability function

Reliability index

Normalized negative gradient vector

Jacobian matrix

Cumulative density function, $\mathrm{CDF}$

Axial yield failure event

Buckling failure event 


\begin{tabular}{|c|c|}
\hline$\varepsilon_{c}$ & Casing axial strain \\
\hline$\sigma_{c}$ & Yield stress of casing \\
\hline$E_{c}$ & Casing Young's modulus of elasticity \\
\hline$\hat{c}$ & Capacity deterministic model \\
\hline$\varepsilon_{b}$ & Casing strain limit before onset of buckling \\
\hline$L$ & Unsupported length of casing \\
\hline$A_{c}$ & Casing cross-sectional area \\
\hline$I$ & Area moment of inertia of casing \\
\hline$\sigma_{o b}$ & Formation total stress \\
\hline $\bar{\sigma}$ & Formation effective stress \\
\hline$\rho$ & Pore pressure \\
\hline$\hat{d}_{c}$ & Deterministic model for reservoir compaction \\
\hline$\gamma_{c}$ & Correction term for bias in deterministic model \\
\hline$\theta_{c}$ & Correction term for deterministic model \\
\hline$\sigma_{c}$ & Model standard deviation \\
\hline$\varepsilon_{c}$ & Model error \\
\hline$\varepsilon_{z}$ & Reservoir compaction strain \\
\hline$v_{s}$ & Reservoir Poisson ratio \\
\hline$E_{s}$ & Reservoir Young's modulus of elasticity \\
\hline$\Delta P$ & Depletion pressure \\
\hline$A_{i}$ & Actual data \\
\hline$F_{i}$ & Predicted data \\
\hline
\end{tabular}


Y

$H$

$\eta$

$\chi^{-2}$

$\nabla_{u^{*}} \beta$

$\nabla_{(\mathrm{x} 0, \Theta)} \beta$

$x 0$
Simulation strains minus deterministic strains

Constant matrix

Degree of freedom

Inverse Chi Square distribution function

Gradient vector of reliability index $\beta$ with respect to parameter $u^{*}$

Gradient vector of reliability index $\beta$ with respect to parameter $x 0$

and $\Theta$

Vector of deterministic parameters in the limit state function 


\section{REFERENCES}

Adams, A.J., Parfitt, S.H.L., Reeves, T.B., Thorogood, J.L. et al. 1993. Casing System Risk Analysis Using Structural Reliability. Paper SPE 25693 presented at the 1993 SPE/IADC Drilling Conference, Amsterdam, Netherlands.

API. 1999. Bulletin on Formulas and Calculations for Casing, Tubing, Drill Pipe, and Line Pipe Properties, sixth edition. Washington, D.C.

Bruno, M.S. 2001. Geomechanical and Decision Analyses for Mitigating CompactionRelated Casing Damage. Paper SPE 79519 presented at the 2001 SPE Annual Technical Conference and Exhibition, New Orleans, Lousiana.

Bruno, M.S, 1990. Subsidence-Induced Well Failure. Paper SPE 200584 presented at the $199060^{\text {th }}$ California Regional Meeting, Ventura, California.

Bjerager, P. and Krenk, S. 1989. Parametric Sensitivity in 1st Order Reliability Theory. Journal of Engineering Mechanics-ASCE 115 (7): 1577-1582.

Chia, Y.P. and Bradley, D.A. 1989. Evaluation of Reservoir Compaction and Its Effects on Casing Behavior. Paper SPE 14985 presented at the 1986 SPE Deep Drilling and Production Symposium, Amarillo, Texas.

Ditzhuijzen, P.J.D.v. 1984. Reservoir Compaction and Surface Subsidence in the Central Luconia Gas Bearing Carbonates, Offshore Sarawak, East Malaysia. Paper presented at the 5th Offshore Southeast Asia, Singapore.

FERUM (Finite Element Reliability Using Matlab). 1999. Department of Civil and Environmental Engineering, University of California-Berkeley California. 
Fjaer, E., Holt, R.M., Horsrud, P., Raaen, A.M., Risnes, R., et al. 1992. Petroleum Related Rock Mechanics. Ed Chilingarian. Reservoir compaction, Subsidence and well problems, 287-314. G.V. Amsterdam: Elsevier.

Fredrich, J.T., Arguello, J.G., Deitrick, G.L., de Rouffignac, E.P., et al. 1998. Geomechanical Modeling of Reservoir Compaction, Surface Subsidence, and Casing Damage at the Belridge Diatomite Field. Paper SPE 65354 presented at the 1998 SPE/ISRM Eurock, Trondheim, Norway.

Gardoni, P., Kiureghian, A.D., and Mosalam, K.M. 2002. Probabilistic Models and Fragility Estimates for Bridge Components and Systems. Berkeley CA: Pacific Earthquake Engineering Research Center, College of Engineering, University of California, Berkeley.

Hohenbichler, M. and Rackwitz, R. 1983. 1st-Order Concepts in System Reliability. Structural Safety 1 (3): 177-188.

Ibekwe, I.A., Coker-III, O.D., Fuh, G.F., Actis, S.C., et al. 2003. Magnolia Casing Design for Compaction. Paper SPE 7981 presented at the SPE/IADC Drilling Conference, Amsterdam, Netherlands.

Settari, A. 2002. Reservoir Compaction. Journal of Petroleum Technology 54 (8): 62-69.

Yudovich, A., Chin, L.Y., and Morgan, D.R. 1988. Casing Deformation in Ekofisk. Paper OTC 17856 presented at the 1989 Offshore Technology Conference, Houston, Texas.

Zhang, Y. and Der Kiureghian, A. 1994. Two Improved Algorithms for Reliability Analysis. 6th IFIP WG 7.5 Working Conference, ed. Rackwitz, R., Augusti, G., and Borri, A.:297-304. Assisi, Italy. London Chapman \& Hall. 


\section{VITA}

Name: $\quad$ Prasongsit Joe Chantose

Address: $\quad$ Harold Vance Department of Petroleum Engineering

Texas A\&M University

3116 TAMU - 507 Richardson Building

College Station, TX 77843-3116

Email Address: mj_ball23@hotmail.com

Education: $\quad$ B.S., Civil Engineering, Utah State University, 2007

M.S., Petroleum Engineering, Texas A\&M University, 2011 